\title{
WestVirginiaUniversity
}

THE RESEARCH REPOSITORY @ WVU

Graduate Theses, Dissertations, and Problem Reports

2004

\section{Particle breakage in sand blasting due to impact on ductile materials}

Ravi Kishore Bandaru
West Virginia University

Follow this and additional works at: https://researchrepository.wvu.edu/etd

\section{Recommended Citation}

Bandaru, Ravi Kishore, "Particle breakage in sand blasting due to impact on ductile materials" (2004). Graduate Theses, Dissertations, and Problem Reports. 1481.

https://researchrepository.wvu.edu/etd/1481

This Thesis is protected by copyright and/or related rights. It has been brought to you by the The Research Repository @ WVU with permission from the rights-holder(s). You are free to use this Thesis in any way that is permitted by the copyright and related rights legislation that applies to your use. For other uses you must obtain permission from the rights-holder(s) directly, unless additional rights are indicated by a Creative Commons license in the record and/ or on the work itself. This Thesis has been accepted for inclusion in WVU Graduate Theses, Dissertations, and Problem Reports collection by an authorized administrator of The Research Repository @ WVU. For more information, please contact researchrepository@mail.wvu.edu. 


\title{
PARTICLE BREAKAGE IN SAND BLASTING DUE TO IMPACT ON DUCTILE MATERIALS
}

\author{
Ravi Kishore Bandaru
}

\author{
Thesis Submitted to the \\ College of Engineering and Mineral Resources \\ at West Virginia University \\ in partial fulfillment of the requirements \\ for the degree of \\ Master of Science \\ in
}

Mechanical Engineering

Kenneth H. Means, Ph.D., Chair

Victor H. Mucino, Ph.D.

Scott W. Wayne, Ph.D.

Department of Mechanical and Aerospace Engineering

\author{
Morgantown, West Virginia \\ 2004
}

Keywords: Sandblasting, Silicosis, Finite Element Analysis, Particle Size Distribution, Failure Criteria. 


\section{ABSTRACT \\ Particle Breakage in Sand Blasting due to Impact on Ductile Materials}

\section{Ravi Bandaru}

Cleaning of rust, paint or removing burrs and many other such applications are done by several processes. Sand blasting is one of them, where a stream of sand particles is forcefully projected onto a surface, with compressed air or steam. These sand particles break up into very small pieces upon impact, which are inhaled by workers to cause silicosis. While much research has been done on the surface being impacted, very little research has been done on the particle itself. Hence, proper analytical modeling of the sand blasting process from the particle perspective, validated by experimental results, is required to predict the sand particle breakage.

In the present thesis, a finite element model of the sand particle is developed in LS-INGRID and a transient dynamic analysis is performed in LS-DYNA3D. This study focuses mainly on the propagation of stress waves and the volume loss of the sand particle upon impacting an aluminum plate. Three different shapes of the sand particle and five different sizes with varying impact angles and particle velocities were chosen to analyze the influence of impact. The results of the model showed close correlation with the experimental results of A.J.Sparks and I.M.Hutchings. These results were presented in the form of graphs of dependencies between volume loss and other parameters

affecting the impact. It was concluded that $100 \mu \mathrm{m}$ size is the optimum size of the sand particle that increases the safety of the workers performing sandblasting due to its lesser volume loss. 


\section{ACKNOWLEDGEMENTS}

I would like to take this opportunity to express my sincere appreciation to Dr.Kenneth Means for having provided me an opportunity to work under him. I thank him for extending his valuable guidance and suggestions during this study.

I am also very grateful to Dr.Victor Mucino and Dr.Bruce Kang for being in my committee.

I would also like to thank my parents, my friend Murali and post-doctorate William Gergis for their motivation, support and help. 


\section{TABLE OF CONTENTS}

Title Page $\quad$ i

Abstract $\quad$ ii

Acknowledgements $\quad$ iii

Table of Contents $\quad$ iv

List of Figures $\quad$ vi

List of Tables $\quad$ vii

1. Introduction 1

1.1 Sand Blasting Phenomenon 1

1.2 Types of Abrasive Blasting Systems 1

1.3 Components used in Sand Blasting 2

1.4 Problems Associated with Sandblasting 5

$\begin{array}{lll}1.5 & \text { Silicosis } & 6\end{array}$

1.6 NIOSH Recommendations for Silicosis 6

$\begin{array}{lll}1.7 & \text { Diagnosis of Silicosis } & 7\end{array}$

1.8 Treatments and Management of Silicosis $\quad 7$

1.9 Need for Single Particle Analysis $\quad 7$

2. Erosion Models 8

2.1 Erosion Phenomenon 8

2.2 Erosion of Brittle Materials 8

2.3 Erosion of Ductile Materials 10

2.4 Parameters Affecting Erosion 14

$\begin{array}{lll}2.4 .1 & \text { Erodent Velocity } & 14\end{array}$

$\begin{array}{lll}\text { 2.4.2 Erodent Size } & 14\end{array}$

$\begin{array}{lll}2.4 .3 & \text { Erodent Shape } & 15\end{array}$

2.4.4 Impact Angle or Incidence Angle 16

2.4.5 Material Properties of Erodent and Target 17 
3. Finite Element Analysis 26

3.1 Introduction 26

3.2 Particles 27

3.3 Finite Element Model 28

3.3.1 LS-INGRID 29

3.3.2 Boundary Conditions 30

3.3.3 Material Models 31

3.3.4 LS-DYNA3D 31

3.3.5 LS-TAURUS 32

3.4 Failure Criteria 35

3.5 Estimation of Material Loss due to Impact 35

4. Results and Discussions 37

4.1 Introduction 37

4.2 Influence of Shape 37

4.3.1 Influence of Shape 1 (Point Contact) 38

4.3.2 Influence of Shape 2 (Line Contact) 50

4.3.3 Influence of Shape 3 (Area Contact) 62

$\begin{array}{ll}4.3 \text { Model Validation } & 76\end{array}$

4.4 Comparison of FEM and Experimental Results 81

4.5 Discussion 83

5. Conclusions and Recommendations $\quad 84$

5.1 Conclusions 84

5.2 Future Recommendations 85 


\section{LIST OF FIGURES AND TABLES}

Figure 2.1: Erosion Behavior of Brittle and Ductile Materials

Figure 2.2: Energy balance for a spherical particle before and after normal impact 22

Figure 2.3: Plastic strain directing radially outward in the plane of the surface due to single impact 22

Figure 3.1: Basic Types of Impact Damage 27

Figure 3.2: Half Sectional Isometric View of different types of particles 28

Figure 3.3: Schematic diagram of single particle impact 28

Figure 3.4: Boundary conditions along the symmetric plane of a symmetric model (half modal) for shape 2 (line contact) 30

Figure 3.5: Plot of Energies versus Time 33

Figure 3.6: Plot of Internal Energy versus Time 34

Figure 3.7: Plot of Kinetic Energy versus Time 34

Figure 3.8: Plot of Maximum Principal Stresses versus Element Numbers 36

Figure 3.9: Plot of Minimum Principal Stresses versus Elements 36

Figure 4.1: Half sectional front view of different particle shapes 37

Figure 4.2: Fringes of Maximum Principal Stress of $200 \mu \mathrm{m}$ size particle impacting the plate at $20^{\circ}$ with a velocity of $40 \mu \mathrm{m} / \mu \mathrm{s}$

Figure 4.3: Fringes of Minimum Principal Stress of $200 \mu \mathrm{m}$ size particle impacting the plate at $20^{\circ}$ with a velocity of $40 \mu \mathrm{m} / \mu \mathrm{s}$

Figure 4.4: Volume Loss versus Impact Angle for Shape 1 (Point Contact) 47

Figure 4.5: Volume Loss versus Velocity for Shape 1 (Point Contact) 49

Figure 4.6: Fringes of Maximum Principal Stress of $100 \mu \mathrm{m}$ size particle impacting the plate at $16^{0}$ with a velocity of $35 \mu \mathrm{m} / \mu \mathrm{s}$

Figure 4.7: Fringes of Minimum Principal Stress of $100 \mu \mathrm{m}$ size particle impacting the plate at $16^{0}$ with a velocity of $35 \mu \mathrm{m} / \mu \mathrm{s}$

Figure 4.8: Volume Loss versus Impact Angle for Shape 2(Line Contact) 59

Figure 4.9: Volume Loss versus Velocity for Shape 2 (Line Contact) 62 
Figure 4.10: Fringes of Maximum Principal Stress of $250 \mu \mathrm{m}$ size particle impacting the plate at $24^{0}$ with a velocity of $40 \mu \mathrm{m} / \mu \mathrm{s}$

Figure 4.11: Fringes of Minimum Principal Stress of $250 \mu \mathrm{m}$ size particle impacting the plate at $24^{0}$ with a velocity of $40 \mu \mathrm{m} / \mu \mathrm{s}$

Figure 4.12: Volume Loss versus Impact Angle for Shape 3 (Area Contact)

Figure 4.13: Volume Loss versus Velocity for Shape 3 (Area Contact)

Figure 4.14: Plot of average (mass median) particle size versus number of cycles for silica and ballotini under the conditions indicated

Figure 4.15: Particle size distribution after (cumulative mass undersize) for erodent samples after repeated impact by (a) Silica at $98 \mathrm{~m} / \mathrm{s}$

(b) Ballotini at $89 \mathrm{~m} / \mathrm{s} 87$

Figure 4.16: Erosion rate of glass-ceramic by silica particles at $90^{\circ}$ plotted against

(a) Number of cycles (b) Particle size

Table 4.1: Comparison of Size Results

Table 4.2: Comparison of Weight Percentage Reduction Results

References

Appendix A

Appendix B

91

Approval of Examining Committee 


\section{CHAPTER 1. INTRODUCTION}

\subsection{Abrasive Blasting Phenomenon}

The process of projecting a stream of abrasive materials forcefully onto a surface, with compressed air or steam is known as abrasive blasting. Different types of abrasive materials used can be silica sand, aluminum oxide, silicon carbide, corn cob, walnut shells, plastic media, steel media, glass beads, ground cullet, etc. When this process is carried out with sand, it is known as sand blasting. It has a variety of different applications. It is used in:

- Cleaning rust, scale, dirt and paint.

- Roughening surfaces while preparing for bonding, painting or coating.

- Removing burr.

- Developing a matte surface finish.

- Removing flash from molding operations.

- Eliminating the usage of organic solvent stripping.

- Eliminating the generation of toxic waste material.

- Carving gemstones.

\subsection{Types of Abrasive Blasting Systems}

There are two types of abrasive blasting systems, confined and unconfined abrasive blasting systems. Confined abrasive blasting system contains a permanent enclosure, abrasive reclaiming devices, conveyors, elevators and air pollution control devices. The three basic components present in most abrasive blasting machines are abrasive blasting tank (pot), a propelling device and abrasive blasting nozzle(s) or gun(s). In general, there are three elementary types of propelling methods, air pressure (suction or pressure blast), water pressure (air or hydraulic blast) or centrifugal wheel. The air suction method uses compressed air to propel the abrasive media. The water suction 
method uses either compressed air or high-pressure water as the propelling force. Similarly, the centrifugal wheels use centrifugal and inertial forces. Of these three methods, the air suction and water suction methods are commonly used as propelling devices. A brief description of such devices is as follows:

1. Suction Blast System: The compressed air suction system consists of a blasting gun, which is connected to two rubber hoses. The other ends of these hoses are connected to the compressed air supply and to the bottom of the abrasive supply tank or pot. An air nozzle present in the gun is discharged into a larger nozzle. A partial vacuum is thus created in the chamber, when the high velocity air jet expands into the larger nozzle. This draws in the abrasive and expels them through the discharge nozzle.

2. Pressure Blast System: In the compressed air pressure system, a pressure tank (pot) stores the abrasives. These abrasives are forced through the blast hose rather than siphoning it, due to the usage of the pressure tank. As the compressed air line is connected to the top and bottom of the pressure tank, the abrasives flow into the discharge hose by gravity, without loss of pressure.

3. Barrel Blasters: These are usually used with suction systems since they can be run continuously or for long periods. These are efficient when more parts are to be processed and lower labor costs are the requirements in finishing operation.

4. Wet Blasting System: These systems comprise of a seal-less slurry pump to agitate the abrasive blast gun, where it is accelerated to the desired pressure rating by the air pressure. The abrasive is prevented from escaping the system by the cabinet exhaust blower and filter, which maintain a negative cabinet pressure.

\subsection{Components used in Sand Blasting}

In general, sandblasting requires a blaster, abrasives, a cabinet, a compressor and a dust collector. These are described briefly below:

1. Blasters: Siphon feed and pressure feed guns are the two different varieties of blasters. In the siphon feed gun, a stream of air sucks up the abrasive (sand) and blasts out through a large nozzle of up to $1 / 4$ ". Thus it works as an atomizer or an airbrush. These 
guns are expensive, ranging from $\$ 10$ and are readily available. But these guns have nonreplaceable nozzles, as the carbides tear them up within hours. In addition, the abrasives get clogged due to improper control, because of the larger nozzle. Also, these guns use up to 5 times more amount of air than other guns. In a pressure feed gun, the air supply pressurizes the pressure pot (or tank) containing the abrasives. The mixture of a stream of air and abrasives travels through a small handheld nozzle of $3 / 32$ " to $1 / 16$ ". This flow is controlled by a foot switch. This blaster has more precise control, smoother flow and requires less air and thus needing a smaller and cheaper compressor. But, the pressure pot used makes the set up very expensive.

2. Abrasive Materials: These are of many kinds. A few of them are described below:

- Silica Sand: It is the cheapest abrasive material. It is mostly used in unconfined abrasive blasting operations, since reclaiming the abrasive is not feasible. For example, it is used to remove paint, but is coarse for glasswork. This is because, sand has 30grit and glass blasting requires 100-180 grit abrasive. Sand has a high breakdown rate and so the silica dust released by it creates a health hazard known as silicosis. This would be dealt in the later part of the paper.

- Aluminum Oxide: It is very hard and lasts longer than slag and sand, as it measures 9 on the MOHS scale. It works well on all surfaces including glass and other hard materials. But it has a disadvantage of picking up static charge on usage and tends to cling to the glass.

- Silicon Carbide: It is one of the hardest abrasives, as it registers 9.5 on the MOHS scale. Though it is costly, it could be called as cheapest as it can be reused many times. During the breakage, the carbide grains maintain their sharpness and remain effective. Hence carbide cuts faster and easier than other abrasives.

- Corn Cob: It measures 4.5 on the MOHS scale. It produces less dust and so is environmentally safe. Its granules are biodegradable, nontoxic and non-sparking.

- Walnut Shells: It measures between 3 and 4 on the MOHS scale and hence lacks grit. They are used for cleaning gasoline and diesel engines, metals, alloys and plastics without scratching or pitting the surface. They are also used to remove paint, lacquer, rust, scale, carbon and chemical deposits and for deflating of molded plastic parts. 
- Plastic Media: This also measures 3 to 4 on the MOHS scale. They are used to remove coatings without altering the substrate materials and stripping of antique automobiles. Also they are used on composites and thin-skinned aircraft.

- Steel Media: Available as 'shot' or 'grit', they have a number of harnesses. Steel shots are used to impart residual compressive stresses to improve fatigue properties of metal products in shot peening and are long lasting.

3. Abrasive Blasting Enclosures: In general, confined abrasive blasting operation and as well as sand blasting use abrasive cabinets and abrasive blasting rooms as enclosures. These are described below in a simple manner:

- Blast Cabinets: It acts as a small enclosure, usually used to clean or prepare small parts. Standing outside the cabinet, the operator works through sealed openings in the cabinet front. This job is done by passing his hands and arms through a pair of protected heavy rubber gloves, connected to the cabinet. The operator adjusts the blasting gun (nozzle) and the objects to be blasted with his hands and alters the abrasive flow and action through a treadle (pedal) type control valve. While blasting, the heavier materials fall through the grated floor by the cleaning action. Whereas the lighter entrained particulate matter is directed to an air pollution control device by an exhaust blower.

- Blast Rooms: In contrast to the blast cabinet, this is a large enclosure and the operator works inside the room. To assist the operator in handling the large and heavy objects, the rooms are equipped with monorail conveyors, rail cars or rotating tables. Also the rooms contain an automatic abrasive recovery system (ARS) with grating floor. During the blast, the heavier materials obtained by the cleaning action fall through the perforated floor plate of the room. The mixture of spent abrasive and abraded materials is taken to screens and cyclones by floor conveyors, elevators and blowers (collectively called as ARS) to separate the components. The abrasives are returned to the abrasive hopper, whereas the undesirable materials are disposed off. The lighter entrained particulate matter is removed in a similar fashion to the blast cabinet. 
4. Air Pollution Control Devices (Abatement Equipment): Dust filters/collectors, bag houses and filtration fabrics come under the air pollution control devices. The dust filters/collectors are divided into dry dust collectors and wet dust collectors. The dry dust collectors are again separated as cartridge collectors, tubular bag collectors and envelope bag collectors. The bag houses are regrouped into reverse-air bag houses and pulsejet bag houses. The basic work done by all of these different devices is to remove all kinds of industrial and foundry dusts from the exhaust system air.

Applications: Sandblasting is used in shipbuilding and maintenance, transportation bridge maintenance and military operations.

\subsection{Problems Associated with Sandblasting}

Even though the frequency of sandblasting is declining, it is still being applied in an uncontrolled fashion in small-scale workplaces. The major problem associated with it is the attack of silicosis. This is due to the reason that the breakage of silicon dioxide particles into smaller pieces on striking the surface and reusage of the same materials increases the respirable dust concentrations, thus leading to the high risk of silicosis. The obstacle associated with the used abrasive blast media is that it may include materials from the cleaned surface that impart hazardous characteristics to the grit. During the removal of paint from the metal surfaces (of ships for example), the heavy metals present in the paint become part of the ABM (abrasive blast material) matrix. This contamination of the abrasive poses a potential restriction for disposal and recycling. Therefore all used ABM must be undergone a Toxicity Characteristics Leaching Procedure (TCLP) test to determine if the material is hazardous. If hazardous, the material must be managed accordingly and if non-hazardous, the grit must be disposed off properly as it is a solid waste. The non-hazardous sandblast grit must be disposed off in a sanitary landfill or used as a feedstock material in the production of Portland cement. 


\subsection{Silicosis}

It is defined as the chronic fibrosing disease of the lungs. It occurs due to the prolonged and extensive exposure to free crystalline silica. The inhalation of crystalline silica (dust) makes the lung tissue react by developing fibrotic nodules and scarring around the trapped silica particles. Breathing becomes difficult and death may occur, if these nodules grow too large. Silicosis victims could easily develop active tuberculosis.

\subsection{NIOSH Recommendations for Silicosis}

For a 40-hour workweek [NIOSH 1974] and 10 hours/day, the NIOSH recommended exposure limit (REL) for respirable crystalline silica is $50 \mathrm{~g} / \mathrm{m}^{3}$. To reduce exposures to respirable crystalline silica in the workplace, to prevent silicosis and deaths in construction workers, NIOSH recommends the following measures:

- Awareness and planning are the best ways to prevent silicosis.

- Usage of less hazardous materials (containing < $1 \%$ crystalline silica).

- Usage of engineering controls and containment methods.

- Regular maintenance of dust control systems.

- Maintenance of good personal hygiene.

- Wearing disposable or washable protective clothes at work.

- Monitoring air regularly.

- Usage of adequate respiratory protection.

- Periodic medical examinations.

- Post warning signs at contaminated areas.

- Training workers.

- Reporting all cases of silicosis to OSHA and State Health Departments. 


\subsection{Diagnosis of Silicosis}

Due to its unique symptoms, chronic silicosis often goes untreated. Only a thorough medical checkup using a chest X-ray and lung function test can determine the presence of silicosis in a person.

\subsection{Treatments and Management of Silicosis}

The best way of treatment is to stop from exposure of contaminated area. As this disease is irreversible, most treatments help relieve pain and suffering. The patients are given oxygen and steroids to breathe easily and sometimes supplied with immunosuppressive drugs to slow down the inflammation. But the only lifesaving treatment to eliminate silicosis is a lung transplant.

\subsection{Need for Single Particle Analysis}

Only a few experimental studies have been conducted on sand particles till now. One of which was done by A.J.Sparks and I.M.Hutchings, discussing about the size variations developed in the particles and the erosion done by them on the material. But none of them conducted finite element analysis, especially for sub-micron particles that are the main cause of silicosis in sand blasting. The nature of the distribution of stresses in these particles, their failures and the size of their fragments is very essential. Hence, to look at these aspects, the need for single particle analysis arises. Also, sand particles consist of different types of shapes and to analyze each one of them is difficult. Hence, in this thesis three types of shapes with different types of contact with the material are considered. 


\section{CHAPTER 2. EROSION MODELS}

\subsection{Erosion Phenomenon}

Erosion is a physical phenomenon, where the impact of solid particles creates loss or removal of material. Sand blasting is a type of erosion process, which is done on two different types of materials, namely brittle and ductile. Brittle materials undergo elastic deformation before developing fractures, whereas ductile materials undergo very large plastic strains before developing fractures. To understand the phenomenon of erosion in both brittle and ductile, a large number of models have been proposed. These are explained as follows:

\subsection{Erosion of Brittle Materials}

The erosion of brittle materials is caused because of the crack formation in the surface and the consequence chipping of the material. The impact of eroding particle radiates cracks in all directions, whose intersection leads to the removal of the material. These materials include all the metals, non-metals, oxide layers, etc. Brittle materials usually offer less resistance to erosion than the ductile materials.

In 1960, Finnie conducted several experiments with an elastic sphere impacting

brittle materials at $90^{\circ}$. Assuming certain equations, he stated that the maximum tensile stress in the material occurs at the surface in the radial direction around the periphery of the contact area. The impact created a ring crack in the brittle material.

In 1966, Sheldon et al. assumed that erosion occurs due to the Hertzian contact stresses developed during impact. These stresses make the cracks to propagate from preexisting flaws in the target surface. This crack propagation occurs at a load, related to the distribution of the surface flaws through the Weibull distribution. Weibull distribution 
is the statistical explanation of the average fracture stress of a particular material. Sheldon expressed the erosion rate $\mathrm{W}$ as

$$
\mathrm{W}=\mathbf{k}_{1} \mathbf{r}^{\mathrm{a}} \boldsymbol{\vartheta}_{0}^{\mathrm{b}}
$$

Where $\mathrm{a}=\frac{3(\mathbf{m}-0.67)}{\mathbf{m}-2}$ for round particles

$$
\begin{aligned}
& =\frac{3.6(\mathbf{m}-0.67)}{\mathbf{m}-2} \text { for angular particles } \\
b & =\frac{2.4(\mathbf{m}-0.67)}{\mathbf{m}-2} \text { for either shape }
\end{aligned}
$$

For particles much stiffer than the target, constant $\mathrm{k}_{1}$ is given as

$$
\mathrm{k}_{1}=\mathbf{E}^{0.8(\mathbf{m}+1)(\mathbf{m}-2)} \boldsymbol{\rho}^{1.2(\mathbf{m}-0.67) /(\mathbf{m}-2)} \boldsymbol{\sigma}_{0}^{-2 /(\mathbf{m}-2)}
$$

Where $\mathrm{E}=$ modulus of elasticity of the target and

$\sigma=$ density of the particle.

Evans et al. proposed a model, where plastic deformation contributed to the process of crack propagation and surface chipping. He assumed erosion to be proportional to the amount of material removed by each impact event. The volume loss per impact was calculated as

$$
\mathrm{V}=\pi \mathrm{c}_{\mathrm{r}}^{2} \mathbf{h}
$$

Where $c_{r}=$ radial crack size or lateral size and

$\mathrm{h}=$ penetration depth

In 1978, the presence of plastic deformation in brittle materials was found by Hockey et al., with the help of transmission electron microscopy. It was seen that plasticity occurred due to the compressive component of the stress field below the impacting particle. Also high dislocation densities were observed in all cases. Eventually, Evans et al. included the effects of elastic as well as plastic waves generated by impacting particle in his model. He proposed the erosion rate to be as

$$
\mathbf{E} \boldsymbol{\alpha} \boldsymbol{\vartheta}_{0}^{3 / 2} \mathbf{d}^{3 / 2} \boldsymbol{\rho}^{1.3} \mathbf{k}_{\mathrm{lc}}^{-4.3} \mathbf{H}^{-0.25}
$$

Where $v_{0}=$ particle velocity

$$
\mathrm{d}=\text { particle diameter }
$$




$$
\begin{aligned}
\rho & =\text { particle density } \\
\mathrm{k}_{1 \mathrm{c}} & =\text { material toughness } \\
\mathrm{H} & =\text { material hardness }
\end{aligned}
$$

Recently, Wiederhorn et al. changed Evans et al. model by neglecting the dynamic effects. Also the particle penetration depth was determined by equating the plastic work to the incident kinetic energy of the particle. The erosion rate was then modified to

$$
\mathbf{E} \boldsymbol{\alpha} \boldsymbol{\vartheta}_{0}^{2.4} \mathbf{d}^{2 / 3} \boldsymbol{\rho}^{1.2} \mathbf{k}_{1 \mathrm{c}}^{-4.3} \mathbf{H}^{-0.25}
$$

\subsection{Erosion of Ductile Materials}

The erosion of ductile materials takes place due to plastic deformation, wherein the eroding particle displaces or cuts through the material. The failure of the material occurs when the impacting particle causes severe, localized plastic strain to occur, which eventually exceeds the strain. The deformations in the material are produced due to the loss of kinetic energy and by the work done during the impact by external forces on the particle.

In 1958, Finnie first developed a model by considering the micro-machining mechanism. A plastic response character was assigned to the material through a flow stress $\sigma_{\mathrm{f}}$. The trajectory of the particle was assumed and the volume removed was equated to the volume swept out by the particle tip. This was shown as

$$
\mathrm{V}=\left(\frac{\mathbf{m} \boldsymbol{\vartheta}_{0}^{2}}{\boldsymbol{\sigma}_{\mathbf{f}} \mathbf{k d}}\right) \mathrm{g}(\alpha)
$$

Where $\mathrm{m}=$ particle mass

$$
\begin{aligned}
\vartheta & =\text { impact velocity } \\
\mathrm{k} & =\text { ratio of vertical force to horizontal force on the particle } \\
\mathrm{d} & =\text { depth of cut } \\
\mathrm{g}(\alpha) & =\text { function describing the effect of attack angle } \alpha
\end{aligned}
$$


By taking an average value of $\mathrm{k}=2$, the volume eroded was modified as

$$
\begin{array}{ll}
V=\left(\frac{\mathbf{m} \vartheta_{0}^{2}}{2 \boldsymbol{\sigma}_{\mathbf{f}} \mathbf{d}}\right)\left(\sin 2 \alpha-3 \sin ^{2} \alpha\right) & \text { for } \alpha<18.5 \text { and } \\
V=\left(\frac{\mathbf{m} \vartheta_{0}^{2}}{6 \boldsymbol{\sigma}_{\mathbf{f}} \mathbf{d}}\right) \cos ^{2} \alpha & \text { for } \alpha>18.5
\end{array}
$$

Finnie experimentally proved that the material removal varied with the direction and the velocity of the eroding particle. He predicted the velocity component as $n=2$. But his model didn't work for $\alpha=90^{\circ}$, as the expression for volume eroded gave zero.

In 1963, Bitter developed a model a model for all attack angles. He found erosion to be associated with two simultaneous processes, indentation deformation wear and cutting wear. For ductile materials, the cutting wear predominates at low angles and the deformation wear predominates at high angles. This was later simplified by Nelson et al. with equations in good relation with experimental data.

In 1972, Sheldon and Kanhere examined the mechanism of single particle erosion of ductile materials. They proposed a model to describe the deformation and machining actions observed using indentation theory and energy balance equation. They represented the erosion volume as

$$
\mathrm{V}=\mathrm{k}\left(\frac{\mathbf{d}^{3} \boldsymbol{\vartheta}_{0}^{3} \boldsymbol{\rho}_{\mathrm{p}}^{3 / 2}}{\mathbf{H}^{3 / 2}}\right)
$$

Where $\mathrm{d}=$ spherical particle diameter

$$
\begin{aligned}
& \rho_{\mathrm{p}}=\text { particle density } \\
& \mathrm{H}=\text { Vickers hardness value of material }
\end{aligned}
$$

Their theory had two results. The velocity component was obtained as $n=3$ and the single and multiple particle erosion of surface had same material removal action.

In 1973, Tilly proposed a two-stage mechanism of erosion. First stage comprised of the particle striking the surface to produce indentation and removing a chip of metal. Second stage comprised of fragments scattering radially from primary site. Secondary damage was done by some of these fragments. He noted a decrease in erosion with 
decrease in particle size and hence introduced the concept of minimum particle size for this type of mechanism.

In 1974, Hutchings et al. explained the erosion of aluminum surface hit by a $3 \mathrm{~mm}$ steel ball at $250 \mathrm{~m} / \mathrm{s}$. Due to this impact, an over-hanging lip was formed at the exit end of the crater by the shearing of the surface layers. This lip got detached from the surface by the propagation of ruptures at the base of the lip. It was seen that the above phenomena was a characteristic of this particular metal and takes place above a certain critical impact velocity.

It was also shown that the material was more easily removed from work-hardened copper than from annealed copper. In the work-hardened material, the deformation is concentrated in the surface layers aiding the formation of fragile lip, whereas in annealed material, the impact energy is spread through a large volume.

In 1981, Hutchings performed a multi sphere impact at normal incidence. Though he incorporated two material strength properties called dynamic hardness and erosion ductility, further investigation of them was required. Also the platelet mechanism used to remove the material had to be better understood. He evaluated the erosion rate as

$$
\mathrm{E}=\mathrm{k}\left(\frac{\boldsymbol{\alpha} \rho \boldsymbol{\sigma}^{1 / 2} \boldsymbol{\vartheta}^{3}}{\boldsymbol{\varepsilon}_{\mathbf{c}}^{2} \mathbf{P}^{3 / 2}}\right)
$$

Where $\alpha=$ fraction of volume of indentation that is plastically deformed

$v=$ impact velocity

$\mathrm{P}=$ constant pressure of resistance by the target material for indentation

$\rho=$ target material density

$\varepsilon_{\mathrm{c}}=$ critical strain

In the same year, Bellman et al. observed erosion at glancing angles of incidence. It was experimentally shown that that material removal during erosion involved the deformation of surface material into platelets by repeated impacts. These platelets get detached and form thin plate like debris particles. Both spherical and angular impacting 
particles were observed to perform the same mechanism of platelet formation. The impact of the particles formed three different types of craters namely indentation, plowing and smear crater on the stress free surface.

In 1986, Hutchings et al. included the softening of the near surface region due to the surface temperature rise because of erosion. This softer material gets deformed against the layer of work-hardened material beneath it, which acts as an anvil. After estimating the temperature rise and looking at the published evidence for and against softening, it was concluded that a thermally softened surface layer wasn't an essential feature of erosion mechanism under all conditions.

Though the platelet mechanism was seen to be a major material removal mechanism at $90^{\circ}$ incidence angle and the micro-mechanism was the major mechanism at low incidence angles, neither theory offered clear mechanisms for either cutting or deformation wear. Morrison et al. argued that a single mechanism of erosion is appropriate for all angles of incidence as velocity exponent; particle size effect and surface features are similar for all incidence angles. Also indentation, plowing and cutting were considered to have similar plastic deformation behavior and occur at all incidence angles.

Finally in 1995, Levy related all experiments and theoretical results of other theories and came upon with some results. He mentioned the erosion mechanism as a series of operations resulting in the formation of platelets and craters. The first stage of the impact produced platelets without material loss. The second stage has adiabatic shear heating on the impacted surface leading to the formation of work hardened zone, beneath its surface, that acts as an anvil increasing the efficiency of impacting particles. When both these stages are completed and are in steady state, the material gets removed. 


\subsection{Parameters Affecting Erosion}

The parameters affecting erosion are very important to evaluate the process of erosion. The different parameters that affect erosion process are explained briefly below:

\subsubsection{Erodent Velocity}

Erodent velocity has a major task in the erosion process because greater velocity imparts higher kinetic energy to degrade the surface. Many experiments were performed in the past to determine the volume loss per impact due to velocity changes. In 1960, Finnie used SAE 1020 steel to find the relation between erosion and velocity as

$$
\varepsilon=\mathbf{b}^{\mathbf{n}}
$$

Where $v=$ erodent velocity and

$\mathrm{n}=2$.

Later on after working with other materials, he provided a range of 2.05 to 2.44 for n. Sheldon's theory predicted it to be equal to 3 . He showed that the velocity component ' $n$ ' varied with particle size for steel but is independent for copper and aluminum.

In 1970, Sheldon et al. observed that for brittle materials, the erosion rate is proportional to $v^{b}$, where the constant ' $b$ ' is different for oblique angles and normal impact. For brittle materials, its value lies between 3 and 6.5. From these results, they concluded that tangential forces contributed to the wear of brittle materials at oblique angles. Also brittle materials were found to be associated with particle velocity and size than ductile materials.

\subsubsection{Erodent Size}

For ductile metals, Goodwin et al. found that as particle size increases the erosion damage increases until a saturation level is reached, beyond which no further change is 
indicated. Smeltzer et al. showed that erosion volume loss per particle varies linearly with particle volume and mass, at constant velocity, through the particle size range from 20 to 175um. Yerramareddy and Bahadur indicated that cutting is the major mechanism for particles larger than 50um, (the critical diameter 'dc' for mode transition from deformation to cutting) and the value of dc depends on the target material and attack angle. According to Finnie, the erosive volume loss increases with the decrease in particle diameter if the total mass of the particles is fixed. C.K.Fang and T.H.Chaung proved that the erosion loss per particle varies linearly with particle size for the cutting mode. Also it was found that fine abrasive particles tend to cause deeper craters than coarse particles. From his erosion experiments on mild steel, Raask found that using lowlevel velocities, 100um sharp quartz particles were 10 times more erosive than glass spheres of the same size. S.Bahadur and R.Badruddin concluded from their experiments that sand particles become less elongated and more circular with increasing size. Though the erosion rate decreased with increasing size of sand particles, it increased with increasing P/A and decreasing W/L.

For brittle materials, material size is directly proportional to erosion rate. Large erodent size removes greater volume of material by impact.

\subsubsection{Erodent Shape}

This is the main factor in predicting the erosion rate due to impact as it determines the contact area between the particle and the metal surface during an impact. Angular particles were found to create more amount of erosion for both ductile and brittle materials. Sheldon et al. proved this through their experiments, when they fired spherical and angular $\mathrm{SiC}$ particles against brittle materials like glass, $\mathrm{Al}_{2} \mathrm{O}_{3}$.

Later on Hutchings et al. used steel spheres of $9.5 \mathrm{~mm}$ diameter and $8 \mathrm{~mm}$ square steel plates through a compressed gas gun system at oblique angles. They found that spherical particles caused plowing deformation and angular particles caused cutting 
deformation. Hutchings along with Winter found that plowing was favored by large negative rake angles, while micro cutting occurred with positive or small values of negative rake angles. The angle between the normal to the target surface and the leading edge of the impacting particle is known as rake angle. Also, it was found that a spherical particle would always hit the target surface with a large negative rake angle, making plowing the only mode of deformation. But an angular particle could impact with either positive or negative rake angle, thus producing both micro cutting and plowing. Hence in the case of $\mathrm{SiO}_{2}$ particles, large particles cause more amount of plowing and finer particles cause more amount of micro cutting, thus increasing the erosion rate.

\subsubsection{Impact Angle or Incidence Angle}

Angle of attack has also an important role in erosion. For ductile materials, the erosion rate increases from a minimum of zero at grazing incidence to a maximum value between $10^{0}-30^{0}$ and then decreases for normal incidence. Whereas for brittle materials, the erosion loss increases from a minimum of zero at grazing to a maximum at $90^{\circ}$. G.Carter, I.J.Bevan, I.V. Katardjiev and M.J.Nobes found in their study that for a given incidence angle, after an elapse of initial short incubation period, the erosion depth becomes directly proportional to the erosion rate. The penetration depth increases with the increase in incidence angle with respect to the normal. The forwarded energy of the particle increases the extruded volume and hence the erosion rate, till the penetration depth becomes so low that the erosion rate decreases again. The following decrease in penetration depth makes the particle rebound with substantial energy, due to energy loss, with reflection angles less than incidence angles. This decrease in penetration depth and rebounding of particle with almost complete incidence energy takes place at grazing incidence. The reason for the differences in incidence and reflection angles is due to energy losses during reflection and from changing conditions at the primary impact zone on the reflector surface. Hence the rebounding particles with greater retainment of energy (kinetic) lead to lesser erosion rate and also secondary erosion processes. 


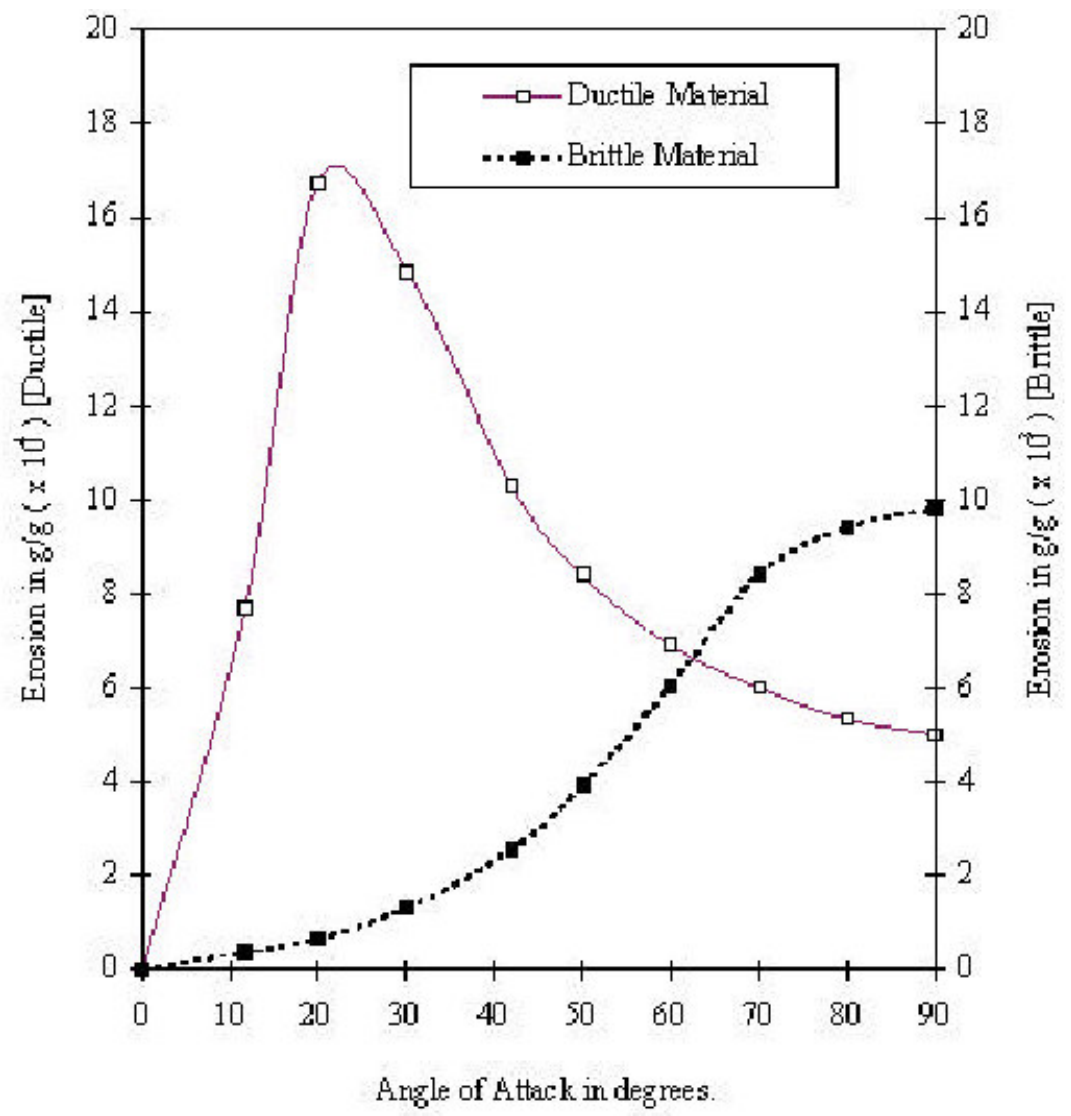

Figure 2.1: Erosion Behavior of Brittle and Ductile Materials

\subsubsection{Material Properties of Erodent and Target}

1 Erodent Hardness: For ductile solids and brittle solids (except ceramic materials), erosion is possible only when the erodent surface hardness is greater than that of the target. In 1957-58, Wellinger and Vetz observed that the erosion rate drops dramatically as particle hardness decreases below that of the eroding material. In 1979, Finnie proved that heat treatment of steel would have almost no effect on their erosion resistance that could be due to the use of hard particles like $\mathrm{SiC}$ and $\mathrm{Al} 2 \mathrm{O} 3$.

2 Erodent Frangibility: For ductile materials, the effect of particle fragmentation to provide additional erosion loss or reflected sand blasting was described by Tilly in 1973, by Maji and Sheldon in 1978 and by G.Carter, I.J.Bevan, I.V.Katardjiev and 
M.J.Nobes in 1990. In 1975, Unemois and Klets observed that the increased erosion potential of abrasive due to water or impurity content might derive from an altered tendency to fragment.

3 Surface Hardness: It is the major factor used in describing ductile material erosion rate variation. In 1977, Sheldon suggested that fully abraded surface hardness could be used for describing erosion. Also dynamic hardness can be used for both ductile and brittle materials.

4 Strain Rate Sensitivity: In 1975, Winter and Hutchings and again in 1977, Hutchings performed studies on single particle erosion. They found that high strain rates related within particle erosion may lead to different deformation modes in different materials, but hasn't been examined for both ductile and brittle materials.

5 Grain Orientation and Grain Size Effects, Surface Thermal Parameters and Target Toughness have little effect on erosion, but more studies have to be performed in these areas.

6. Temperature: In 1977, Young et al. showed that for 310 stainless steel as the temperature increased from $25^{\circ} \mathrm{C}$ to $975^{\circ} \mathrm{C}$, erosion increased largely. In 1990, Sundarajan found that the erosion rate increased with temperature in some cases and decreased in other cases. Varying amounts of erosion damage is caused by the difference in environmental variables like temperature and humidity. Hence their effects are to be determined to estimate the lifetime of the materials. In 1970, Smeltzer et al. found that erosion losses decreased with increasing temperatures for Ti-6Al-4V, 17-7 PH, 410 stainless steel and $2024 \mathrm{Al}$ at room temperature, $204^{\circ} \mathrm{C}$ and $371^{\circ} \mathrm{C}$. In 1978, Gat and Tabakoff observed that erosion damage varied as the temperature increased from $10^{\circ} \mathrm{C}$ to $204^{\circ} \mathrm{C}$ for different materials, depending upon the incidence angle and test temperature with respect to the thermal properties of the material. 


\subsection{Single Particle Erosion}

Of the numerous models present in the literature to model the erosion of ductile and brittle materials, empirical models based on experimental results are in large numbers than analytical models.

In 1958, Finnie proposed an erosion model of a single particle impact on a ductile surface. The material volume displaced by the particle was estimated through the particle trajectory. This estimation was based on the assumptions that plastic deformation of the surface material produces surface cutting, no cracks develop ahead of the cutting particle and erosion is caused only due to surface material displacement. The formulae used in the model were as follows:

$$
\mathrm{w}_{\mathrm{i}}=\frac{\Gamma \mathbf{g}^{2} \mathbf{F}(\boldsymbol{\alpha})}{\varphi}
$$

Where $g=\frac{\mathbf{r}_{w} \mathbf{m}_{p}}{\mathbf{p}}$

And $F(\alpha)=\sin 2 \frac{\alpha}{\mathbf{k}}-6 \sin ^{2} \frac{\alpha}{\mathbf{k}^{2}}$ for $\tan \alpha<\frac{\mathbf{k}}{6}$

$$
=\cos ^{2} \frac{\alpha}{6} \quad \text { for } \tan \alpha>\frac{\mathbf{k}}{6}
$$

Where $\mathrm{wi}=$ material mass removed

$\rho_{\mathrm{w}}=$ surface material density

$\mathrm{m}_{\mathrm{p}}=$ particle mass

$\mathrm{p}=$ horizontal component of contact stress or plastic flow stress

$\mathrm{k}=$ ratio of vertical to horizontal forces on the particle caused by the surface, which is assumed to be constant during the cutting period

$\psi=$ ratio of length to depth of cut, which is also assumed to be constant throughout

$\alpha=$ impact angle measured from the eroding surface 
The value of force ratio $\mathrm{k}$ for ductile materials was found to be from 1.6-2.4 to highest of 6 , from scratch test experiments. $\Psi$ ranged from 2 to 70 in metal cutting experiments. This erosion process was inadequately described, as the erosion was zero at $0^{\circ}$ and $90^{\circ}$ incidence angles.

In 1967, Finnie et al. proposed that 'p' is approximately equal to the Vickers Hardness Number (VHN) of the eroded material. In 1988, Duffenbaugh et al. showed that the flow stress parameter had different surface properties, in contrast to the one shown by Finnie.

In 1963, Bitter assumed that both cutting and deformation erosion mechanism develop simultaneously. His model included particle and surface material properties along with empirically determined deformation wear and cutting wear factors. The mass of material removed was represented as

$$
\mathrm{w}_{\mathrm{i}}=\left(\mathrm{w}_{\mathrm{i}}\right)_{\mathrm{d}}+\left(\mathrm{w}_{\mathrm{i}}\right)_{\mathrm{c}}
$$

Where $\left(\mathrm{w}_{\mathrm{i}}\right)_{\mathrm{d}}$, the deformation wear $=\frac{\rho_{w} \mathrm{~m}_{\mathrm{p}}\left(\mathrm{g} \sin \alpha-\mathrm{k}_{1}\right)^{2}}{2 \varepsilon_{d}}$

and $\left(\mathrm{w}_{\mathrm{i}}\right)_{\mathrm{c}}$, the cutting wear

$$
\begin{aligned}
& =\frac{2 \mathbf{k} 3 \boldsymbol{\rho}_{\mathbf{w}} \mathbf{m}_{\mathbf{p}}\left(\mathbf{g} \sin \boldsymbol{\alpha}-\mathbf{k}_{1}\right)^{2}\left[\mathbf{g} \cos \boldsymbol{\alpha}-\mathbf{k}_{3}\left(\mathbf{g} \sin \boldsymbol{\alpha}-\mathbf{k}_{1}\right)^{2} \boldsymbol{\varepsilon}_{\mathbf{c}} /(\mathbf{g} \sin \boldsymbol{\alpha})^{1 / 2}\right]}{\left.(\mathbf{g} \sin \boldsymbol{\alpha})^{1 / 2}\right)} \\
& \text { for } \alpha \leq \alpha_{0} \\
& =\frac{\boldsymbol{\rho}_{\mathbf{w}} \mathbf{m}_{\mathbf{p}}\left[\mathbf{g}^{2} \cos ^{2} \boldsymbol{\alpha}-\mathbf{k}_{2}\left(\mathbf{g} \sin \boldsymbol{\alpha}-\mathbf{k}_{1}\right)^{3 / 2]}\right.}{2 \boldsymbol{\varepsilon}_{\mathbf{c}}} \text { for } \alpha \geq \alpha_{0}
\end{aligned}
$$

Where $\varepsilon_{\mathrm{d}}=$ deformation wear factor showing the amount of energy required to remove a unit volume of material surface through deformation

and $\varepsilon_{\mathrm{c}}=$ cutting wear showing the amount of energy required to remove a unit volume of material surface through cutting $\alpha_{0}=$ impingement angle when the horizontal component of $\mathrm{g}$ becomes zero and is represented as

$$
\frac{0.576 \boldsymbol{\rho}_{\mathrm{s}}^{1 / 4} \mathbf{g}^{1 / 2} \boldsymbol{\varepsilon}_{\mathrm{c}}}{\mathbf{y}_{\mathrm{el}}^{5 / 4}}=\frac{\cos \boldsymbol{\alpha}_{0}}{\sin ^{3 / 2} \boldsymbol{\alpha}_{0}}
$$


Where $\mathrm{y}_{\mathrm{el}}$ is the elastic load limit and the material constants $\mathrm{k}_{1}, \mathrm{k}_{2}$ and $\mathrm{k}_{3}$ are represented as

$\mathrm{k}_{1}=\left(\frac{\pi^{2} \mathbf{Y}_{\mathrm{el}}^{5 / 2}}{2 \sqrt{10}}\right)\left(\frac{1}{\rho_{\mathrm{s}}}\right)^{1 / 2}\left(\frac{1-\mathbf{q}_{1}^{2}}{\mathbf{E}_{1}}+\frac{1-\mathbf{q}_{2}^{2}}{\mathbf{E}_{2}}\right)^{2}$

$\mathrm{k}_{2}=0.82 \mathbf{y}_{\mathrm{el}}^{2}\left(\frac{\mathbf{y}_{\mathrm{el}}}{\boldsymbol{\rho}_{\mathrm{s}}}\right)^{1 / 4}\left(\frac{1-\mathbf{q}_{1}^{2}}{\mathbf{E}_{1}}+\frac{1-\mathbf{q}_{2}^{2}}{\mathbf{E}_{2}}\right)^{2}$

$\mathrm{k}_{3}=\left(\frac{0.288}{\mathbf{y}_{\mathrm{el}}}\right)\left(\frac{\boldsymbol{\rho}_{\mathrm{s}}}{\mathbf{y}_{\mathrm{el}}}\right)^{1 / 4}$

Where $\mathrm{q}_{1} \& \mathrm{q} 2$ and $\mathrm{E}_{1} \& \mathrm{E}_{2}$ are Poisson's ratios and young's moduli of particle and surface respectively.

The model produced good experimental correlation and the variation of wear with impact angle was well explained.

In 1968a, Neilson and Gilchrist simplified Bitters expression by changing the cutting wear component as

$$
\begin{aligned}
\left(\mathrm{w}_{\mathrm{i}}\right)_{\mathrm{c}} & =\frac{\boldsymbol{\rho}_{\mathbf{w}} \mathbf{m}_{\mathbf{p}} \mathbf{g}^{2} \cos ^{2} \alpha \sin \eta \boldsymbol{\alpha}}{2 \boldsymbol{\varepsilon}_{\mathbf{c}}} & \text { for } \alpha \leq \alpha_{0} \\
& =\frac{\boldsymbol{\rho}_{\mathbf{w}} \mathbf{m}_{\mathbf{p}} \mathbf{g}^{2} \cos ^{2} \boldsymbol{\alpha}}{2 \boldsymbol{\varepsilon}_{\mathbf{c}}} & \text { for } \alpha \geq \alpha_{0}
\end{aligned}
$$

Where $\alpha_{0}=\frac{\pi}{2 \eta}$

and $\eta=$ empirical constant

Bitter couldn't justify properly for his assumptions that deformation wear is the dominant wear mechanism at normal incidence and cutting wear at shallow angles. So in 1981, Hutchings proposed a simple analytical model at normal incidence by platelet formation. He used spherical particles in his model as they develop platelet formation, which is the dominant erosion mechanism at normal incidence and have strong theoretical analysis of impact than angular particles.

In 1980, Suh proposed the failure of fragments through critical criterion, wherein the failure occurs when the maximum plastic strain within the fragment reaches a critical value ' $\varepsilon_{\mathrm{c}}$ '. This idea was later implemented by Hutchings. He represented the energy balance of a simple impact as: 


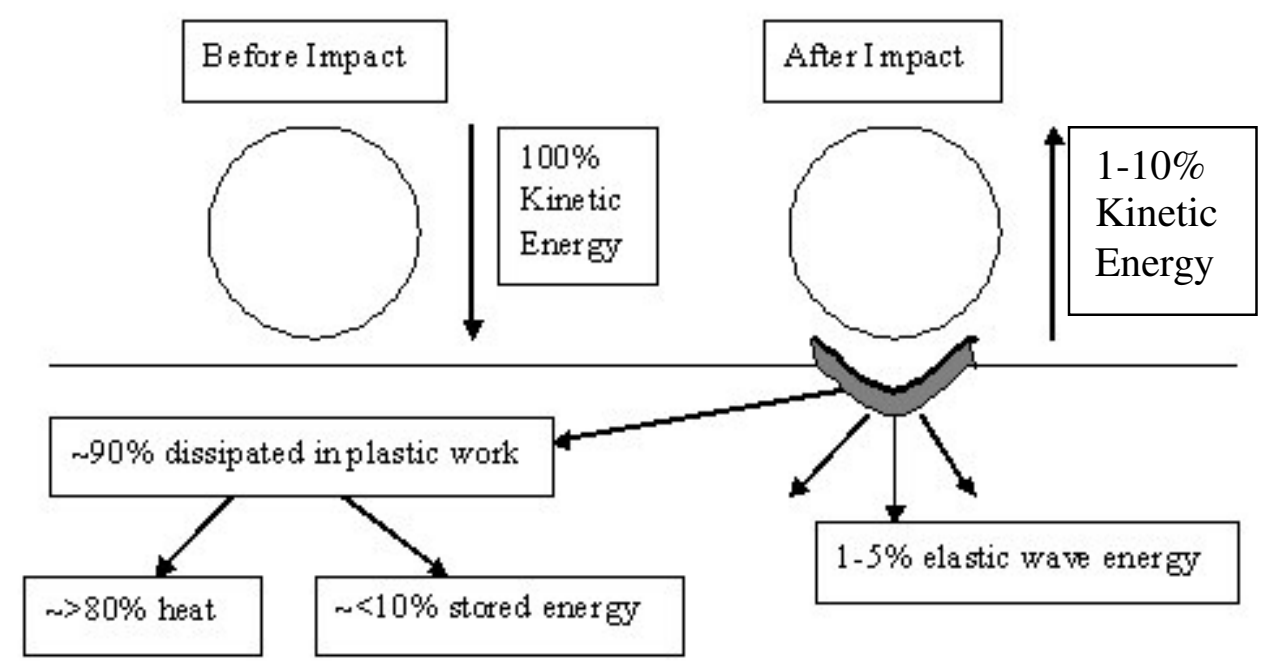

Figure 2.2: Energy balance for a spherical particle before and after normal impact ${ }^{[2]}$

The equations obtained through his theory were explained as follows:

He considered the formation of plastic deformation in the target due to the impact of a large number of spherical projectiles randomly distributed over the surface, each traveling at the same velocity. He assumed that the plastic strain increments ' $\Delta \varepsilon_{\mathrm{p}}$ ' caused by each particle are of same magnitude and are directed with circular symmetry about the line of impact of the sphere.

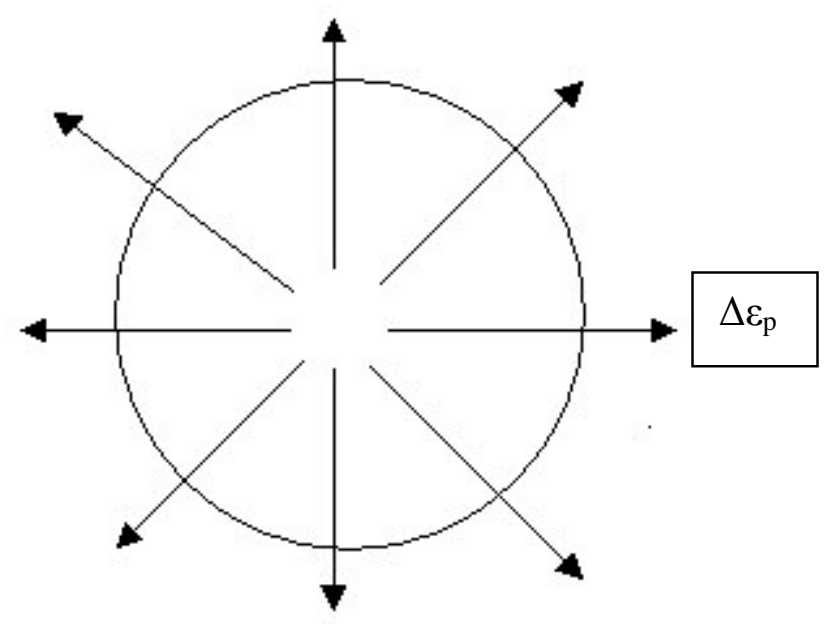

Figure 2.3: Plastic strain directing radially outward in the plane of the surface due to single impact ${ }^{[2]}$ 
Hence any point on the material surface will be subjected to successive increments of strain of magnitude ' $\Delta \varepsilon_{\mathrm{p}}$ ', randomly present in the plane of the surface. Therefore according to random walk theory by Fellar, the value of the resultant strain at any point after ' $\mathrm{N}$ 'impacts was found to be $\Delta \varepsilon_{\mathrm{p}} \mathrm{N}^{1 / 2}$. If ' $\mathrm{N}_{\mathrm{f}}$ ' is the mean number of impacts or strain increments required for material removal, then the failure criterion is given by

$$
\Delta \varepsilon_{p} N_{f}^{1 / 2}=\varepsilon_{c}
$$

For simplicity, Hutchings assumed the material being eroded as rigid perfectly plastic solid with no work hardening and eroding particles as rigid non-deforming spheres of radius $r$ and density $\sigma$. Hence mass of one sphere was as shown as

$$
\mathrm{m}=\frac{4}{3} \pi \mathbf{r}^{3} \boldsymbol{\sigma}
$$

And its kinetic energy with impact velocity $v$ was $m v^{2} / 2$.

The target material was considered to resist indentation with a constant pressure 'P'. Elastic forces were neglected and this was confirmed from the energy balance where $90 \%$ of the initial kinetic energy of the particle was dissipated into plastic deformation in the material. Of all the initial kinetic energy of the particle was used for indentation, then its volume was given as

$$
\mathrm{V}=\frac{m v^{2}}{2 P}
$$

This formula was first found by Martel in 1985 and was true for the velocity range of $10-500 \mathrm{~m} / \mathrm{s}$. He presented that the volume of metal that is plastically deformed around an indentation is some fraction ' $\alpha$ ' of the volume of indentation. Hence the volume of material that is plastically strained by each impact was given by $\alpha v^{2} / 2 \mathrm{P}$. This volume was known as elementary volume. If there were ' $\mathrm{N}_{\mathrm{f}}$ ' impacts, then the volume loss per impact was given by $\alpha \mathrm{m}^{2} / 2 \mathrm{PN}_{\mathrm{f}}$. The mass loss from the target per unit mass of impinging particles was known as the erosion and was represented as

$$
\mathrm{E}=\frac{\alpha \rho \vartheta^{2}}{2 \mathbf{P} \mathbf{N}_{\mathrm{f}}}
$$


Where $\rho=$ target material density.

In 1951, Tabor showed that the average strain developed in a metal by the impact of a rigid sphere of radius ' $r$ ' for a quasi-static indentation was given by

$$
\varepsilon=0.2 \frac{\mathbf{a}}{\mathbf{r}}
$$

Where $\mathrm{a}=$ final cordial radius of indentation

and $\varepsilon=$ strain in an equivalent uniaxial component test.

The parameter ' $\alpha$ ' was found by equating the initial kinetic energy of the impinging sphere with the work done in forming the indentation. It was calculated as

$$
\varepsilon=\mathbf{r} \sqrt{2 \vartheta}\left(\frac{2 \boldsymbol{\sigma}}{3 \mathbf{P}}\right)^{1 / 4}
$$

Hence from the above equations, the erosion was found as

$$
E=\frac{0.033 \alpha \rho \sigma^{1 / 2} \vartheta^{3}}{\varepsilon_{c}^{2} \mathbf{P}^{3 / 2}}
$$

\subsection{Multiple Particle Erosion Models}

Tabakoff at al. developed an empirical wear model to estimate the impact wear per unit mass of impacting coal ash particles, with varying impact angles, impact velocities, tangential restitution ratio and three empirical constants. Bitter results were obtained for impact angles varying from $10^{\circ}-60^{\circ}$ measured with respect to the horizontal. They also proposed semi-empirical impact wear rate equations for numerous metals. Their modals produced perfect results for impact angles ranging from $30^{\circ}-60^{\circ}$ along with impact velocities ranging between $85 \mathrm{~m} / \mathrm{s}$ to $137 \mathrm{~m} / \mathrm{s}$. The wear rate also included the temperature effect, particle impingement velocity magnitude and angle; the normal and tangential restitution ratios and depended on the ratio of material strengths at ambient and operating temperatures. The normal and tangential restitution ratios were considered as the calculated particle velocity ratios before and after impact. 
In 1979, Hutchings analyzed impact pressure at normal impact angles using the one-dimensional elastic wave theory and contact analysis between a non-deforming sphere and the target. He derived at the result that the transient impact pressure had little influence on the wear process, as the duration of the impact pressure was very less than the total time period of the particle-surface impact. The mass wear per unit mass of impacting particles was predicted by performing an analysis of wear at high impact angles with a load-cycle (high strains) fatigue model. The consequent results had good correlation with that of experimental data. But some parameters like the ratio of the volume-deformed metal to that of the indentation and the average strain related to the volume were hard to measure.

In 1991, Sundarajan and Shewmon used critical plastic strain for material removal by particles impacting at normal angles. This model presented fine match with experimental results as they assumed material deformation through the formation and subsequent removal of an extruded material lip along the rim of the indentation crater.

In 1998, Zhu employed surface fatigue as the material deformation mechanism for low velocity impact wear. It was seen that the local plastic deformation, which develops the surface fatigue was directly proportional to the local elastic deformation and the material loss was directly related to the surface material volume that underwent elastic deformation. 


\section{CHAPTER 3. FINITE ELEMENT ANALYSIS}

\subsection{Introduction}

The loss of material due to solid particle impacts was estimated through numerous experimental works performed in the past. Many models were built based on these results for a specified set of materials and environmental conditions. But none of these models studied the effects on the solid particle and its material loss. Also different types of particles are utilized for different applications and it's very difficult to conduct experiments for each of them. So in the current work, a finite element model is proposed, that takes into account all the boundary conditions and estimates material loss for the particle due to impact.

To estimate the material loss of the particle, a particular method is followed. A sand particle (quartz silica) hits an aluminum alloy 6061 plate of T6 type and rebounds. This creates material failure in the particle and the metal plate. The process is run by varying the parameters like particle size, particle velocity, particle shape and angle of attack. These are explained in detail later on.

The material properties of the particle (erodent) and the metal plate (target surface) are the main factors in the modeling of the erosion process. These are taken from the internet ${ }^{[6,9,11,12,19]}$ and are as shown below:

Material Properties of Al 6061 T6:

Young's Modulus E = 72Gpa.

Yield Stress $\sigma_{\mathrm{s}}=320 \mathrm{MPa}$.

Mass Density $\rho=2850 \mathrm{~kg} / \mathrm{m}^{3}$

Poisson's ratio $\gamma=0.34$

Material Properties of Silica:

Young's Modulus E = 100Gpa. 
Tensile Stress $\sigma_{\mathrm{t}}=80 \mathrm{Mpa}$.

Compressive Stress $\sigma_{\mathrm{c}}=800 \mathrm{Mpa}$.

Yield Stress $\sigma_{\mathrm{s}}=800 \mathrm{MPa}$.

Mass Density $\rho=2650 \mathrm{~kg} / \mathrm{m}^{3}$

Poisson's ratio $\gamma=0.17$

\subsection{Particles}

As mentioned in the earlier chapter, particles are generally classified as round and angular. Their shape and orientation usually determine the geometry of the deformation after impact. Rounded particles deform the material surface by ploughing and displacing material to the side and in front of the particle. When the particles strike in the neighboring areas of the deformed surface, the heavily strained material gets detached from the rim of the cater. This leads to both ploughing and wedge forming modes of abrasion (Figure a). In the case of an angular particle, the deformation caused by it depends on its orientation as it impacts the surface and on whether the particle rolls forward or backward during contact. A particle rolling forward is known as "Type I cutting" (Figure b), which indents the surface and lifts the material onto prominent lip, that is removed by subsequent neighborhood impacts. Whereas a particle rolling backwards is known as "Type II cutting" (Figure c), which rarely occurs, but with true machining action.

(a) Ploughing
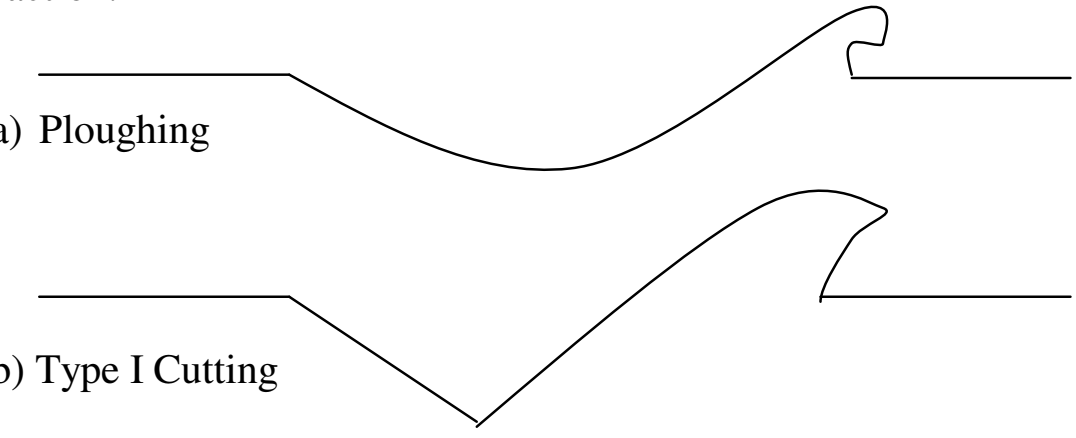

(c) Type II Cutting

Figure 3.1: Basic Types of Impact Damage ${ }^{[26]}$ 
In the present work, three different shapes of silica particles are considered. According to their contact area with the material surface, they are divided into the following categories:

1. Point Contact (Shape 1)

2. Line Contact (Shape 2)

3. Quadrilateral Area of Contact (Shape 3)

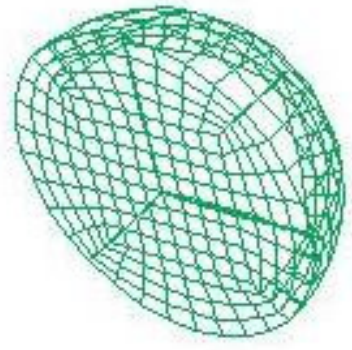

Point Contact (Shape 1)

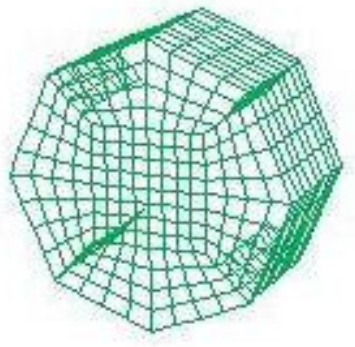

Line Contact (Shape 2)

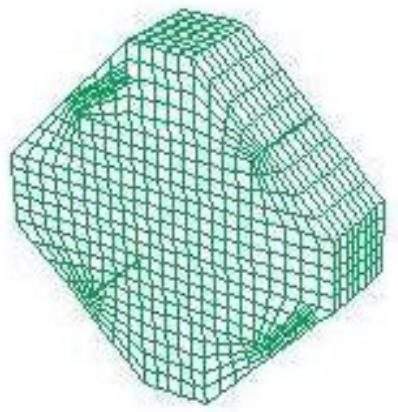

Area Contact (Shape 3)

Figure 3.2: Half Sectional Isometric View of different types of particles

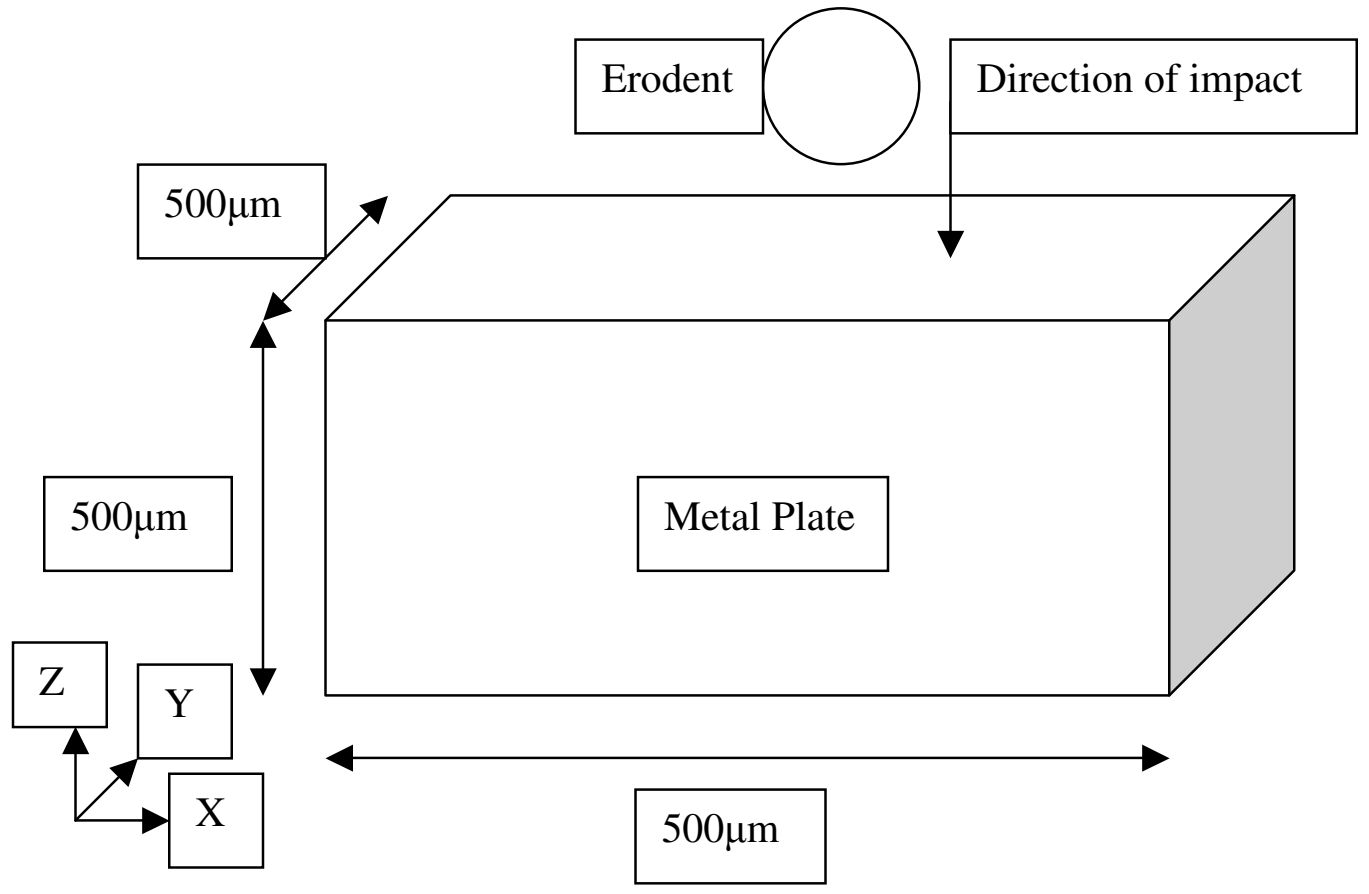

Figure 3.3: Schematic diagram of single particle impact ${ }^{[2]}$ 


\subsection{Finite Element Model}

The analysis of any model through finite element simulation undergoes three steps:

1. LS-INGRID (Pre-processor)

2. LS-DYNA3D (Solver)

3. LS-TAURUS (Post-processor)

\subsubsection{LS-INGRID}

It can build complex 3D models; specify boundary conditions and sliding surfaces. The LS-INGRID model is generated by writing a user input file. This input file includes all the part definitions, control commands, boundary conditions, sliding surfaces and material commands, which can be modified interactively. The model is meshed using index progressions and the units are required to be constant (which are to be entered by the user).

In the present model, both the aluminum plate and the sand particle use "Material Number 3' called "Kinematic/Isotropic Elastic-Plastic". This material uses 3-D Hexahedral Brick elements for meshing. The aluminum plate is meshed in such a way that fine mesh is obtained near the contact area and course mesh away from the contact area. This is because the deformation in plate is maximum at the contact area. Whereas the sand particle is meshed uniformly throughout, to look at the stress patterns developed in it and the subsequent regions of failure. The INGRID input file is written in such a way that all the parameters involved like particle velocity, size, etc. could be varied easily with minimum user output. 


\subsubsection{Boundary Conditions}

In the present report, the modal is built in the $\mathrm{XZ}$ plane. Due to the symmetric nature of the materials, only one half of the modal is considered for analysis in order to reduce the computation time. The modal is built at the center of the three coordinate axes. All the sides (except the front side) and bottom surface of the plate are constrained for translation in all directions. The front side of the plate and the particle are constrained for translation only in Y-direction as the symmetrical plane $\mathrm{XZ}$ passes through them. When the particle hits the plate, to account for the impact and friction between, a sliding surface is defined for both of them. A small region around the impact area on the top surface of the plate and the lower half surface of the particle are defined as the sliding surfaces. A symmetric diagram with the boundary conditions is shown below.

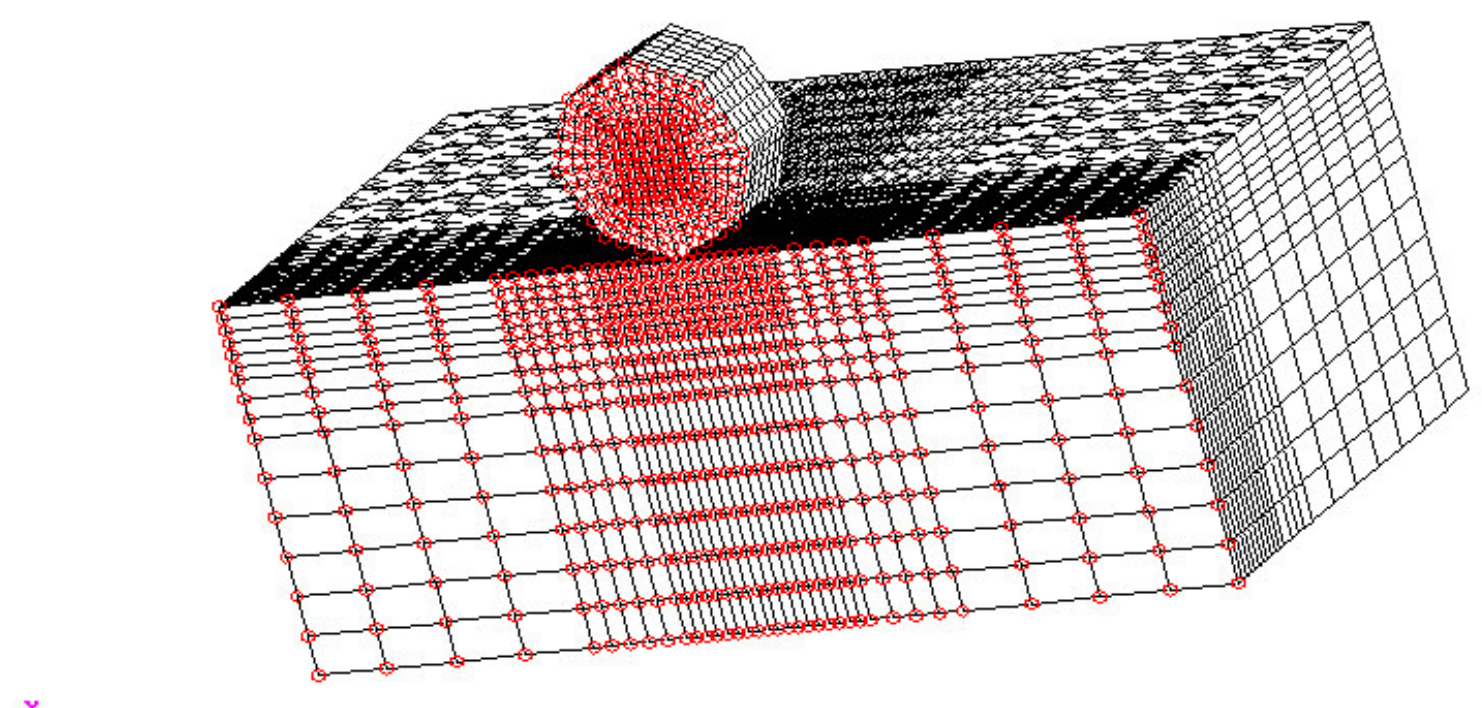

Figure 3.4: Boundary conditions along the symmetric plane of a symmetric model (half modal) for shape 2 (line contact) 


\subsubsection{Material Models}

The last step in writing the input file in LS-INGRID is assigning the material properties for the materials. Though the properties are mentioned in LS-INGRID, they can also be given in LS-DYNA3D, which has several built-in material types for different material characteristics.

In the present model as both metal plate (target surface) and the brittle sand particle (erodent) under elastic and plastic deformations, they have been assigned 'Material Number 3' called "Kinematic/Isotropic Elastic-Plastic". This material requires the following properties:

Modulus of Elasticity

Mass Density

Poisson's Ratio

Yield Stress

Tangent Modulus

Failure Strain

After assigning the material properties, a LS-DYNA3D file is created, which is sent into LS-DYNA3D for solving.

\subsubsection{LS-DYNA3D}

In 1995, Hallquist et al. described LS-DYNA3D as a fully vectorized, explicit, three dimensional, dynamic analysis code, which can analyze problems having high deformation rates and large deflections. This thesis deals on a non-linear transient dynamic analysis. The modal is run for a period ranging from $1-4 \mu \mathrm{s}$, whose time step is based on the smallest element size in the modal. Basically, the time period is taken in such a way that the particle rebounds after impact. 
As the impact takes place, the kinetic energy of the particle is converted into the internal energy of the metal surface or the oxide layer. In 1997, Yalamanchalli assumed in his study that when the internal energy of the system reaches a peak, maximum damage occurs to the material surface. He estimated the failure by comparing the effective stresses of all elements with a failure stress at this instant of time. Later on in 1998, Balasubramaniyam showed that the elements would not have the same stress levels during the initial contact and at the time of maximum internal energy. He used critical strain as the failure criteria for finding the volume fraction of critical elements. But a careful observation at the stage of maximum stresses and at the stage of maximum internal energy reveals that at the later stage, more number of elements fail. Hence the method chosen by Yalamanchalli is correct and the same method is used in this thesis. At the stage of maximum internal energy, both the maximum principal stresses and the minimum principal stresses are taken and are compared with tensile and compressive stresses respectively to estimate failure.

\subsubsection{LS-TAURUS}

It acts as the post-processor of any analysis being performed. The solved dyna file is sent into LS-TAURUS to be post processed. LS-TAURUS is an interactive and userfriendly post processor that can read the binary plot files and time history files produced from LS-DYNA3D. The various results that are generated in LS-TAURUS are stresses, strains, displacements, nodal forces, reaction forces and different types of energies. These results are displayed in various forms like contour plots, arrow plots, data reports and XY graph plots. Of these results, the stresses and the displacements are necessary for the failure analysis. The stress results estimate the quantitative failure, whereas the displacement results estimate the qualitative failure. These stresses are in turn categorized into the following:

1 Von Mises Effective Stress

2 Maximum Shear Stress

3 Maximum Principal Stress 


\section{Middle Principal Stress}

\section{Minimum Principal Stress}

A sample plot for each of the graphs of energies versus time, kinetic energy versus time and internal energy versus time and maximum and minimum principal stresses versus elements for Shape 3 Particle at $18^{0}$ Impact Angle and 45um/us Velocity is shown below. These graphs are generated from the binary plot files.

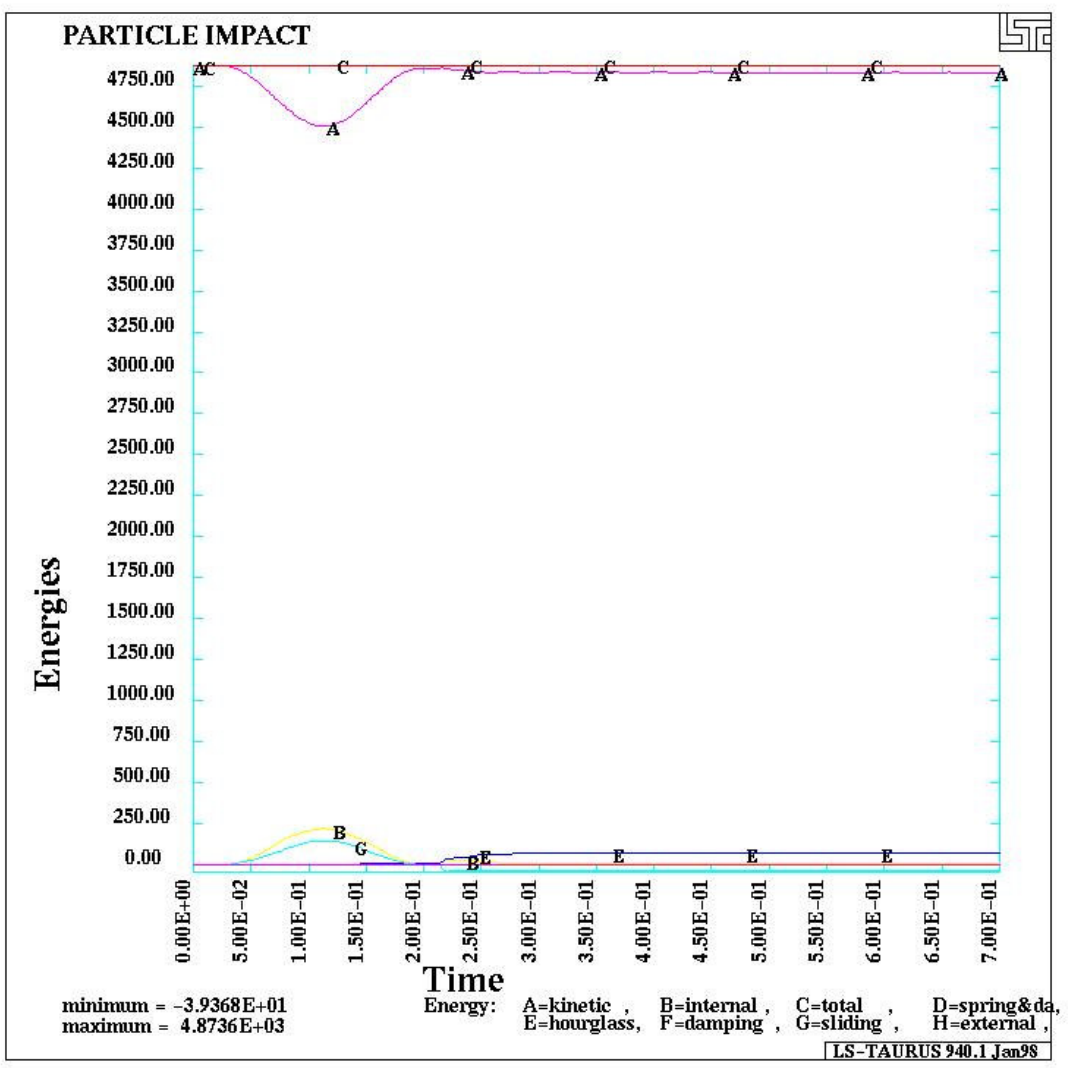

Figure 3.5: Plot of Energies versus Time 


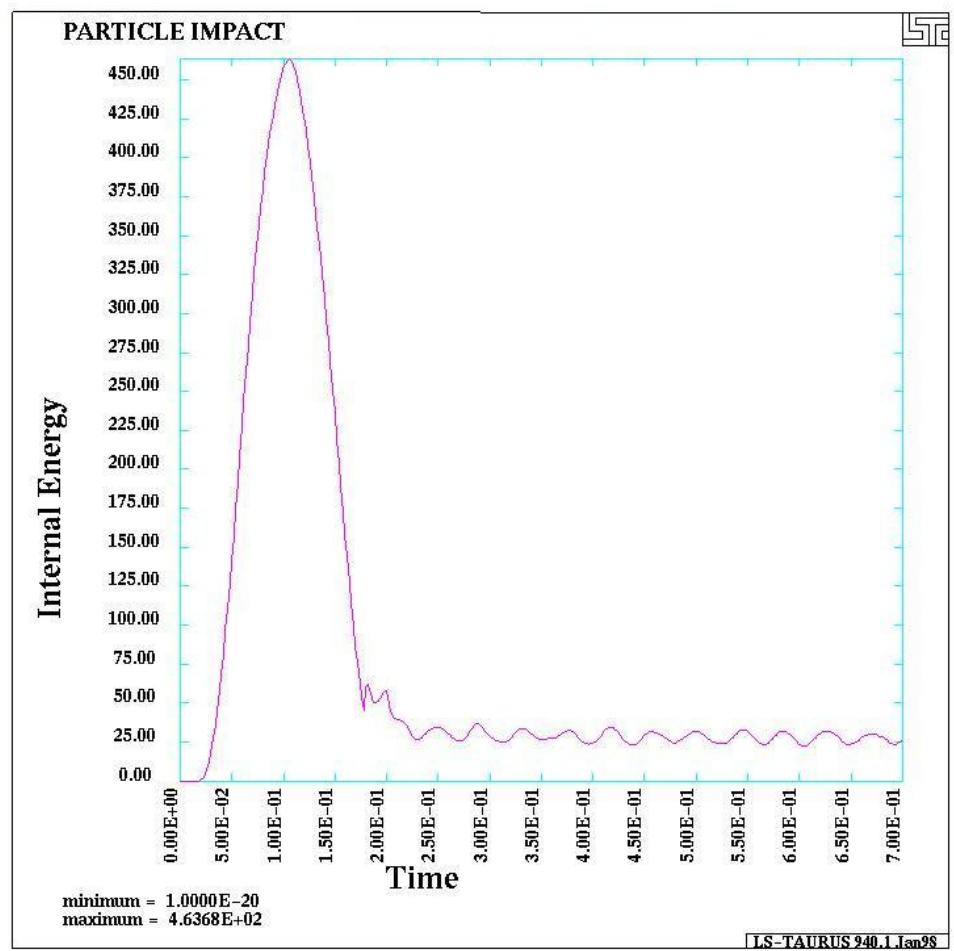

Figure 3.6: Plot of Internal Energy versus Time

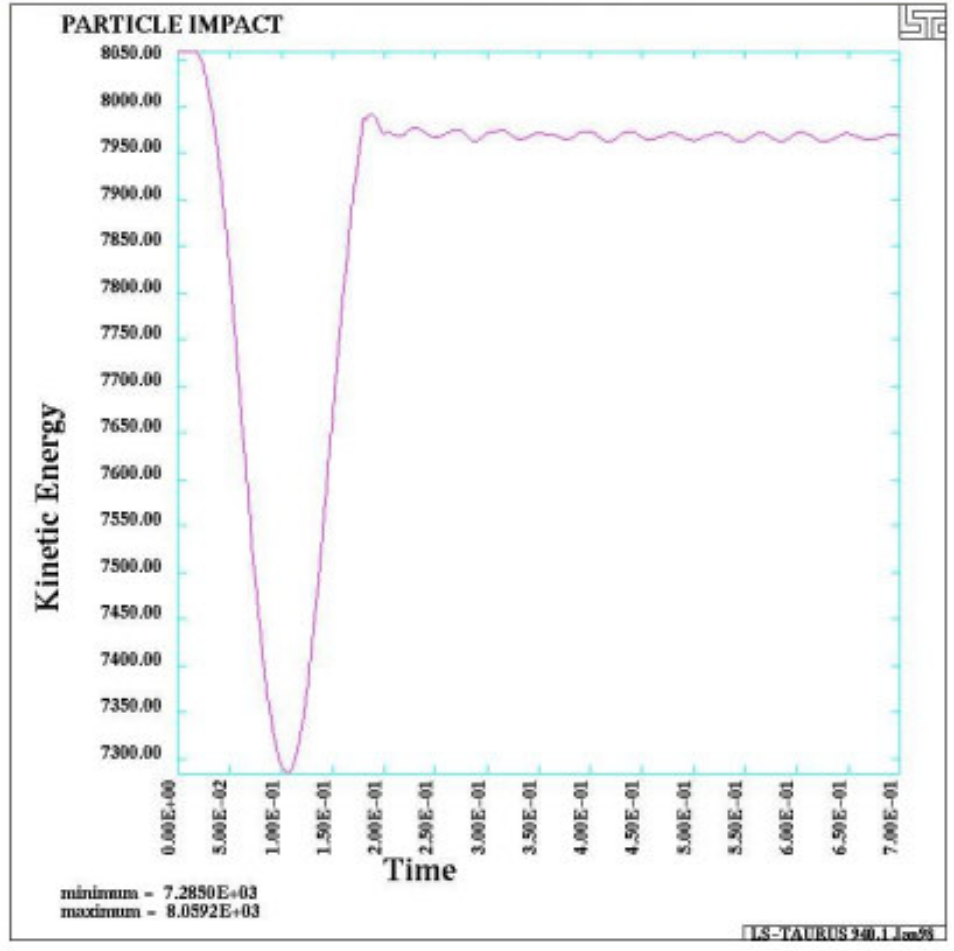

Figure 3.7: Plot of Kinetic Energy versus Time 


\subsection{Failure Criteria}

In the present analysis, Maximum Normal Stress Criterion is used to predict the failure of sand particle, a brittle material. This criterion is also known as Normal Stress or Coulomb or Rankine Criterion. According to this theory, when the maximum (normal) principal stress reaches either the uniaxial tension strength $\sigma \mathrm{t}$ or the uniaxial compression strength $\sigma c$, failure occurs i.e.

$$
-\sigma_{c}<\left(\sigma_{1}, \sigma_{2}\right)<\sigma_{t}
$$

Where $\sigma_{1}$ and $\sigma_{2}$ are the maximum and minimum principal stresses.

\subsection{Estimation of Material Loss due to Impact}

The amount of material lost in the sand particle is estimated by considering the maximum and minimum principal stresses of all its elements at the stage of maximum internal energy. The maximum principal stresses are compared with the tensile strength of the sand particle whereas the minimum principal stresses are compared with the compressive strength. For rock materials, the compressive strength increases by a factor of ' $\mathrm{k} *$ the corresponding maximum principal stress', where $\mathrm{k}$ is taken as 3 . Thus the minimum principal stresses are compared with this new increased compressive strength. To find the elements that have exceeded the corresponding stress values, a macro is written in MS-EXEL. An example of the each of the graphs of maximum and minimum principal stresses versus elements is shown below. The volume loss is estimated by calculating the volume of one failed element and multiplying it with the total number of elements. The volume loss is represented in the form of graphs between itself versus impact angle ranging from $16^{0}-24^{0}$ at velocities ranging from $30-50 \mu \mathrm{m} / \mu$ s for different sizes and shapes of the sand particle. 
Variation of maximum principal stresses at $16 \mathrm{degs}$ impact angle and a velocity of $45 \mathrm{um} / \mathrm{us}$

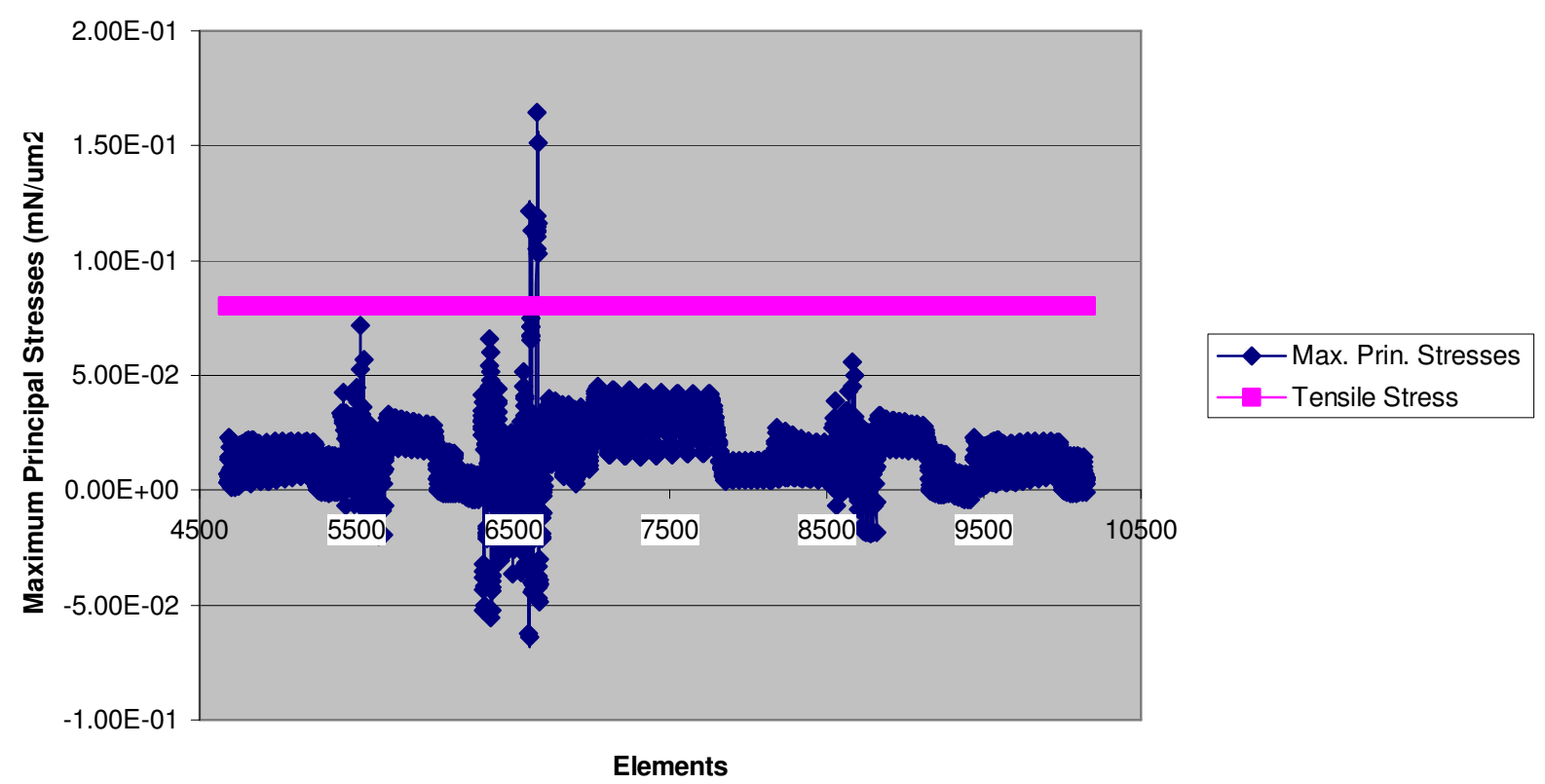

Figure 3.8: Plot of Maximum Principal Stresses versus Element Numbers

Variation of Minimum Principal Stress at 18degs impact angle and a velocity of $45 \mathrm{um} / \mathrm{us}$

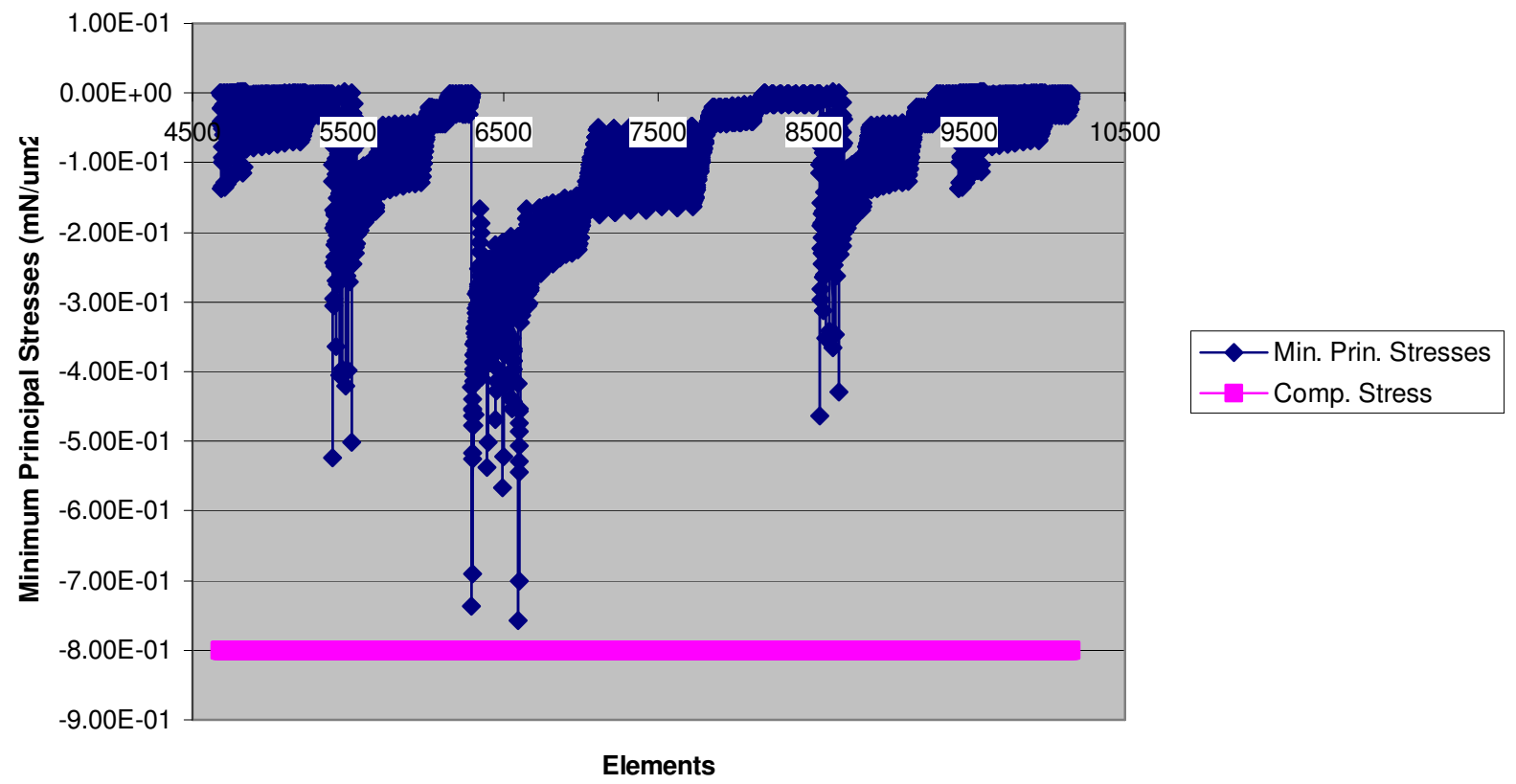

Figure 3.9: Plot of Minimum Principal Stresses versus Elements Numbers 


\section{CHAPTER 4. RESULTS AND DISCUSSIONS}

\subsection{Introduction}

This chapter deals with the variation of stress distribution in the sand particle and the estimation of volume loss in it during its impact with the metal plate. The results were compared with the experimental results of A.J.Sparks and I.M.Hutchings and were found to be a good match.

The different parameters and their variations used to calculate the volume loss are mentioned below:

- $\quad$ Particle Velocity $(30-50 \mu \mathrm{m} / \mu \mathrm{s}$ with a step of $5 \mu \mathrm{m} / \mu \mathrm{s})$

- $\quad$ Impact Angle $\left(16^{0}-24^{0}\right.$ with a step of $\left.2^{0}\right)$

- $\quad$ Particle Diameter (100-300 $\quad$ ms with a step of $50 \mu \mathrm{m})$

- $\quad$ Particle Shape (Point Contact, Line Contact and Area Contact)

\subsection{Influence of Shape}

The shape of the particle actually determines the area of contact between the particle and the plate. As mentioned above, based on the area of contact, the particles are classified as point contact, line contact and area contact. A schematic diagram of all these particles is shown below. The first three of the four parameters used were varied for all the three contact type particles. The changes caused by these parameters in the stress levels and volume loss of the particle is explained briefly below:

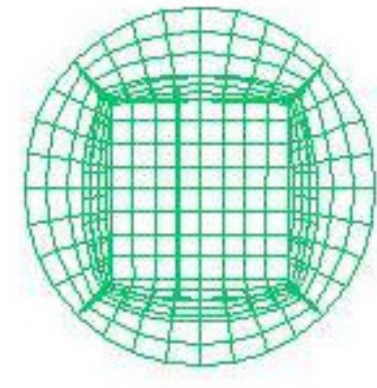

Point Contact (Shape 1)

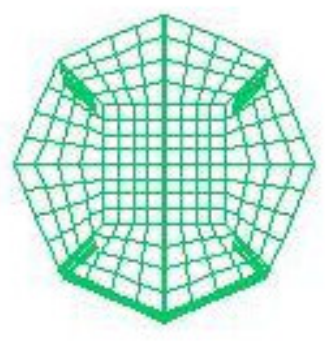

Line Contact (Shape 2)

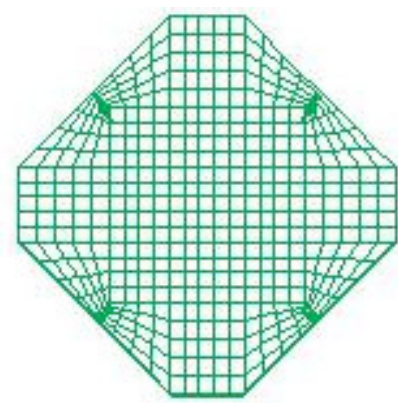

Area Contact (Shape 3)

Figure 4.1: Half sectional front view of different particle shapes 


\subsubsection{Influence of Shape 1 (Point Contact)}

For the particle having a point contact with the metal plate, a sphere is considered. Its size is varied from $100-300 \mu \mathrm{m}$ with a step of $50 \mu \mathrm{m}$. For all these sizes, the velocity is varied from $30-50 \mu \mathrm{m} / \mu \mathrm{s}$ for an impact angle ranging from $16^{0}-24^{0}$. As the particle impacts the plate, the stresses are developed at the point of contact in the particle, with the maximum stress at it. These stress waves travel upwards and keep expanding and contracting. During expansion, the medium stress accumulated at four corners of a square within the sphere. In contraction, the stresses shaped themselves in the form of " $U$ " above the point of contact, but when hit it with greater velocity; they get accumulated at the center of the particle. A set of figures for a sample model showing the variation of these stress levels is shown below. These stresses include the maximum and minimum stresses.

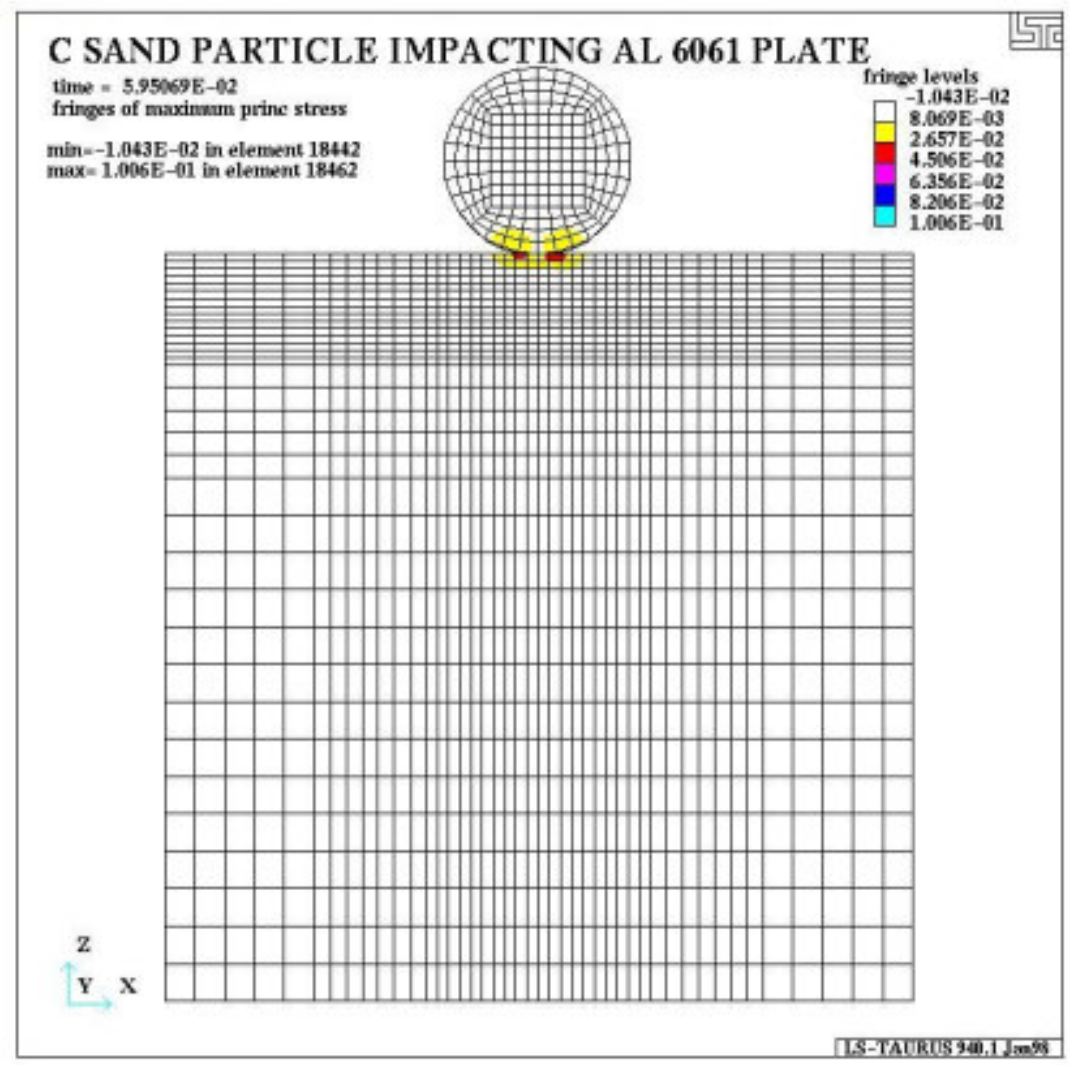



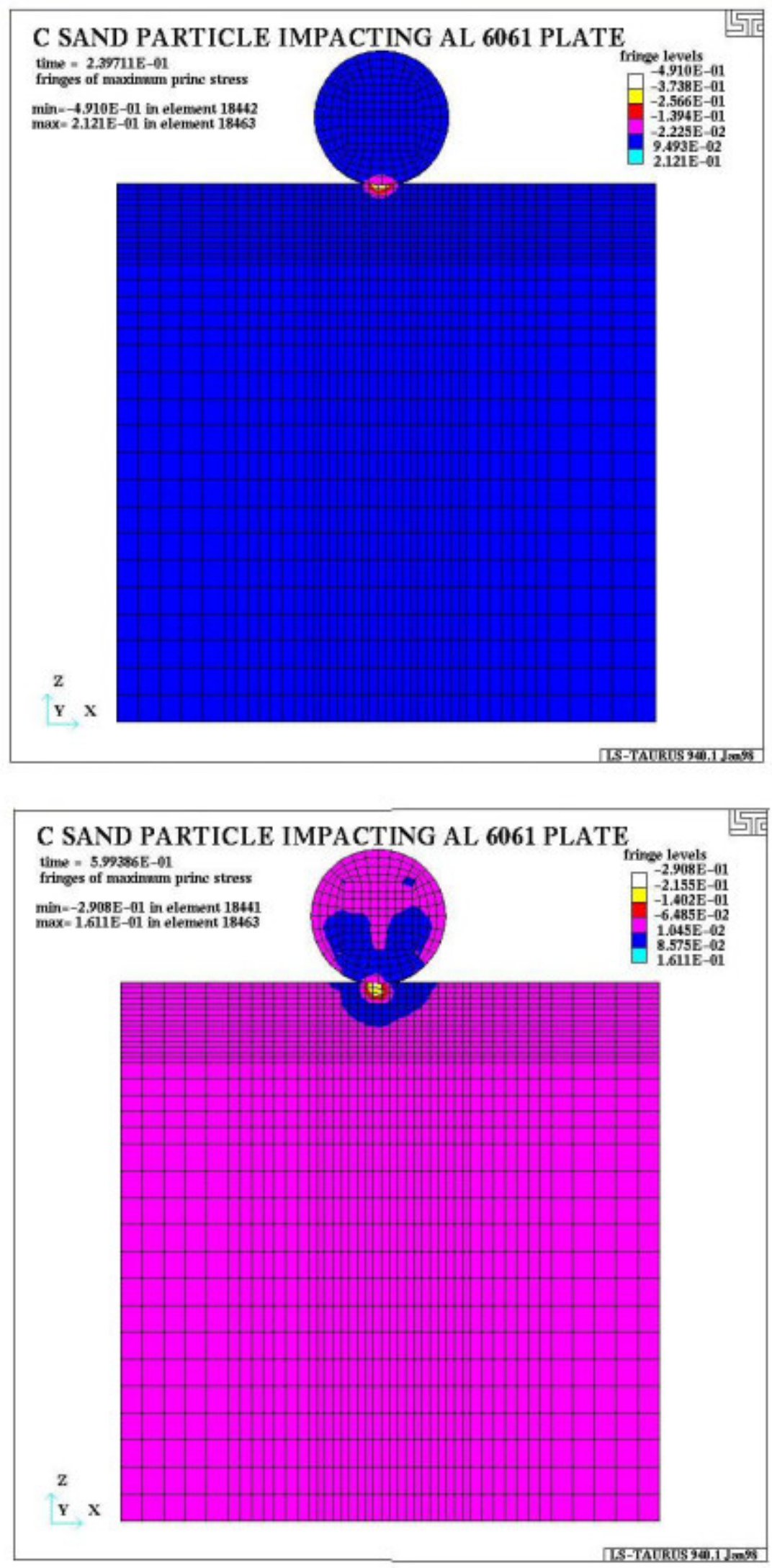

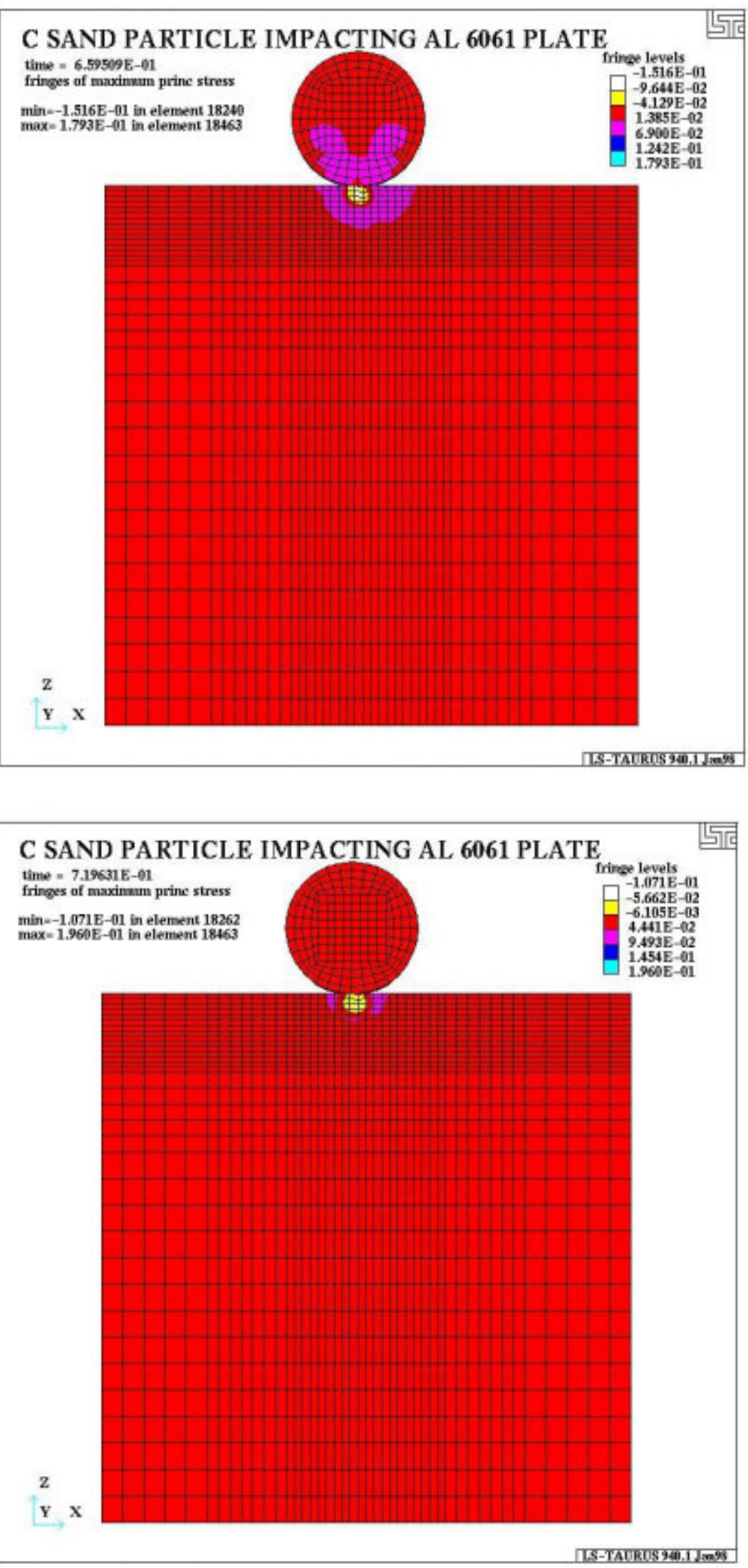
Figure 4.2: Fringes of Maximum Principal Stress of $200 \mu \mathrm{m}$ size particle impacting the plate at $20^{\circ}$ with a velocity of $40 \mu \mathrm{m} / \mu \mathrm{s}$

The stress flow in the minimum principal stresses was observed to be quite clear and uniform. Also the expansion and contraction occurs one more time than in maximum principal stresses. These changes are shown in the below figures.

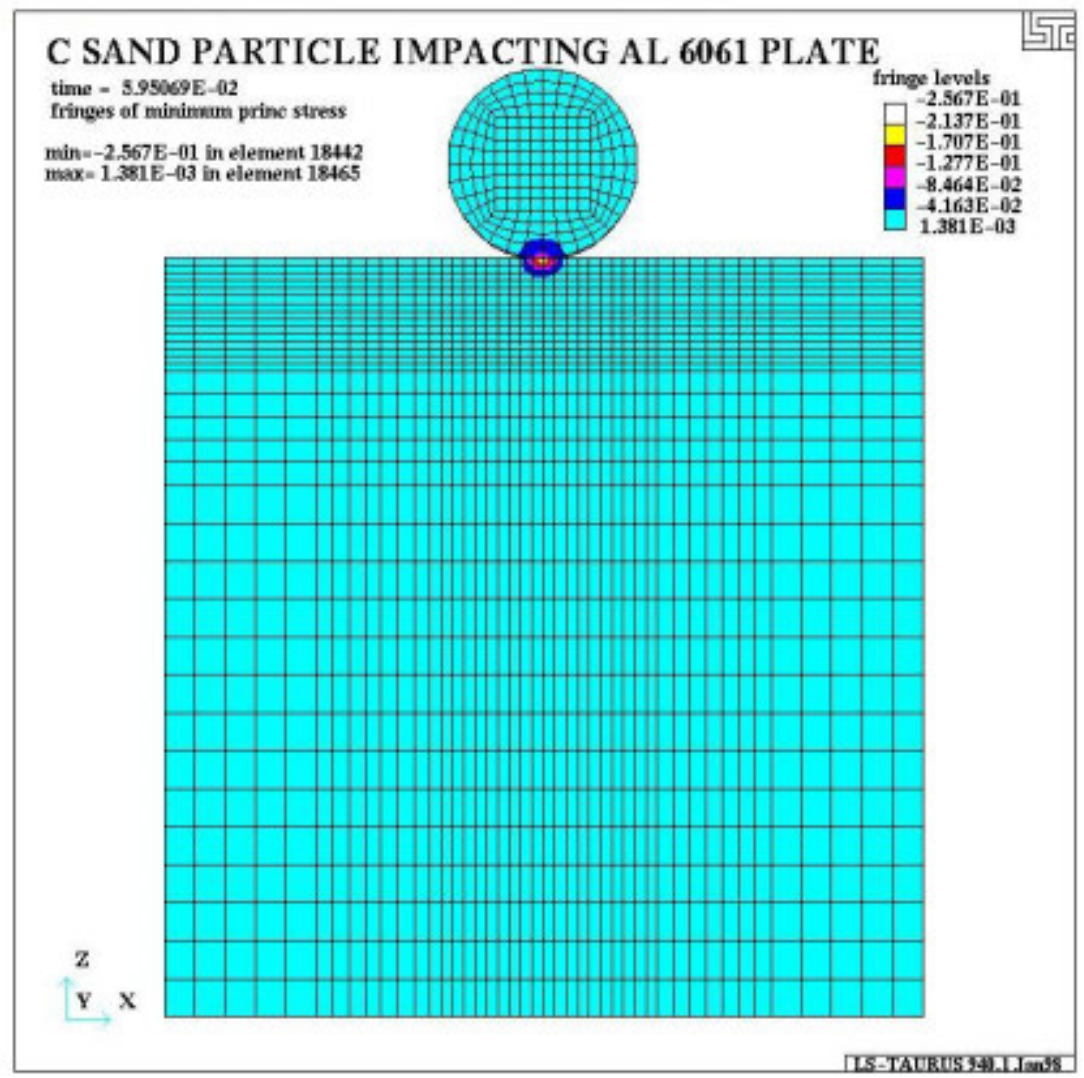



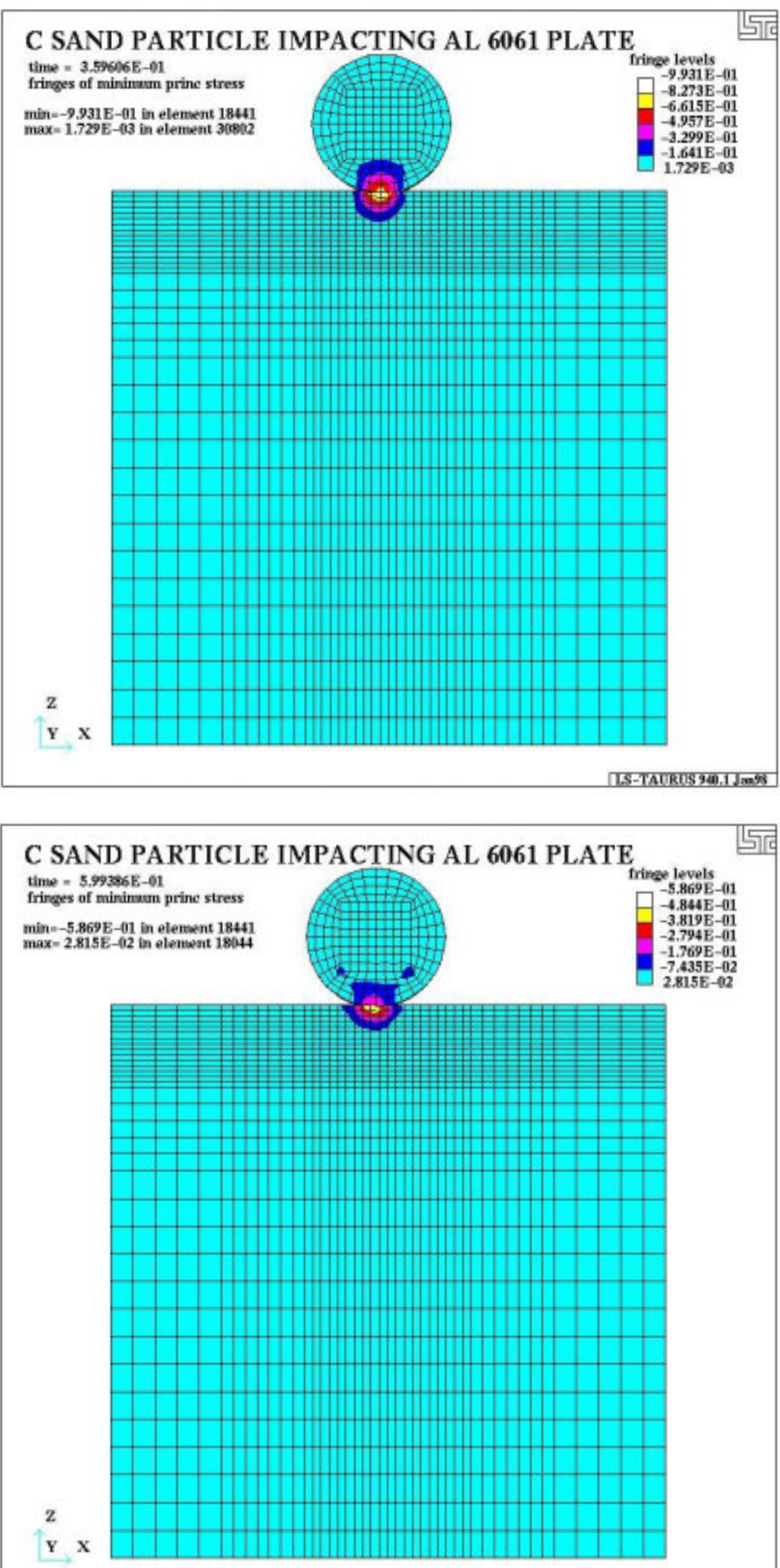

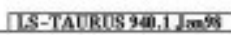



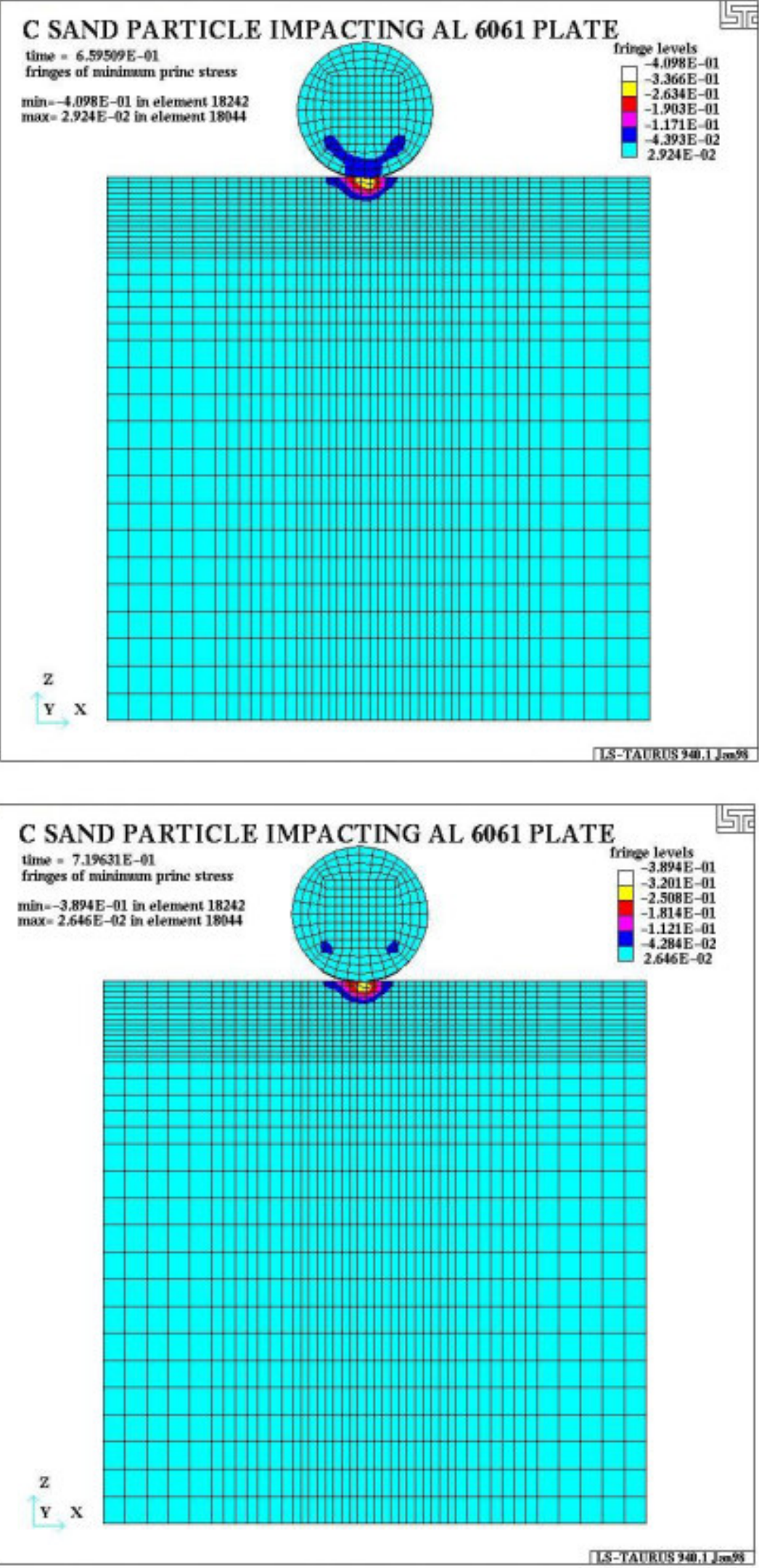


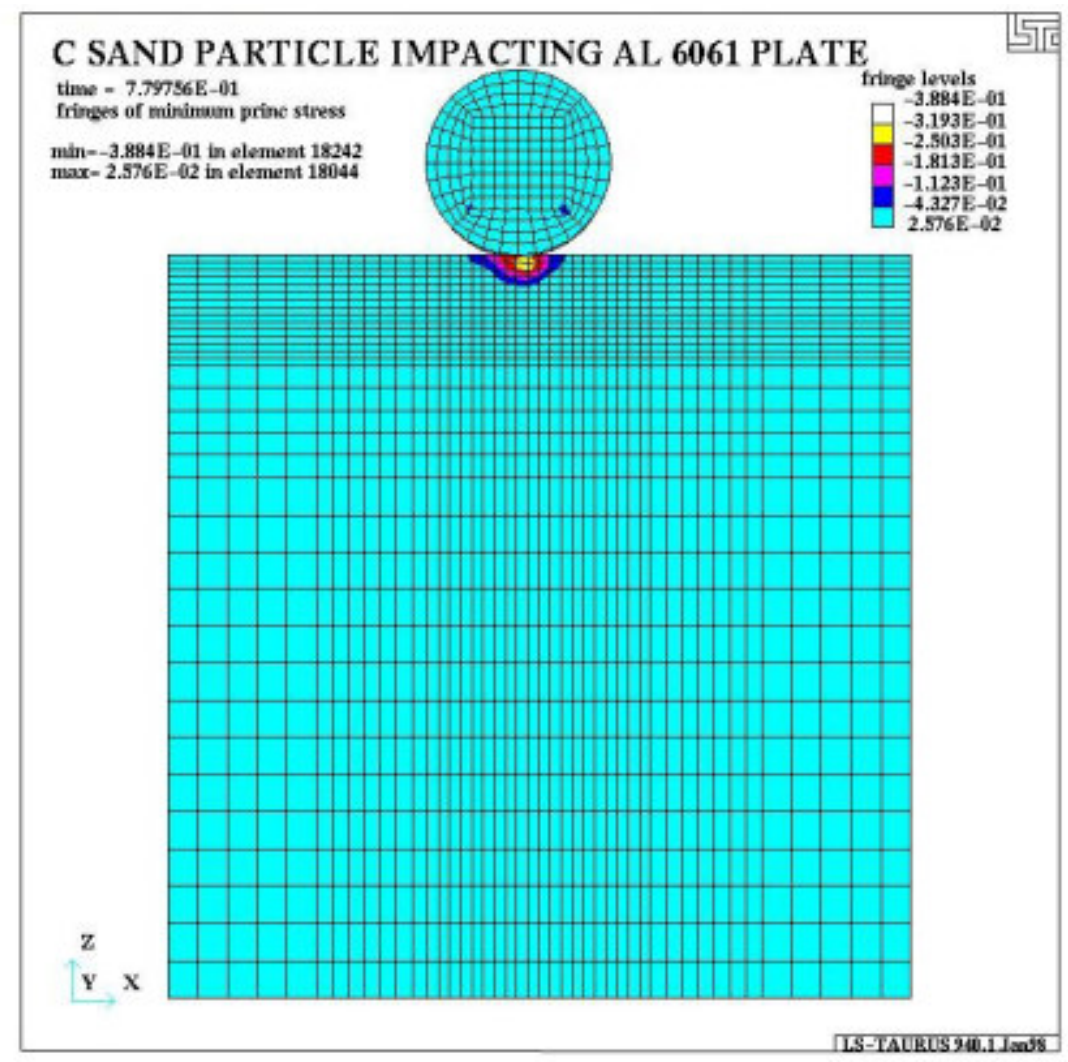

Figure 4.3: Fringes of Minimum Principal Stress of $200 \mu \mathrm{m}$ size particle impacting the plate at $20^{\circ}$ with a velocity of $40 \mu \mathrm{m} / \mu \mathrm{s}$

The variation of the first three parameters made significant changes in determining the volume loss of the particle. These are shown in the form of graphs for all the sizes, impact angles and impact velocities in the below figures. A look at these figures shows that in general, as the particle velocity, impact angle and particle size increases, the volume loss increases linearly. However, a few ups and downs in the graphs are encountered. The reason for this being that the measurement of maximum stresses are to be taken at the time where the internal energy is maximum and thus at the stage which is closer to this time. The peaks in the graphs are obtained when this time overlaps the time of a stage and the drops are obtained when this time falls correctly in between two stages. Hence, in the latter case, the stresses are taken at the stage, which has greater stress values of either of them. Of all the sizes used to run the model, the greatest size of $300 \mu \mathrm{m}$ diameter particle has a greater amount of volume loss. This might be due to the fact that 
the volume of the element breaking apart is greatest compared to the other elements of smaller sizes. Also as the size increases, the strength and toughness decreases. Hence bigger particles are more tentative towards breakage.

\section{Variation of volume loss at a velocity of $30 \mathrm{um} / \mathrm{us}$ and imapct angle ranging from $30-50 \mathrm{um} / \mathrm{us}$ for a particle diameter ranging from $100-300$ ums}

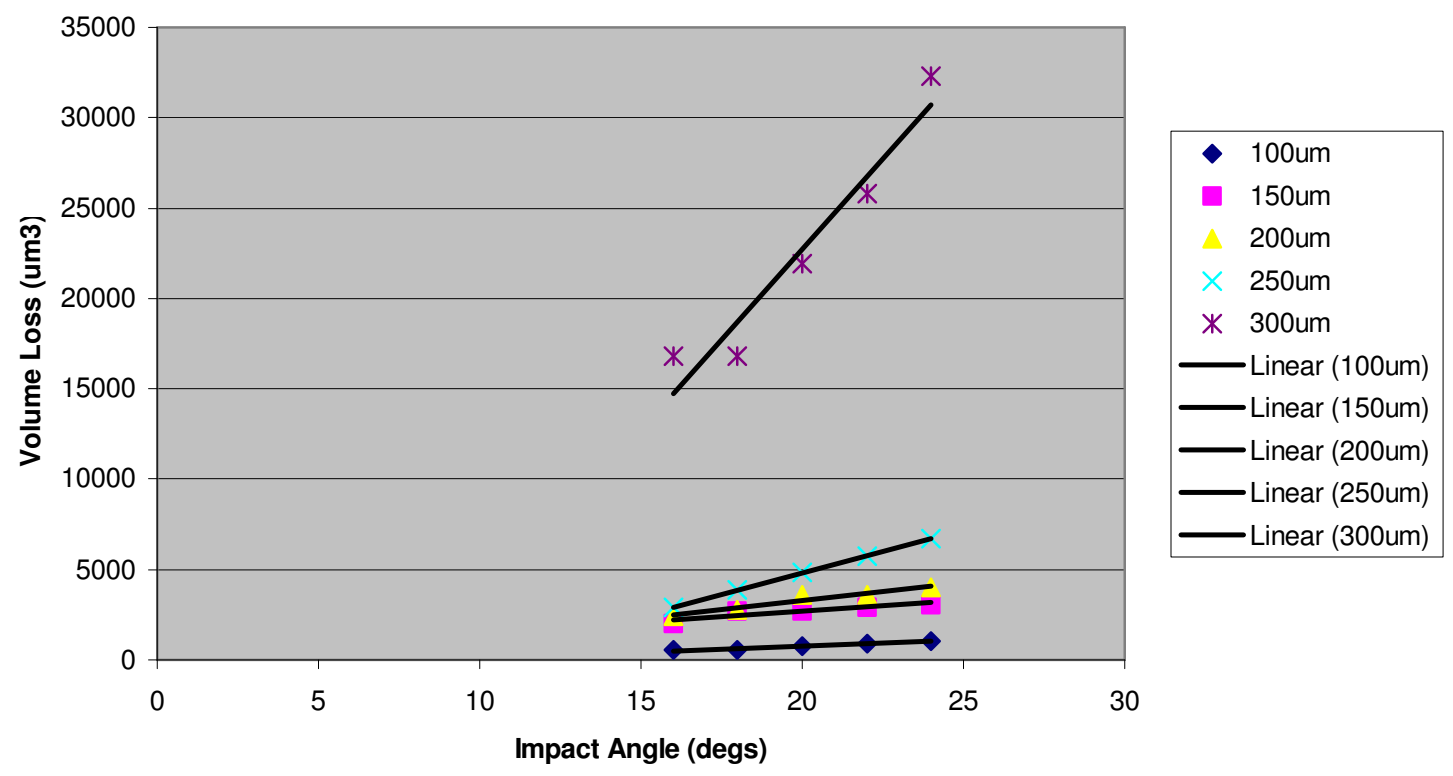

Variation of volume loss at a velocity of $35 \mathrm{um} / \mathrm{us}$ and impact angle ranging from 16-24degs for a particle diameter ranging from 100-300ums

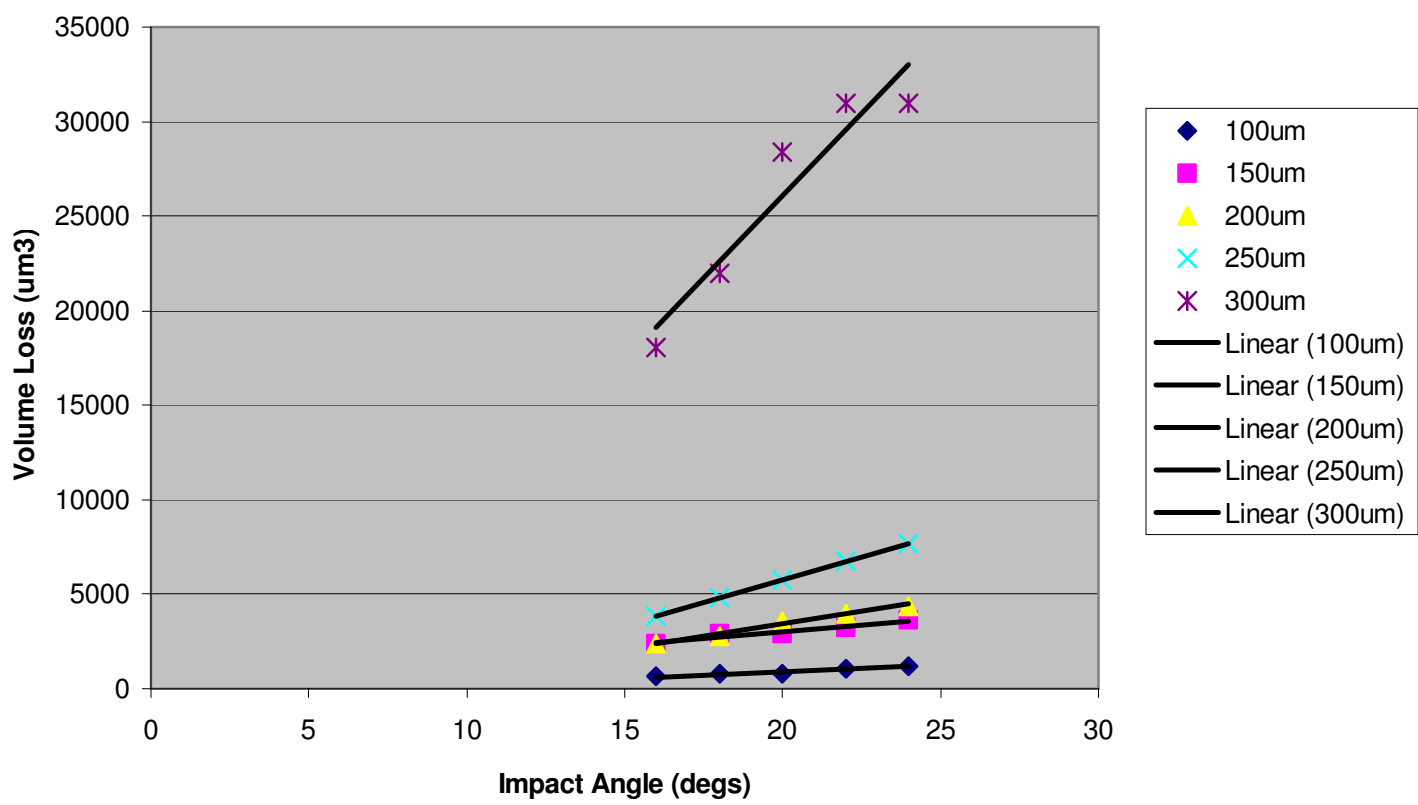


Variation of volume loss at a velocity of $40 \mathrm{um} / \mathrm{us}$ and impact angle ranging from $30-50 \mathrm{um} / \mathrm{us}$ for a particle diameter ranging from 100-300ums

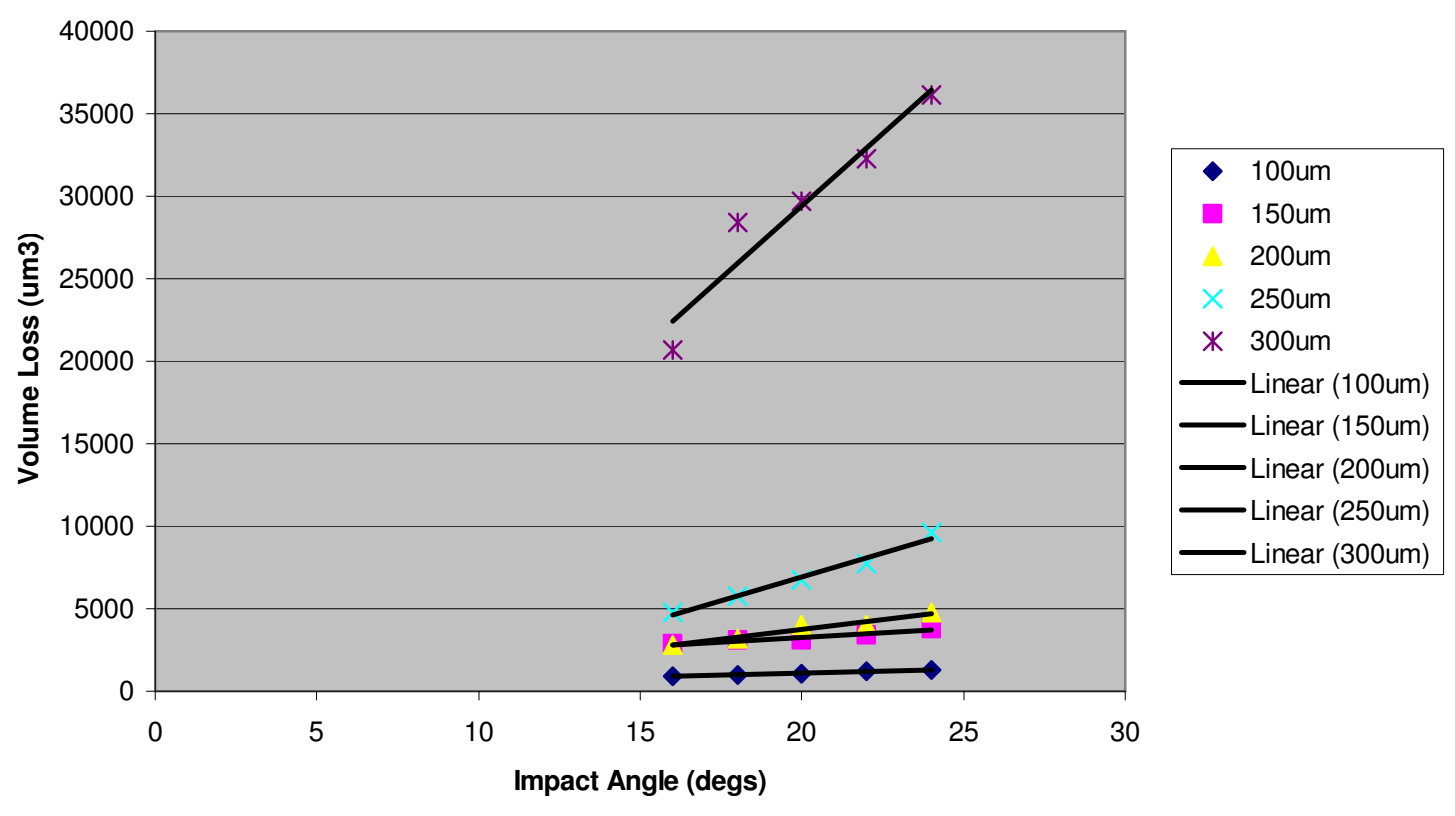

Variation of volume loss at a velocity of $45 \mathrm{um} / \mathrm{us}$ and impact angle ranging from 16-24degs for a particle diamter ranging from 100-300ums

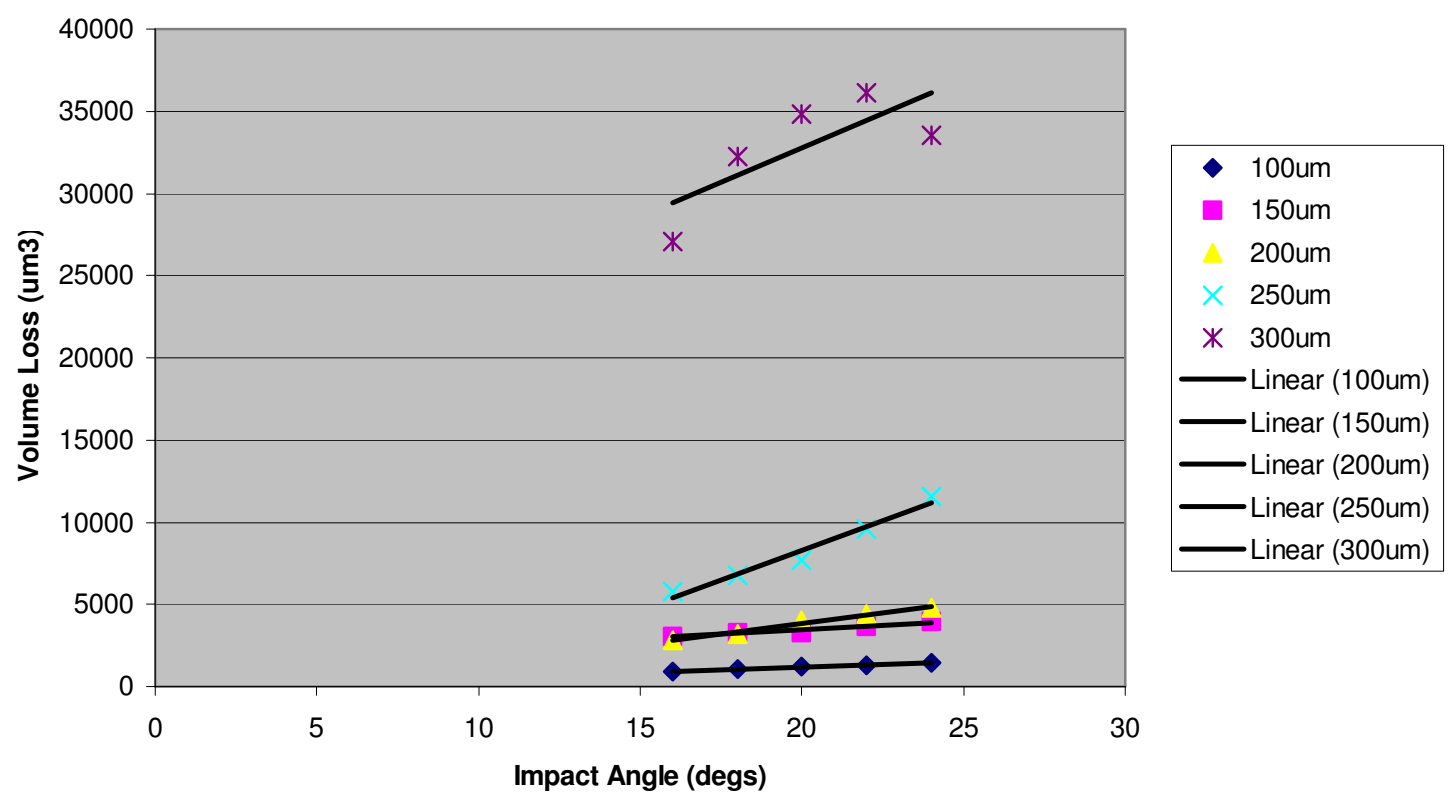


Variation of volume loss at a velocity of $50 \mathrm{um} / \mathrm{us}$ and impact angle ranging from 16-24degs for a particle diamter ranging from 100-300ums

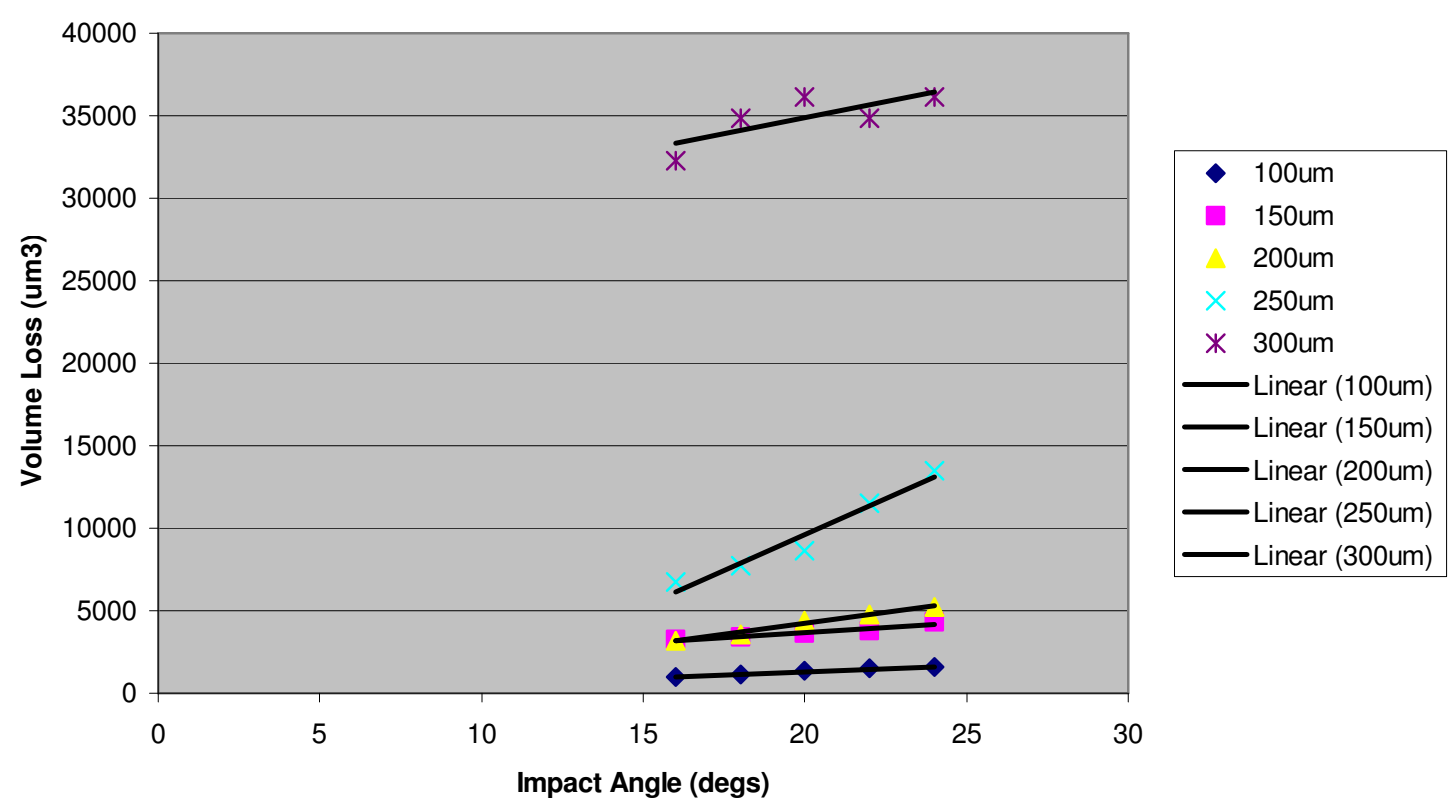

Figure 4.4: Volume Loss versus Impact Angle for Shape 1 (Point Contact)

Variation of volume loss at 16 degs impact angle and velocity in the range of $30-50$ um for a particle diameter ranging from $100-300$ um

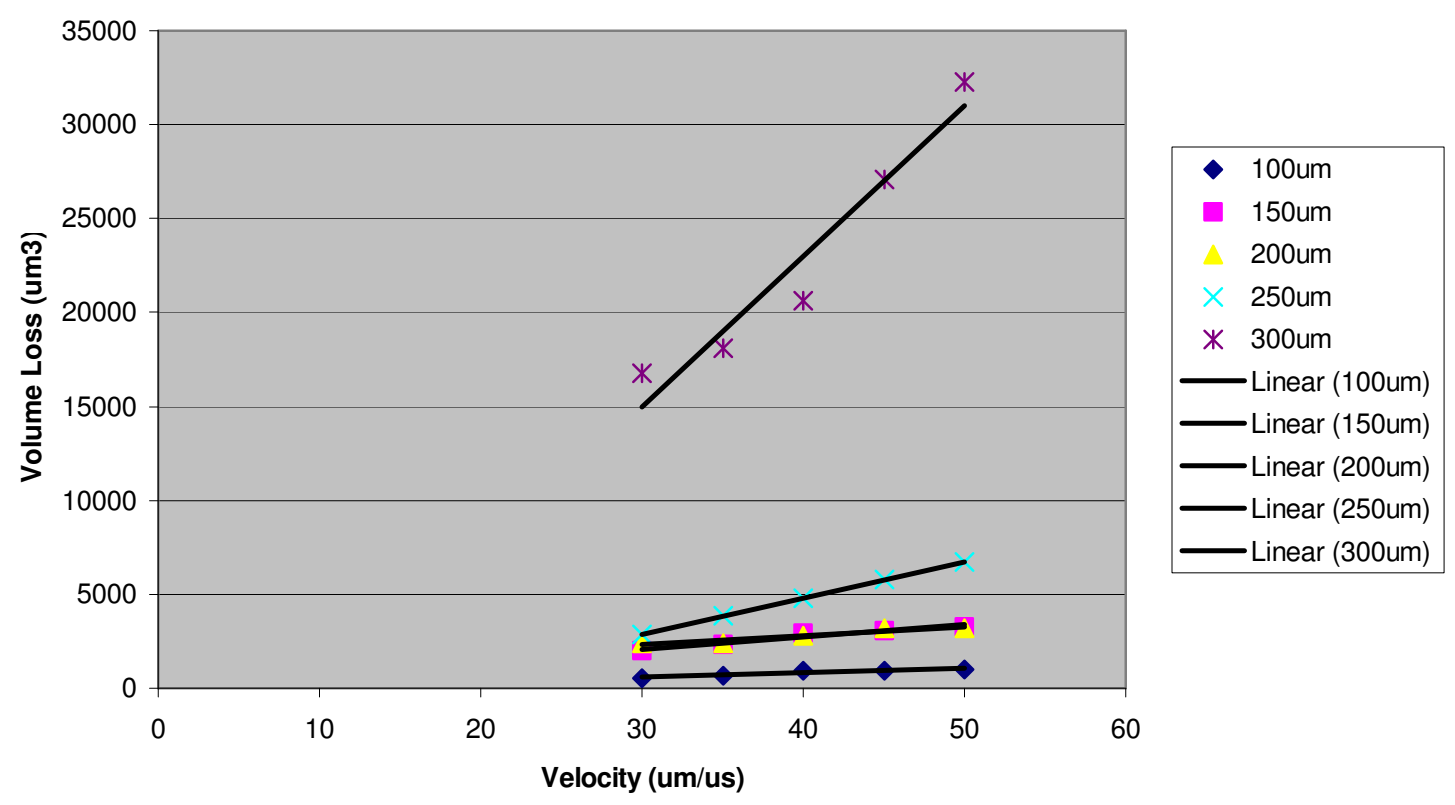


Variation of volume loss at $18 \mathrm{degs}$ impact angle and velocity in the range of $30-50 \mathrm{um} / \mathrm{us}$ for particle diamter ranging from 100-300um

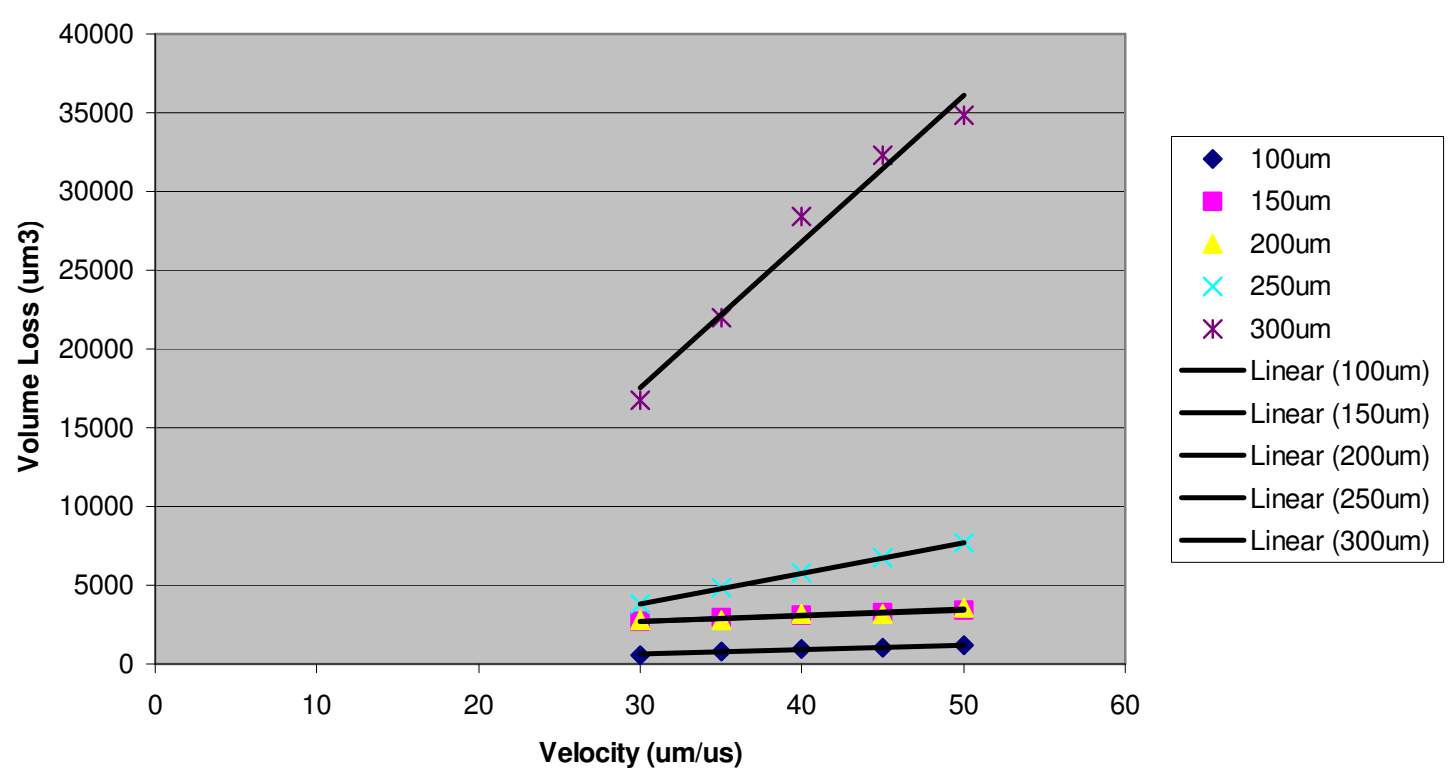

Variation of volume loss at 20degs impact angle and velocity in the range of $30-50 \mathrm{um} / \mathrm{us}$ for a particle diameter ranging from $100-300$ um

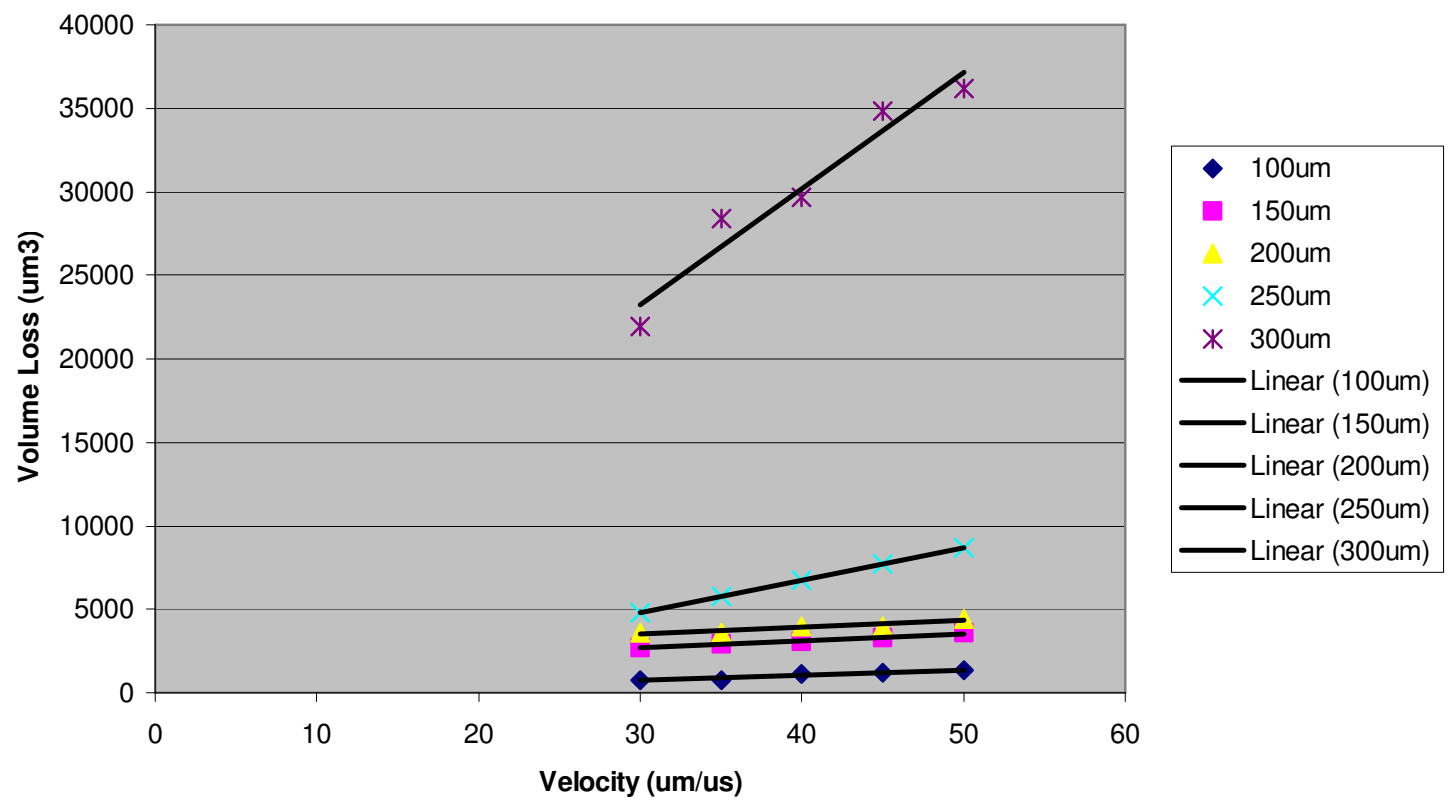


Variation of volume loss at 22degs impact angle and velocity in the range of $30-50 \mathrm{um} / \mathrm{us}$ for a particle diameter ranging from $100-300 u m$

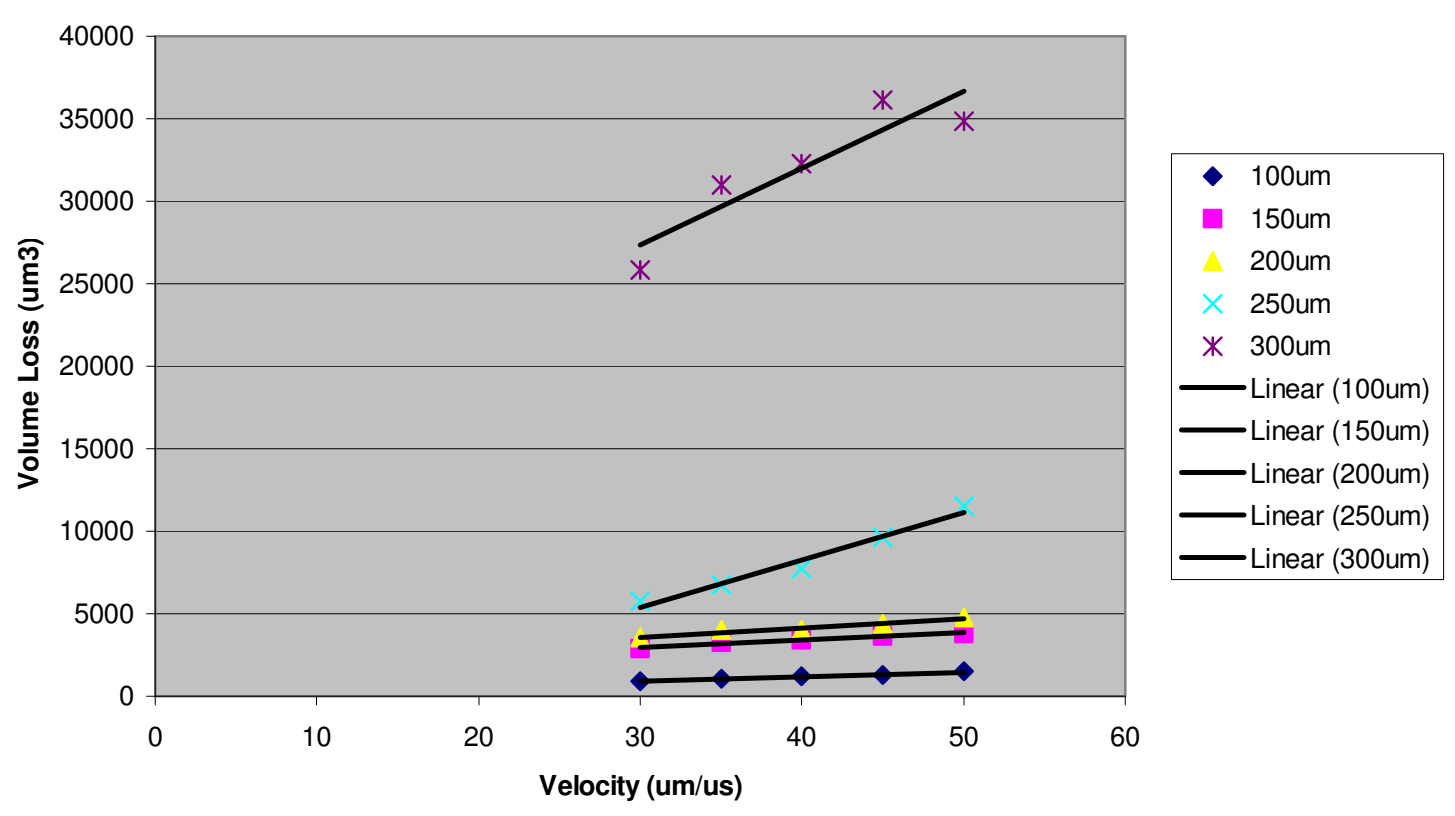

Variation of volume loss at 24degs impact angle and velocity in the range of $30-50$ um/us for a particle diameter ranging from $100-300 u m$

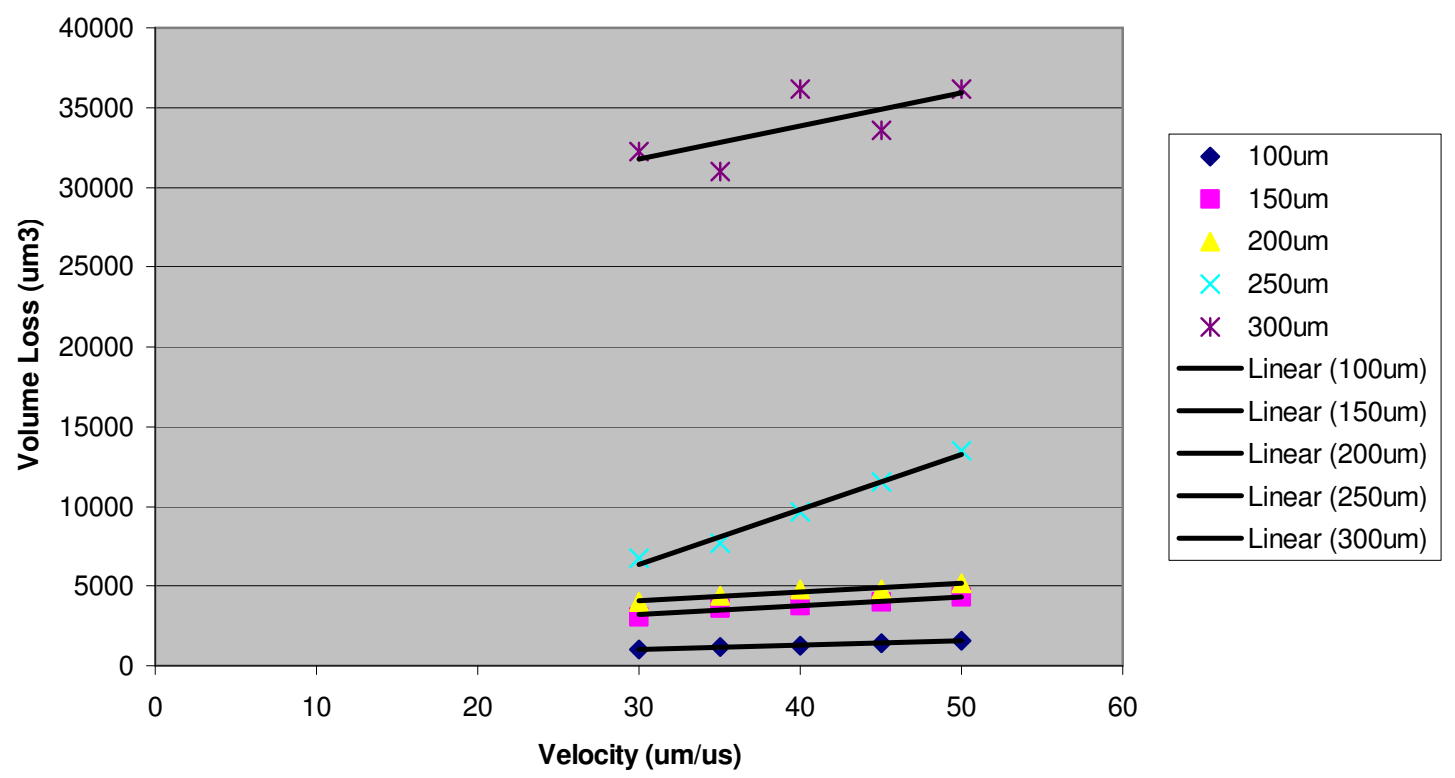

Figure 4.5: Volume Loss versus Velocity for Shape 1 (Point Contact) 


\subsubsection{Influence of Shape 2 (Line Contact)}

The shape of the particle having line contact with the plate is taken as a perfect hexagon, with one of its edges pointing downwards. All the specifications of the parameters are similar to those used for the sphere. The hexagon is built in such a way that its width, height and thickness are same for all the sizes. As the impact takes place, the stress waves travel in a similar fashion to that in the sphere. But in this case, there are greater expansions and contractions as compared to the sphere. During contraction, similar to sphere, the stresses get accumulated at the bottom and sometimes in top too. While in expansion, the stresses get split into the four corners of the hexagon initially, but later on they get split up along a set of sides, which keep alternating. A set of figures for a sample model showing the stress variations are shown below.

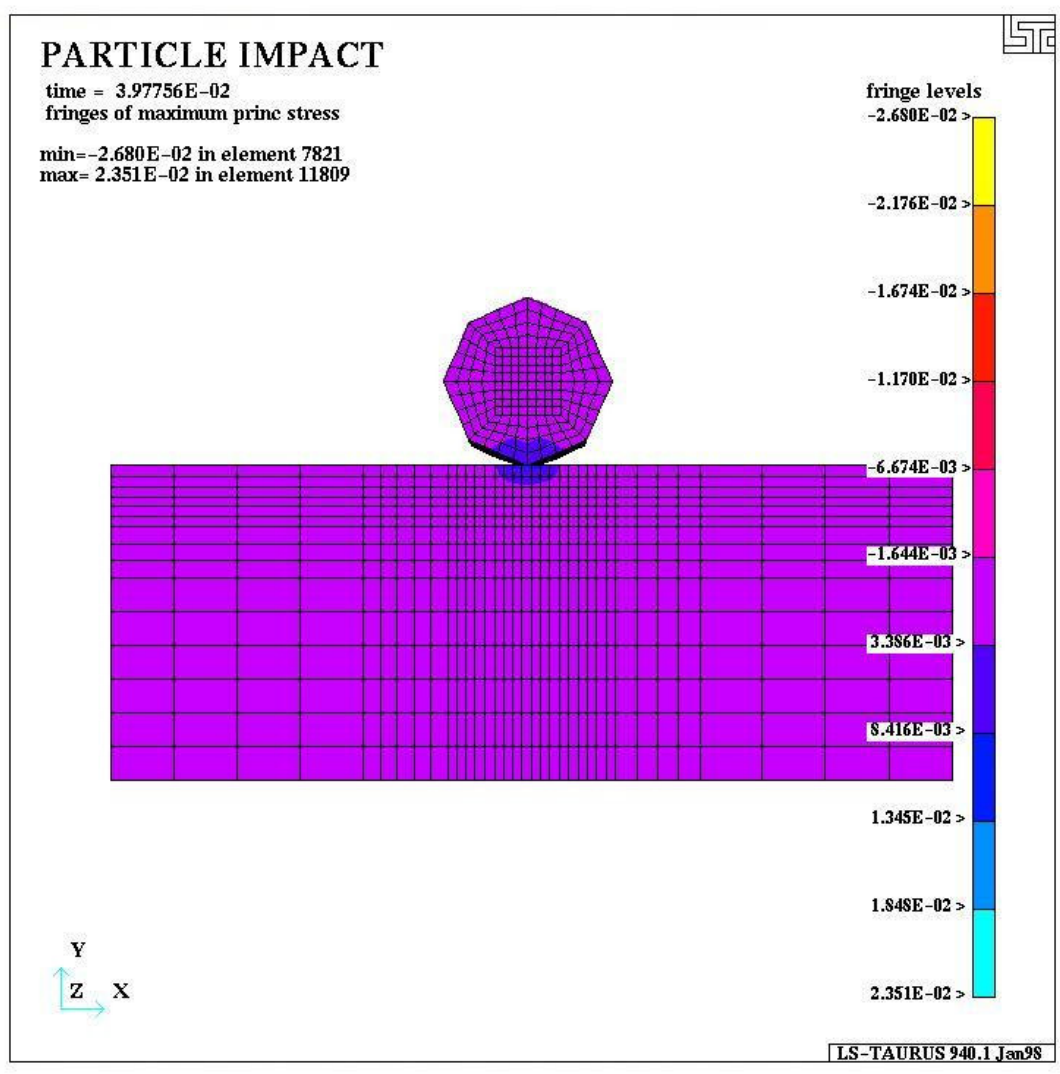



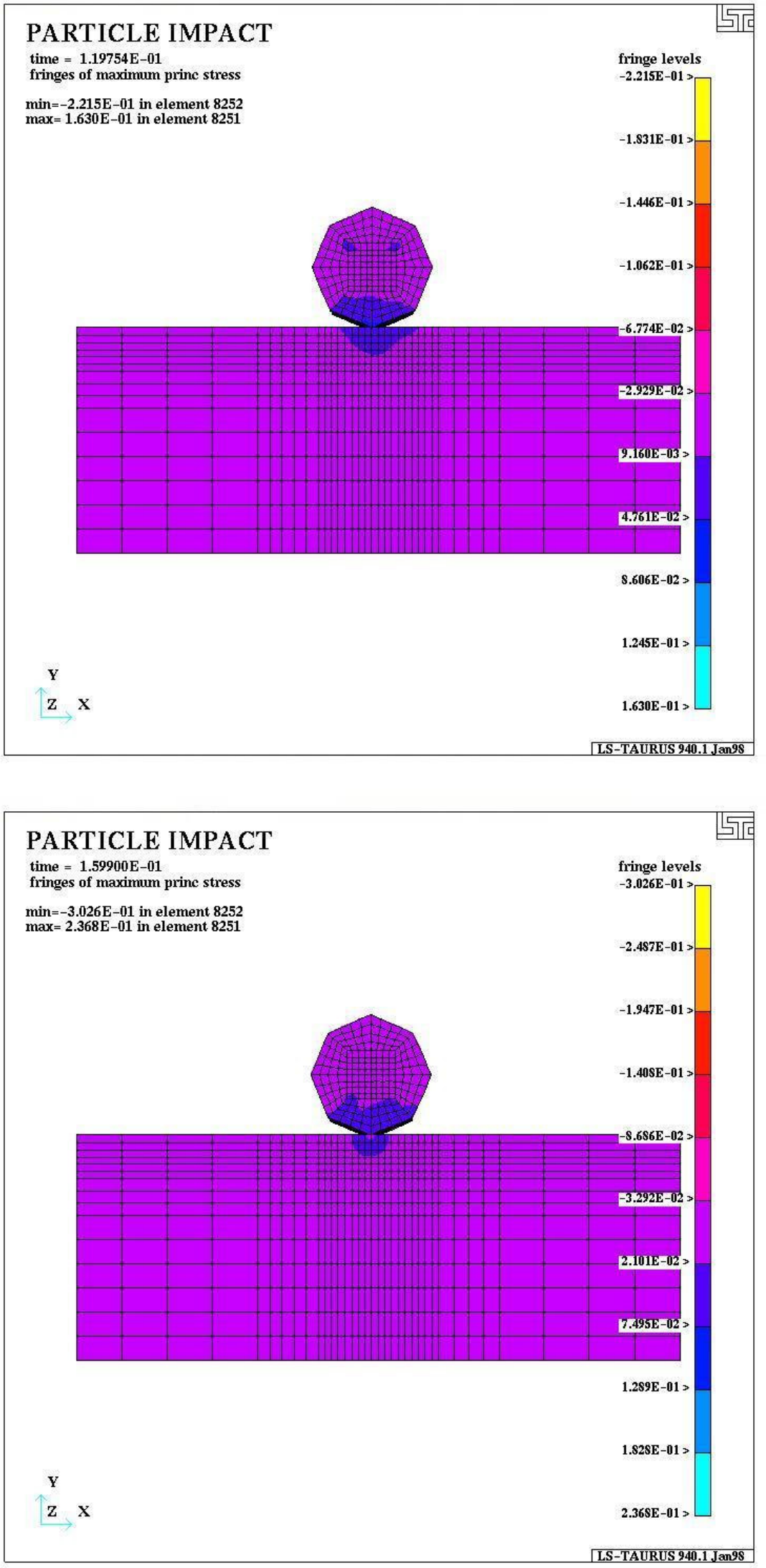

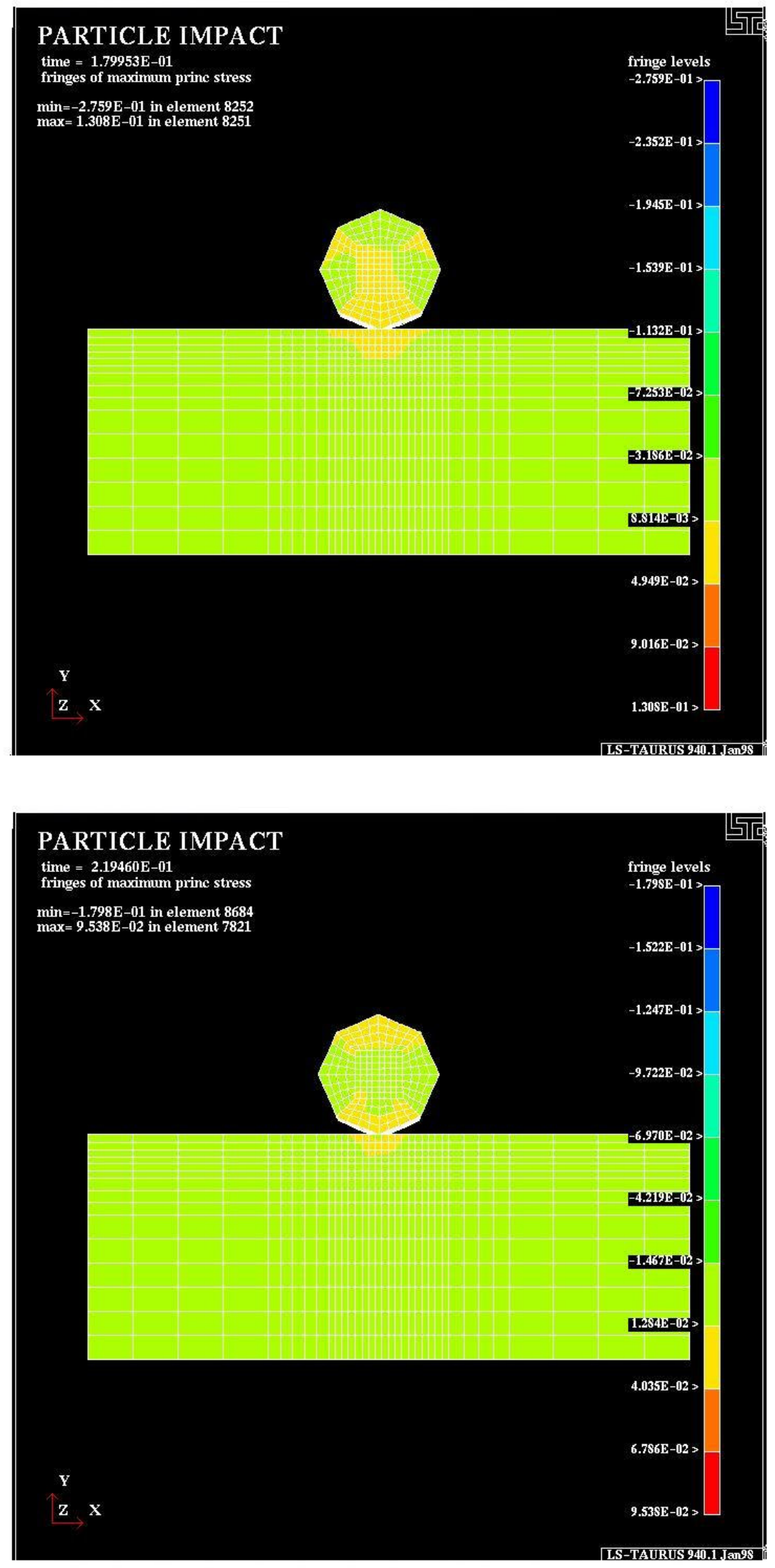
Figure 4.6: Fringes of Maximum Principal Stress of $100 \mu \mathrm{m}$ size particle impacting the plate at $16^{0}$ with a velocity of $35 \mu \mathrm{m} / \mu \mathrm{s}$

The stress flow in the minimum principal stresses is similar to the maximum principal stresses. Also, the expansions and contractions occur more number of times in the minimum principal stresses. These changes are shown in the below figures.

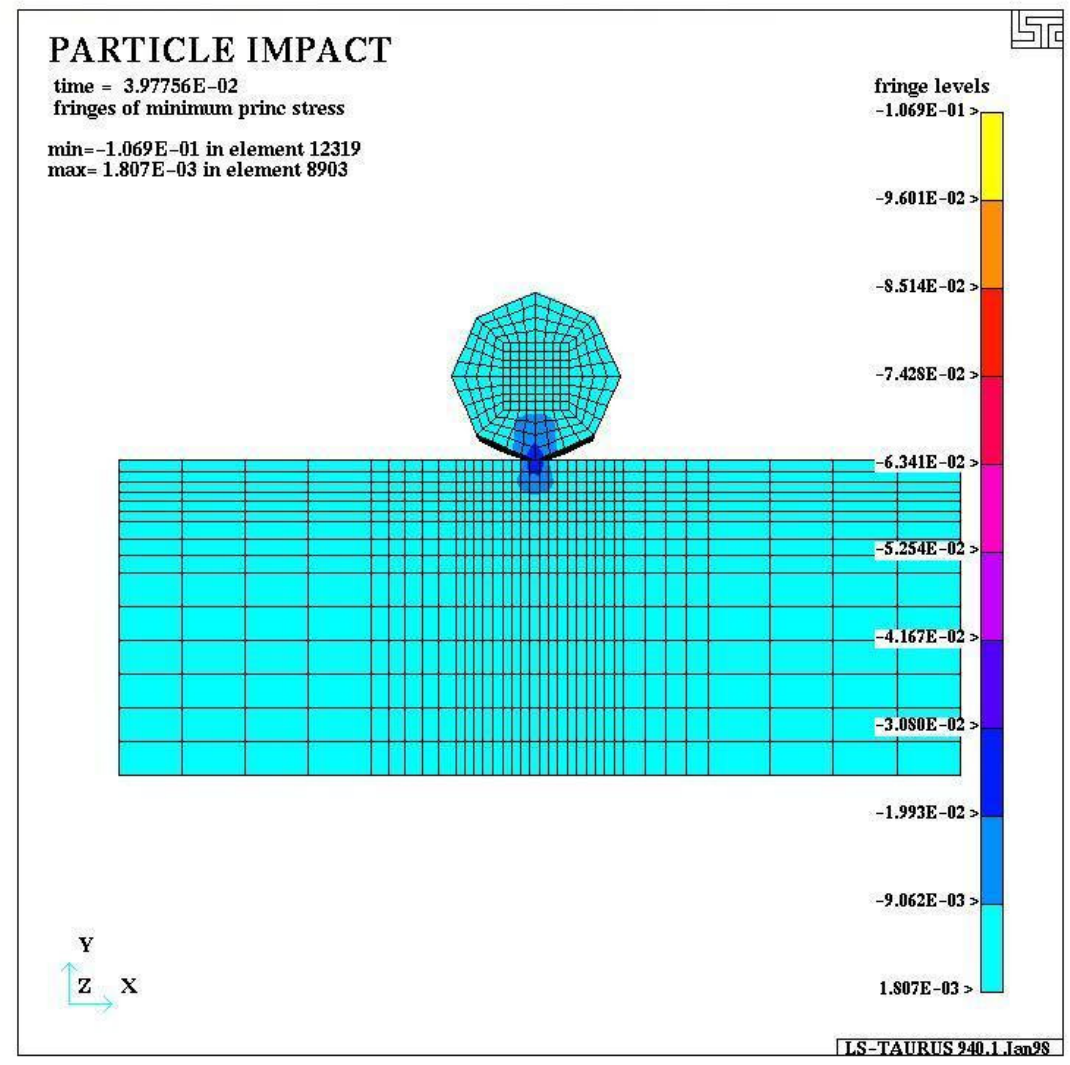



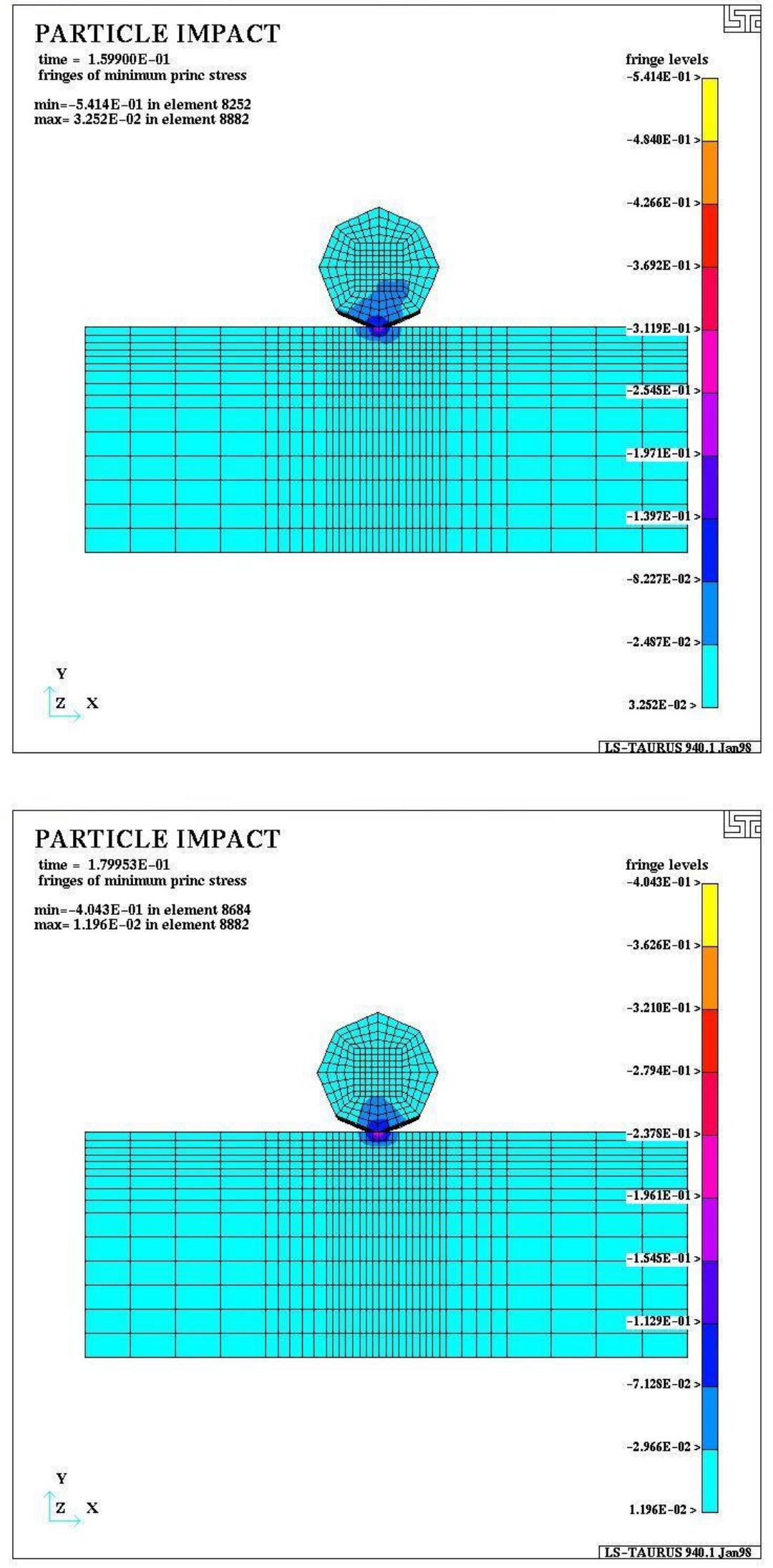

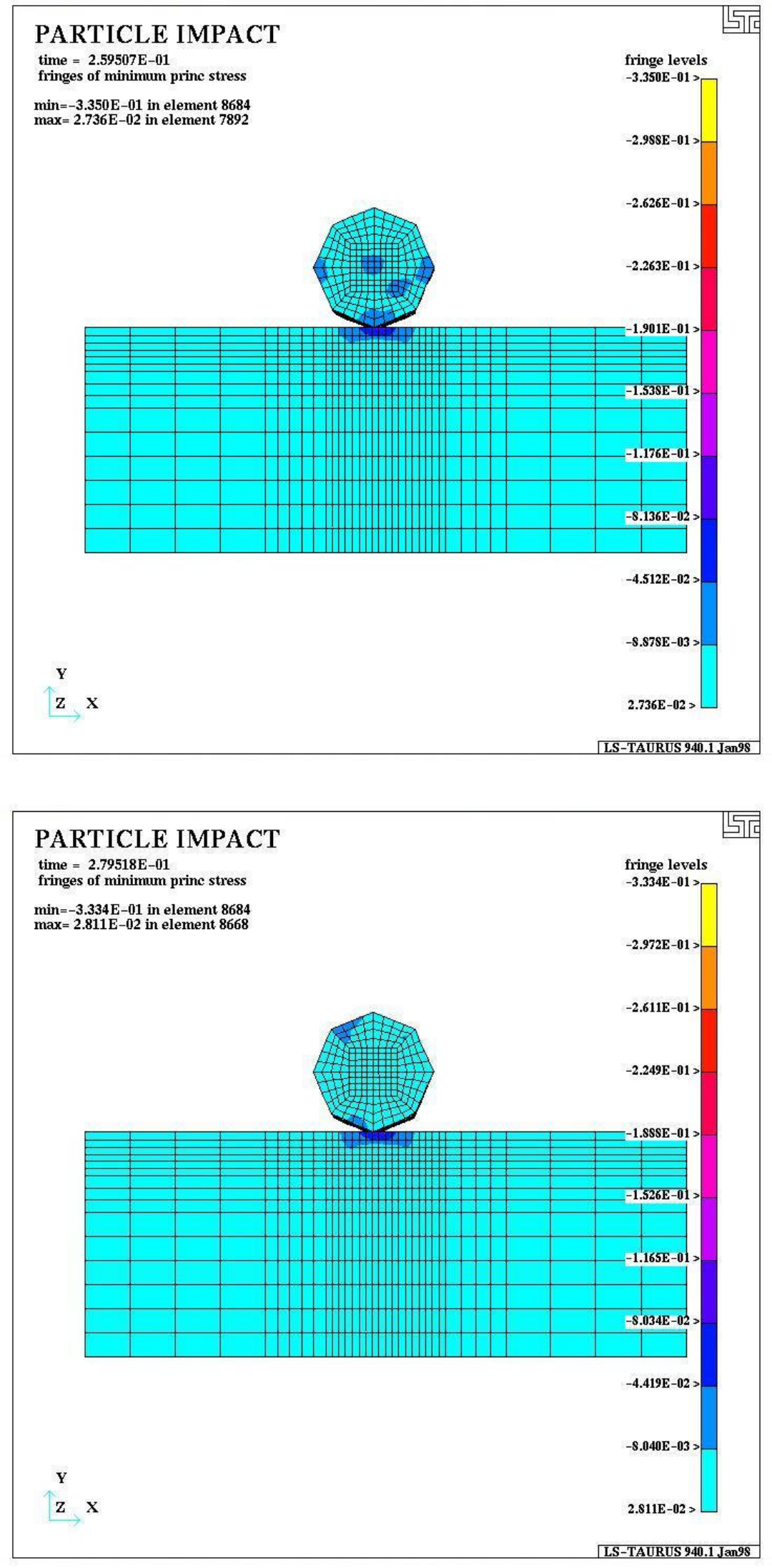

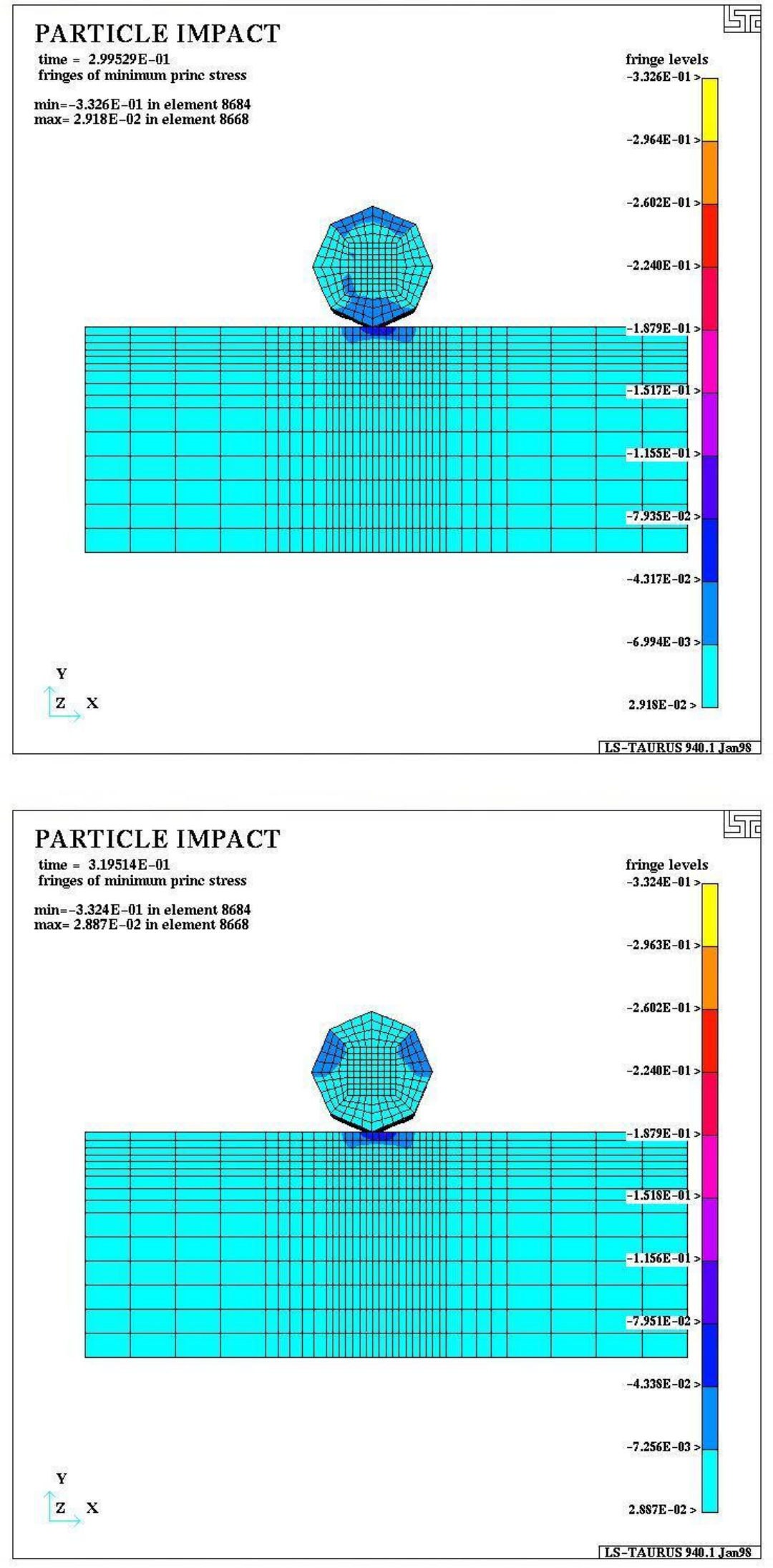
Figure 4.7: Fringes of Minimum Principal Stress of $100 \mu \mathrm{m}$ size particle impacting the plate at $16^{0}$ with a velocity of $35 \mu \mathrm{m} / \mu \mathrm{s}$

Similar to the sphere, graphs are plotted for the line contact hexagon with all the parameters. These graphs indicate that as the impact velocity, impact angle and particle size increases, the particle volume increases uniformly. But a few ups and downs in the graph are seen in here too; whose reason is the same as mentioned for the sphere. These graphs are shown below.

Variation of volume loss at a velocity of $30 \mathrm{um} / \mathrm{us}$ and impact angle ranging from 16-24degs for a particle diameter ranging from 100-300ums

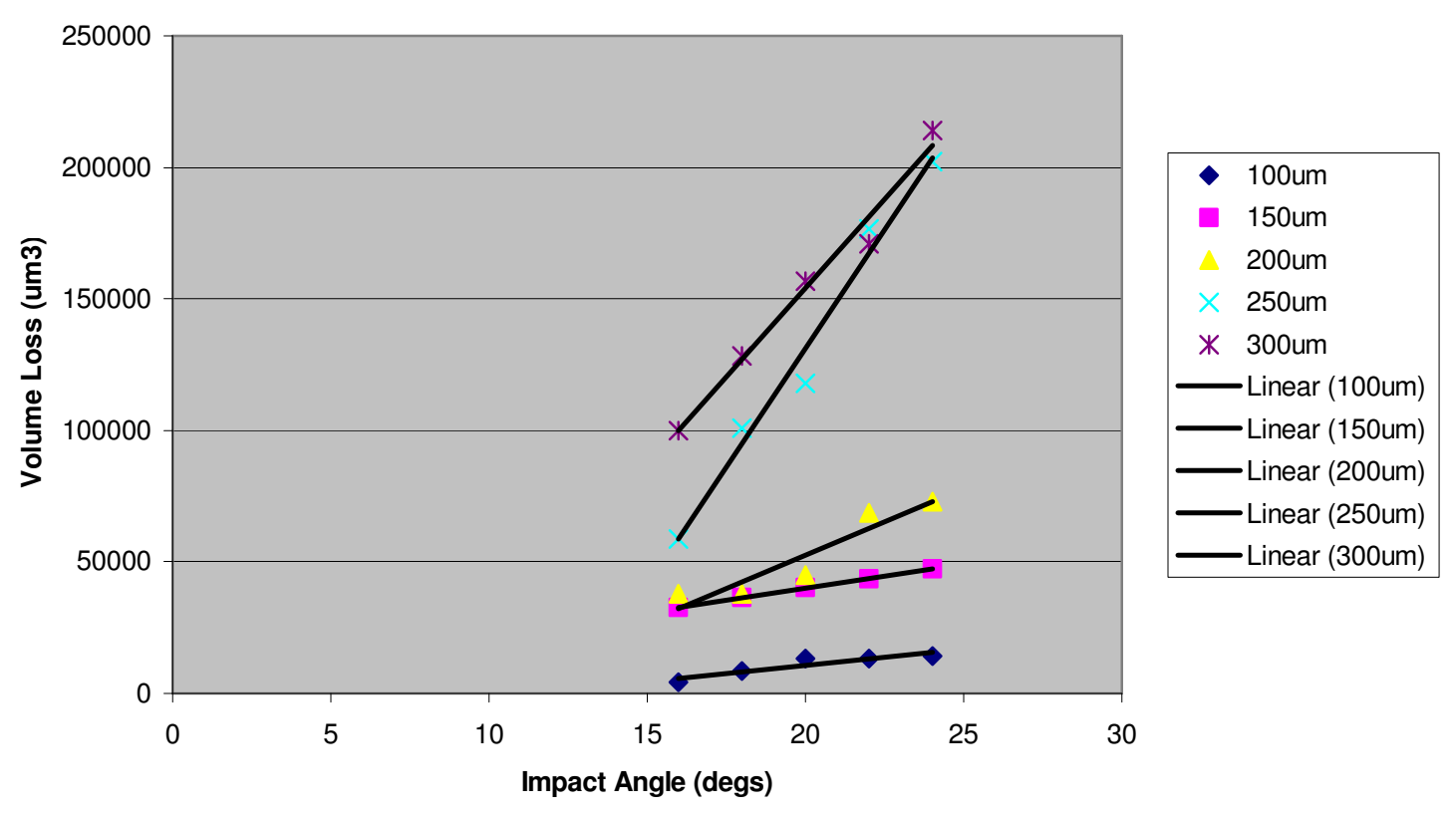


Variation of volume loss at a velocity of $35 \mathrm{um} / \mathrm{us}$ and impact angle ranging from 16-24degs for a particle diameter ranging from 100-300um

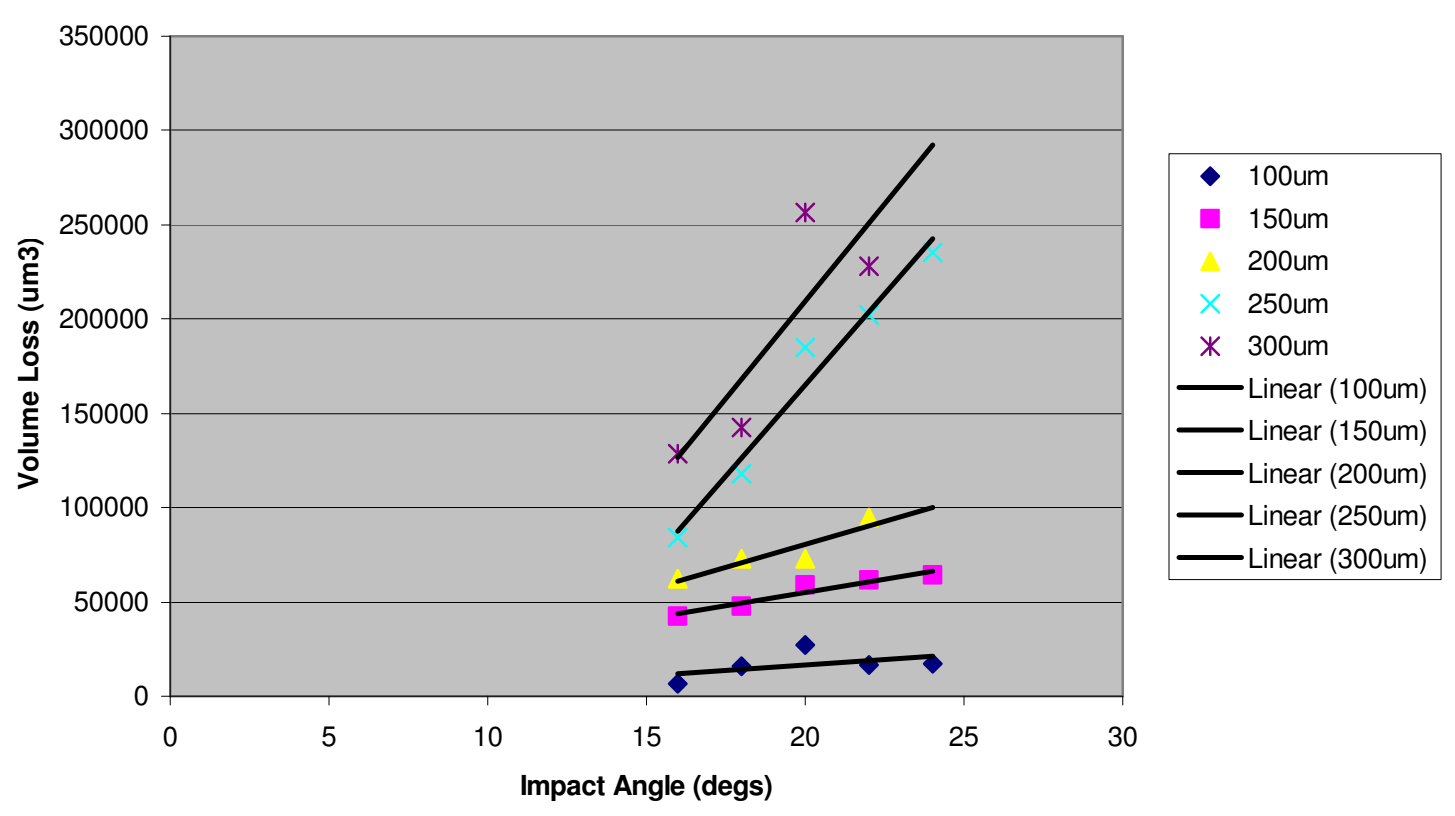

Variation of volume loss at a velocity of $40 \mathrm{um} / \mathrm{us}$ and impact angle ranging from 1624degs for a particle diamter ranging from 100-300ums

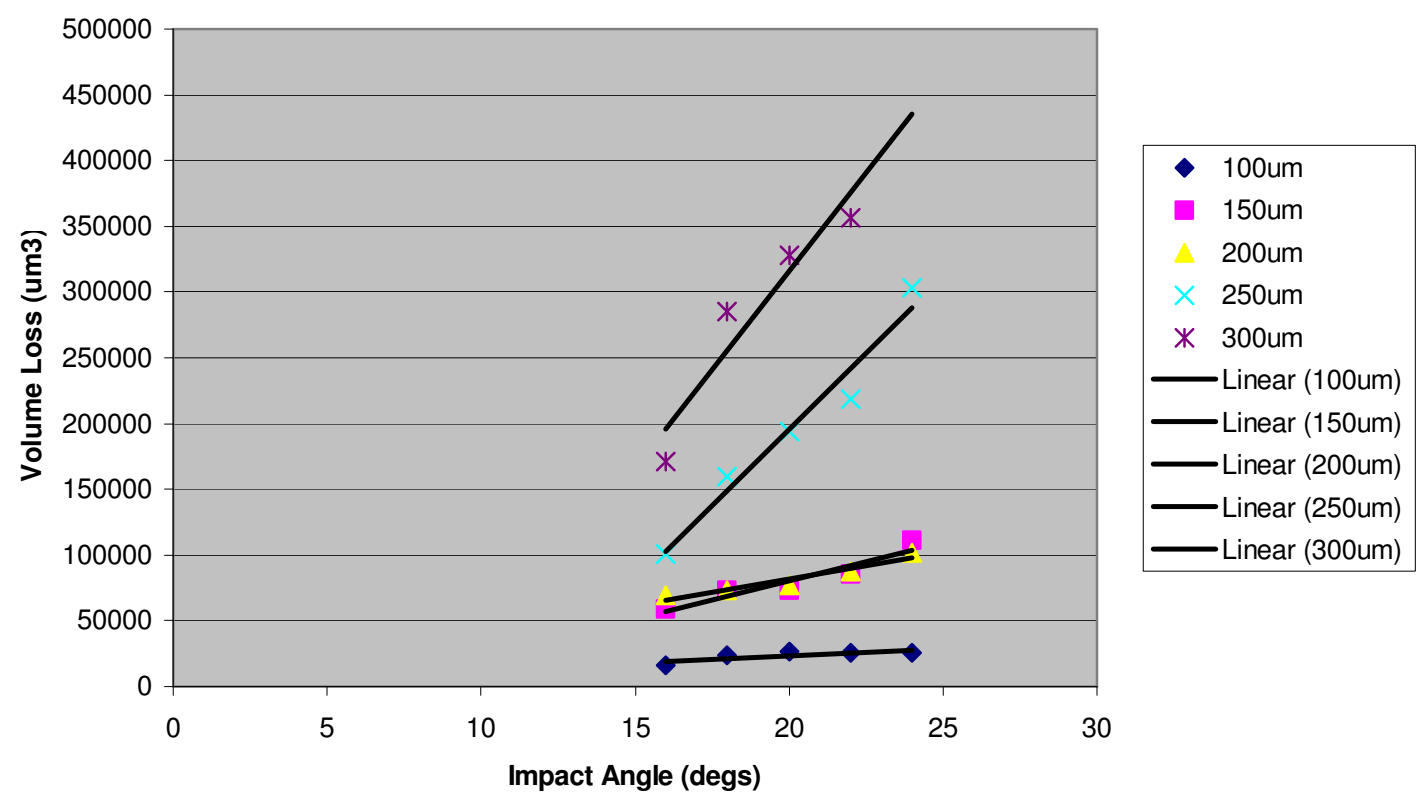


Variation of volume loss at a velocity of $45 \mathrm{um} / \mathrm{us}$ and impact angle ranging from $16-24 \mathrm{degs}$ for a particle diamter ranging from $100-300$ ums

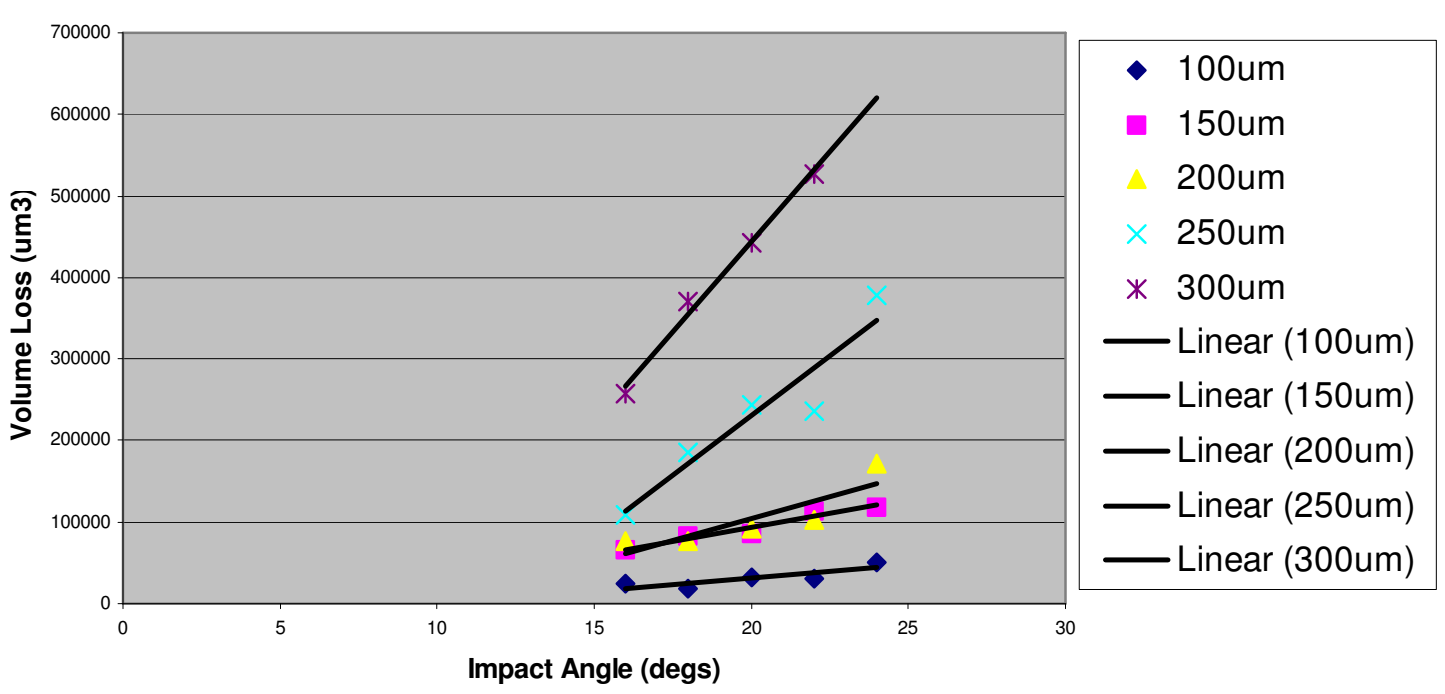

Variation of volume loss at a velocity of 50 um/us and impact angle ranging from 16-24degs for a particle diameter ranging from 100-300ums

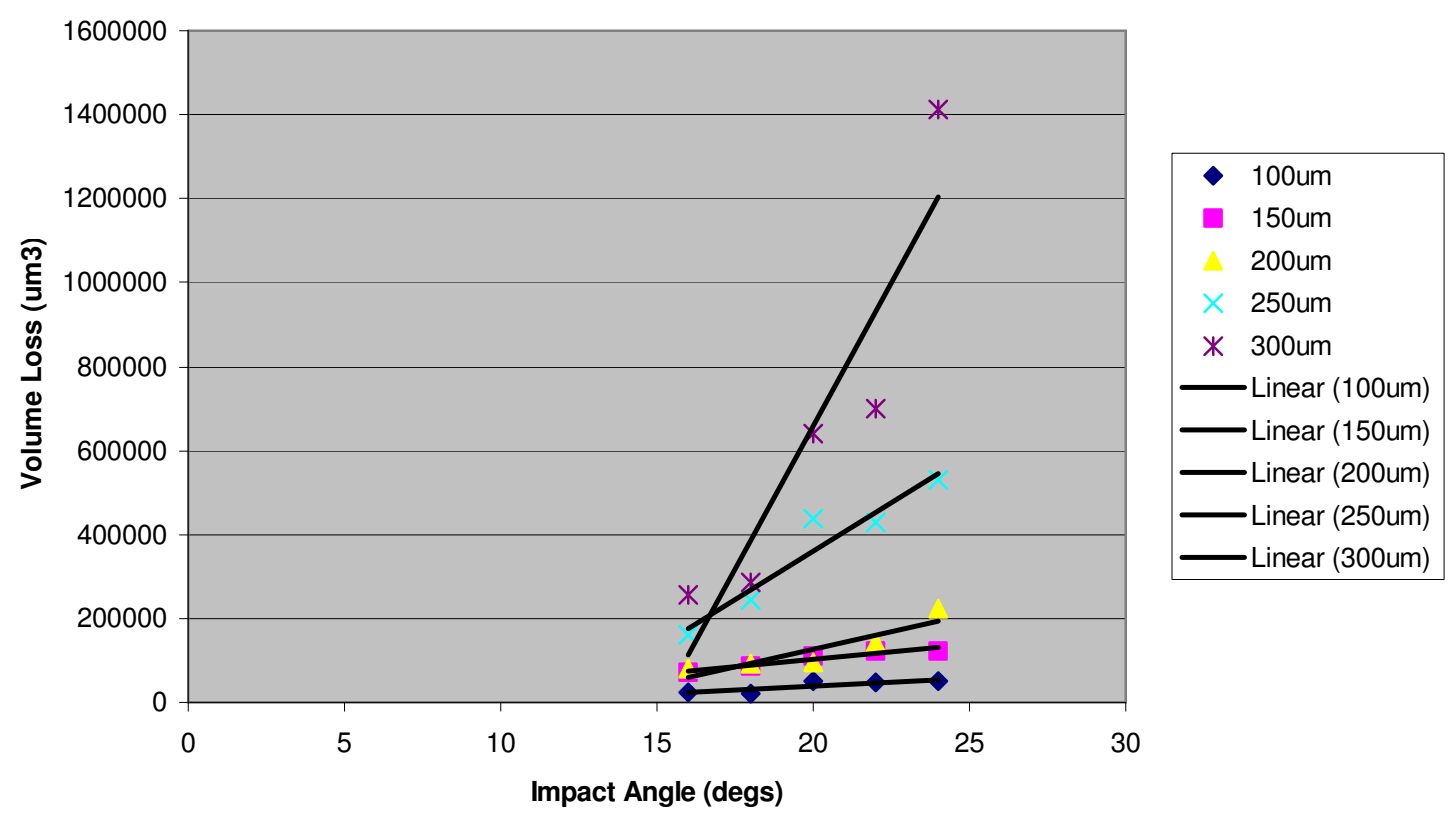

Figure 4.8: Volume Loss versus Impact Angle for Shape 2 (Line Contact) 
Variation of volume loss at $16 \mathrm{degs}$ impact angle and velocity in the range of $30-50$ um/us for a particle diamter ranging from $100-300$ um

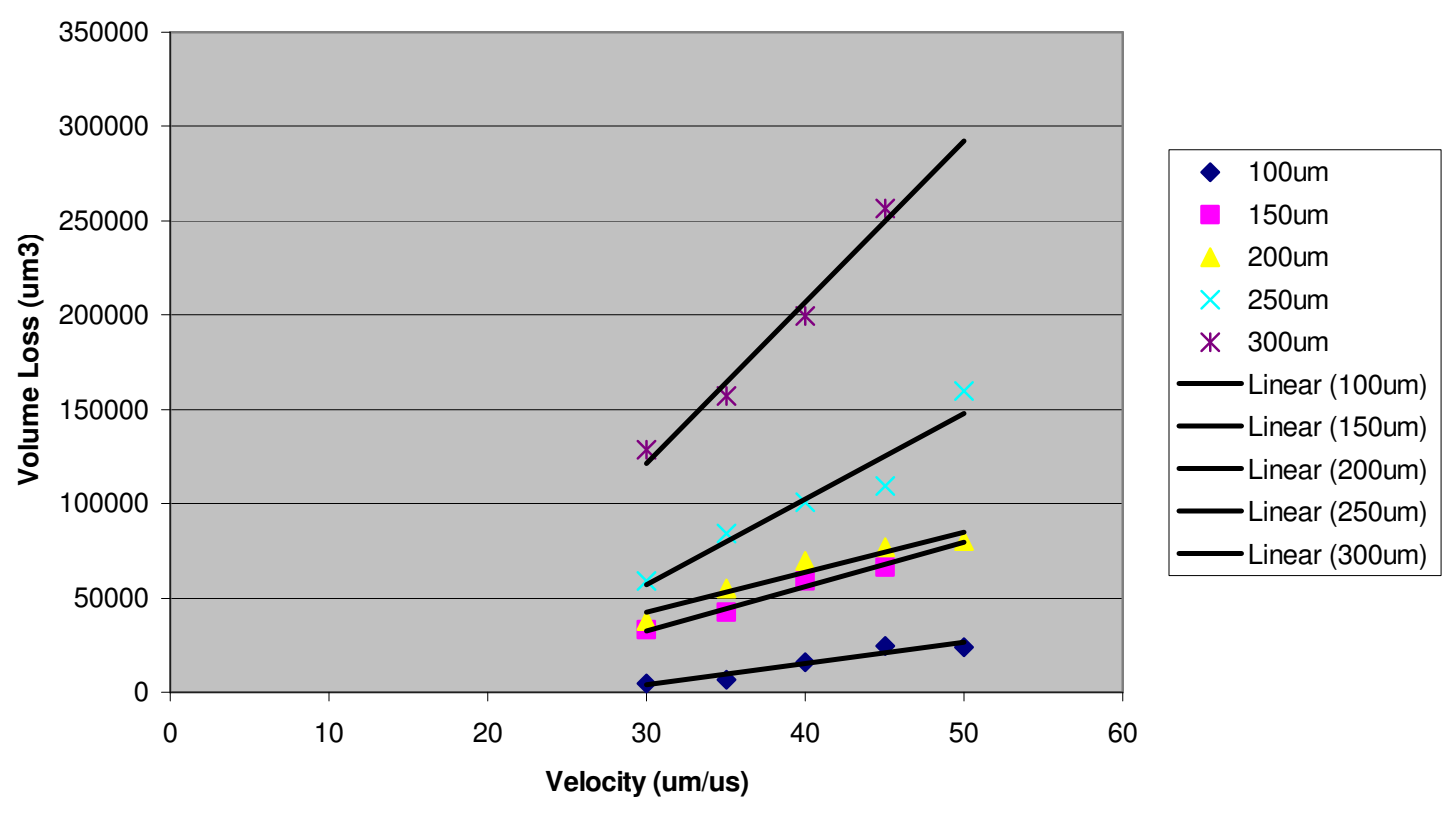

Variation of volume loss at 18degs impact angle and velocity in the range of $30-50 \mathrm{um} / \mathrm{us}$ for a particle diameter ranging from $100-300 u m$

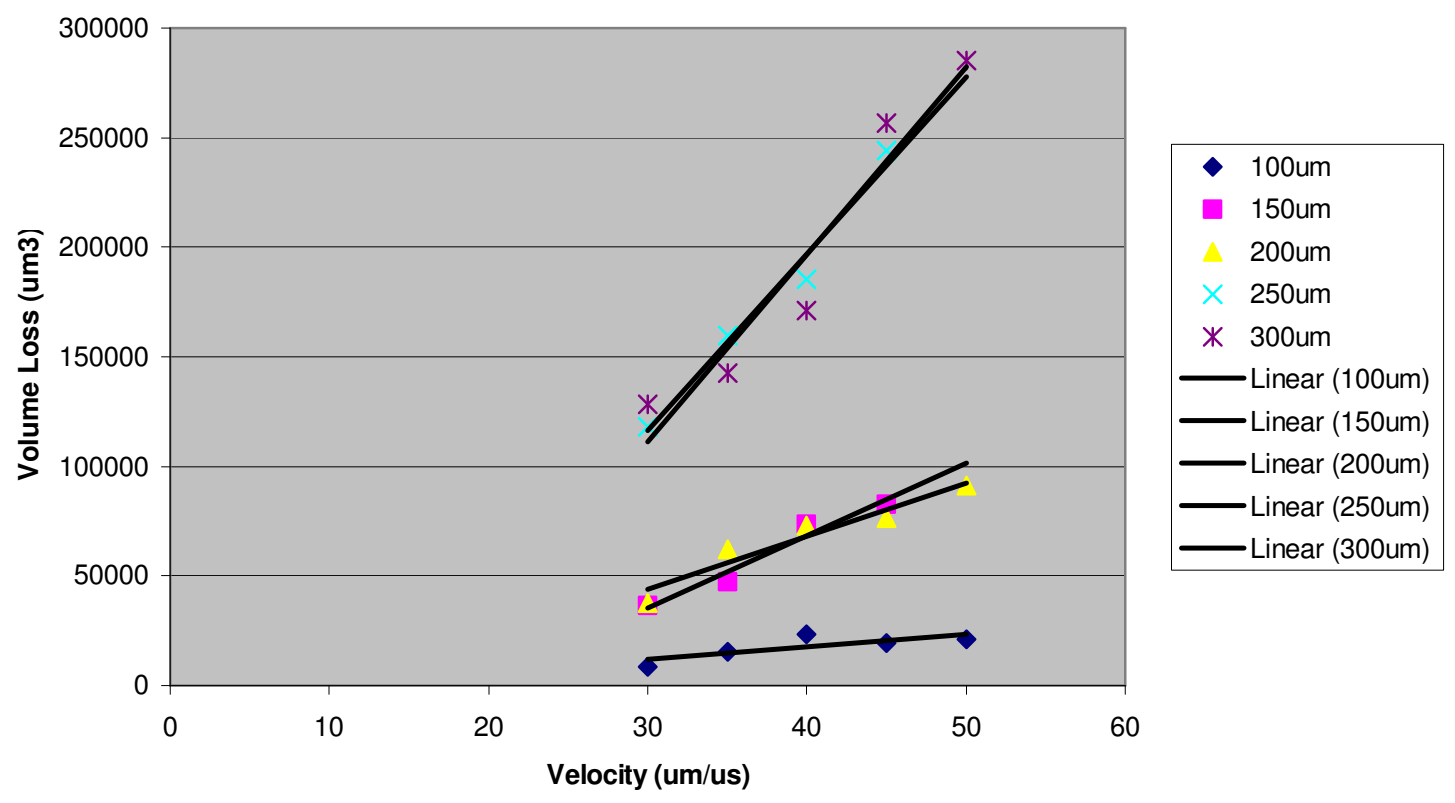


Variation of volume loss at 20degs impact angle and velocity in the range of $30-50 \mathrm{um} / \mathrm{us}$ for a particle diameter ranging from $100-300 u m$

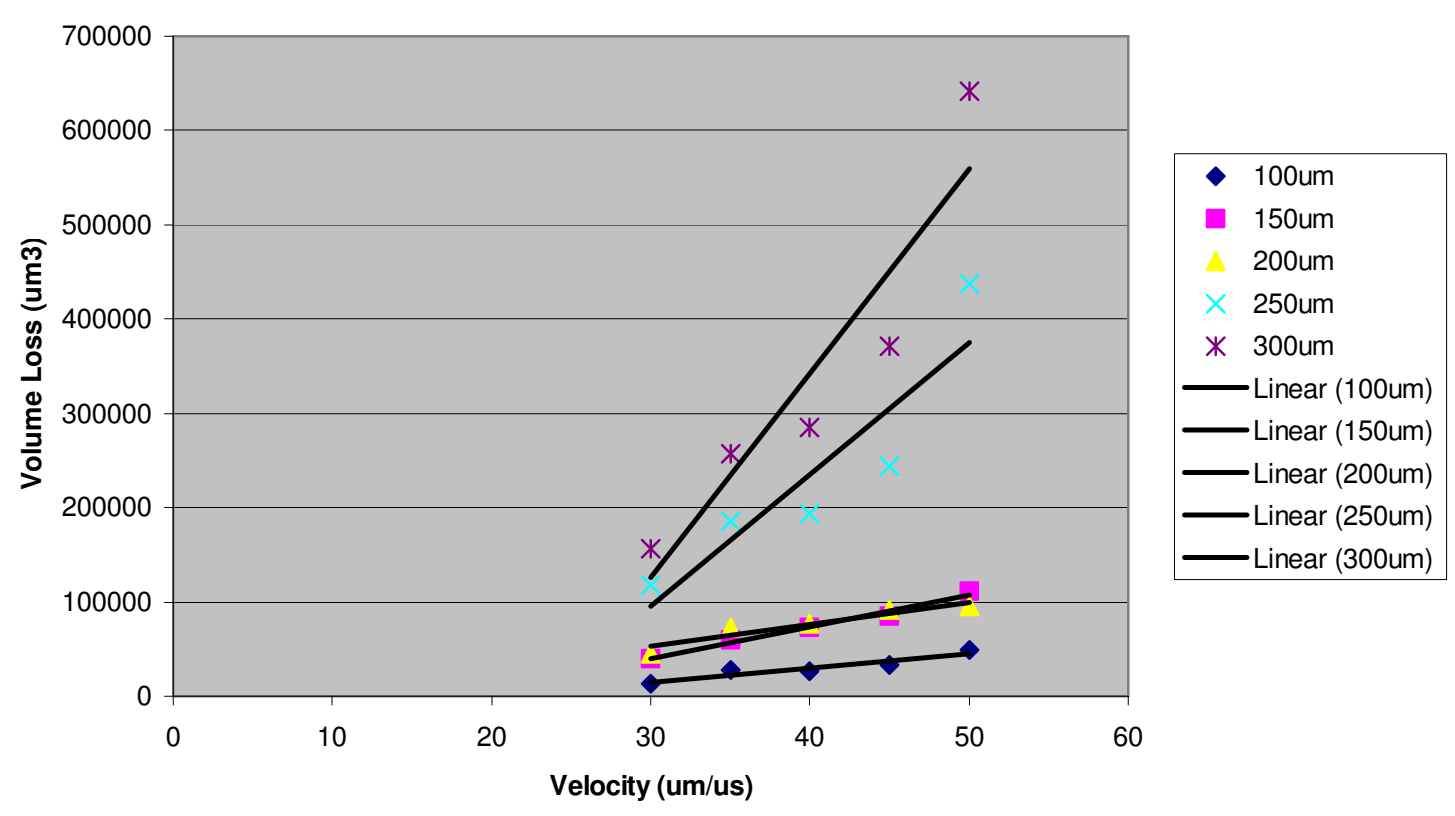

Variation of volume loss at 22degs impact angle and velocity in the range of $30-50 \mathrm{um} / \mathrm{us}$ for a particle diameter ranging from $100-300$ um

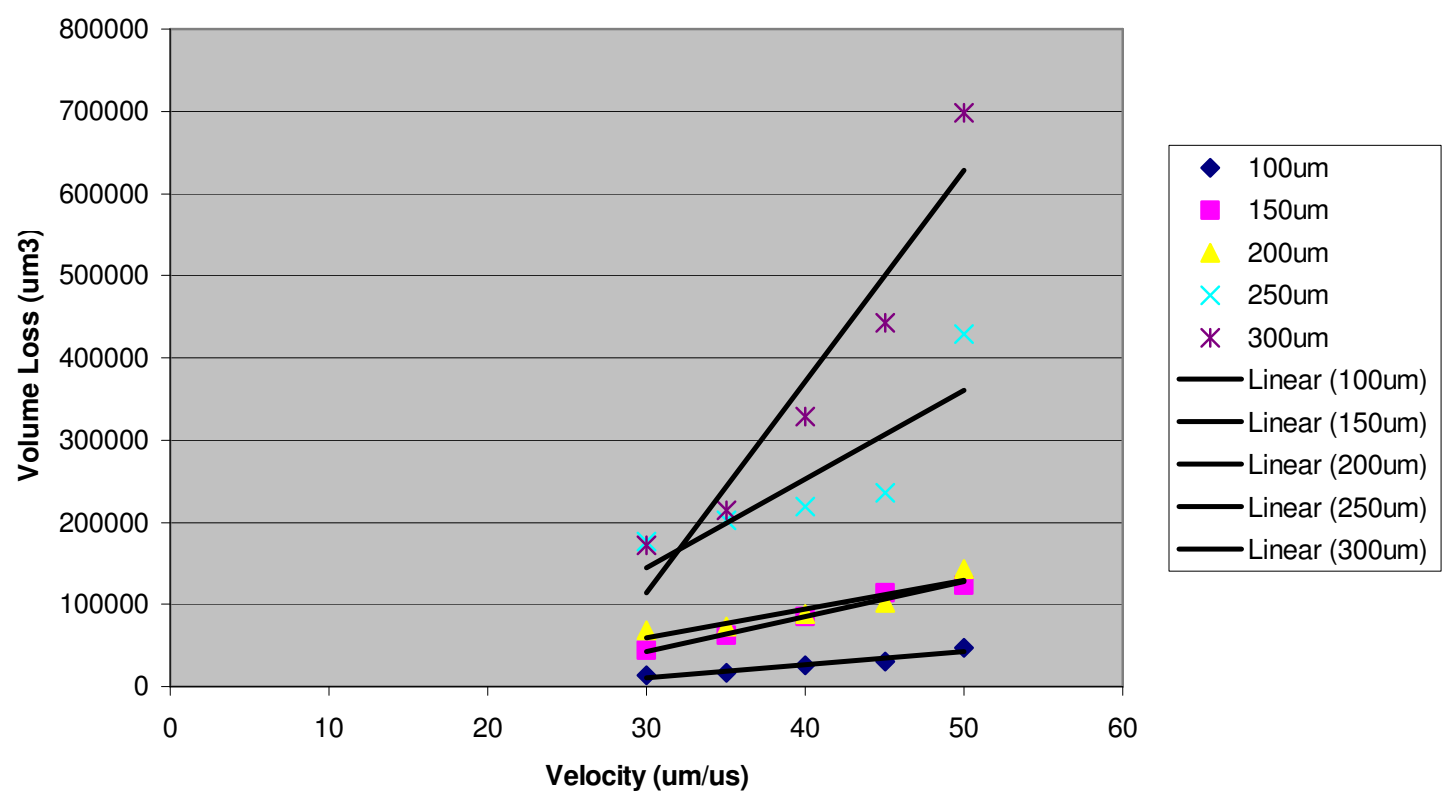


Variation of volume loss at 24degs impact angle and velocity in the range of $30-50$ um/us for a particle diameter ranging from $100-300 u m$

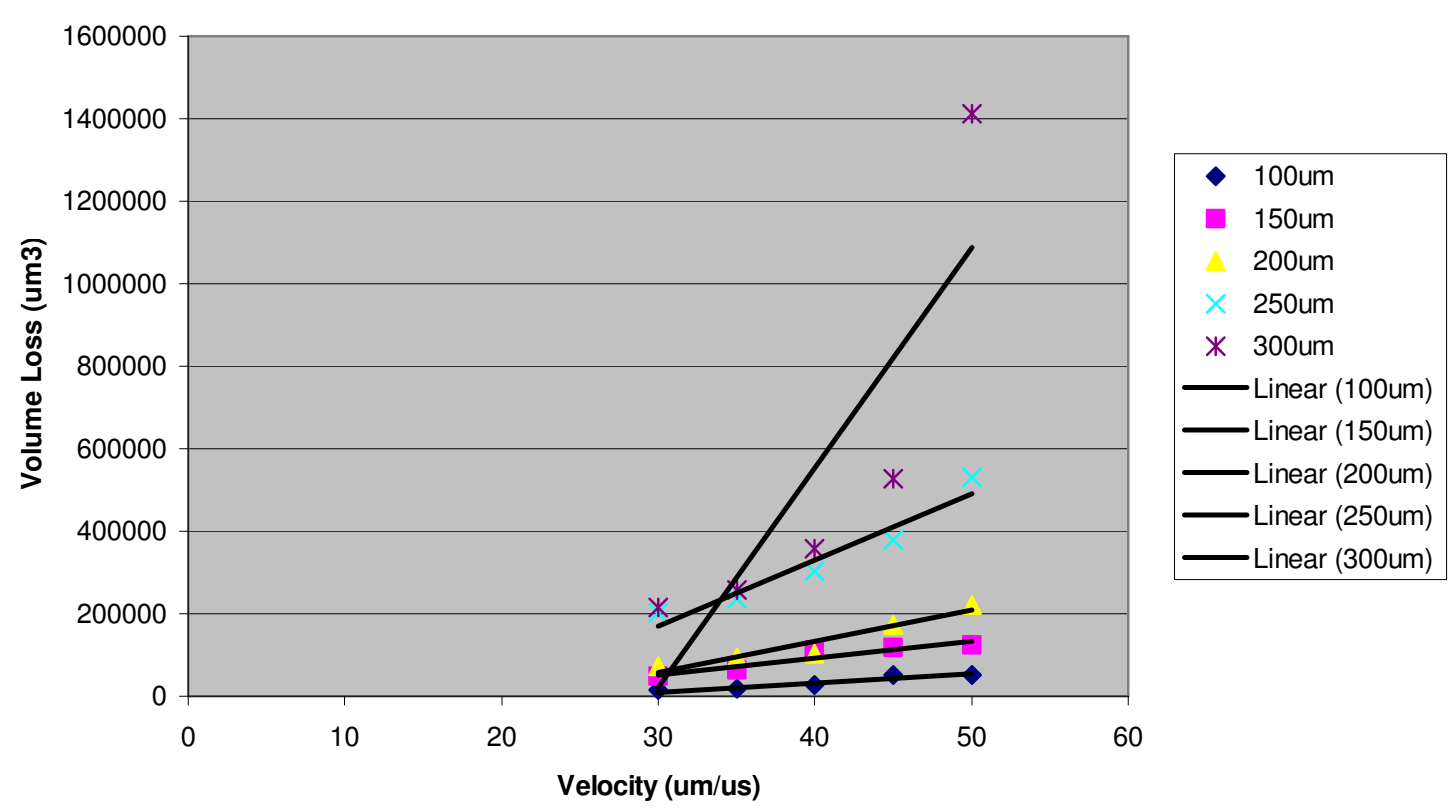

Figure 4.9: Volume Loss versus Velocity for Shape 2 (Line Contact)

\subsubsection{Influence of Shape 3 (Area Contact)}

The particle having an area contact with the plate is taken in the shape close to a hexagon, with a face at the bottom of the particle. All the parameters are taken in a similar manner as that taken for the previous shapes of the particles. For all the sizes, the width and height are same, but the thickness is taken as half the width. Also the length of the side touching the plate is varied accordingly for all the sizes. When impacted with the plate, the travel of the stress waves is a combination of that taking place in the point contact and line contact particles. The stress waves travel from the bottom to the top of the particle and keep expanding and contracting greater than those in line contact. The contraction in the center of the particle takes place similar to that of the point contact. But the expansion of stress points along a set of sides of the particle and their alteration takes place similar to that of the line contact. These stress variations can be seen in the following set of figures for a sample model. 

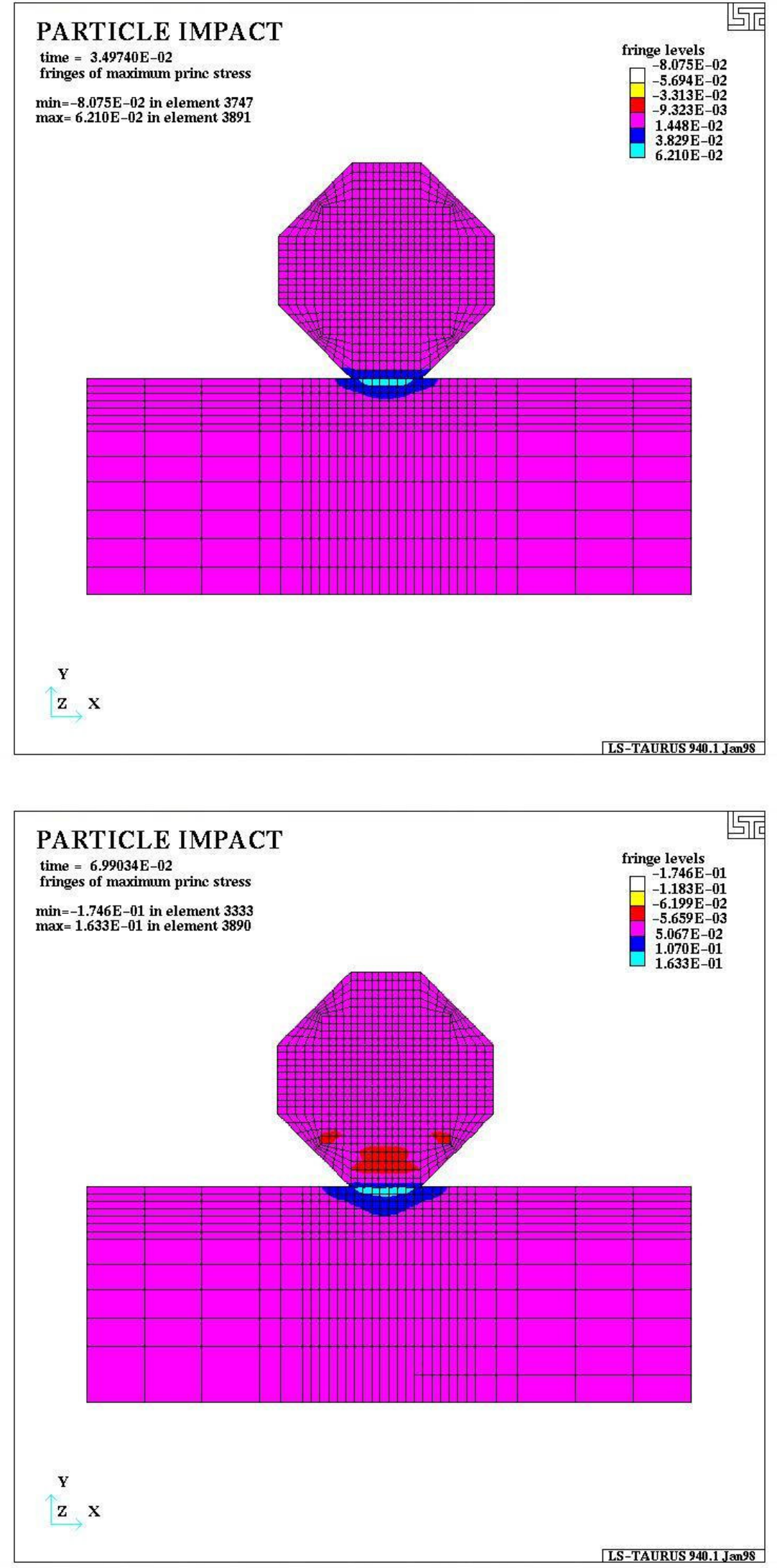

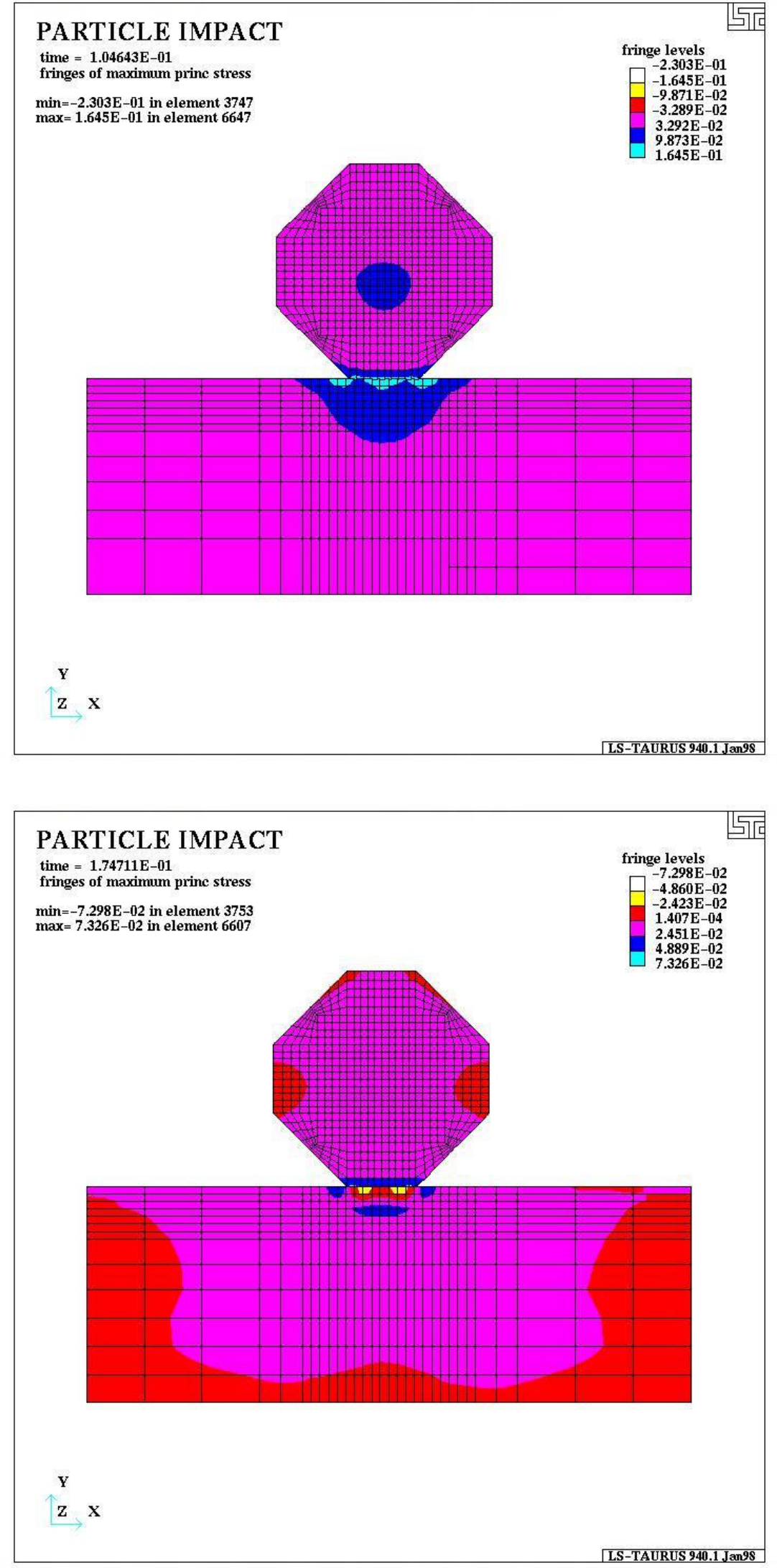

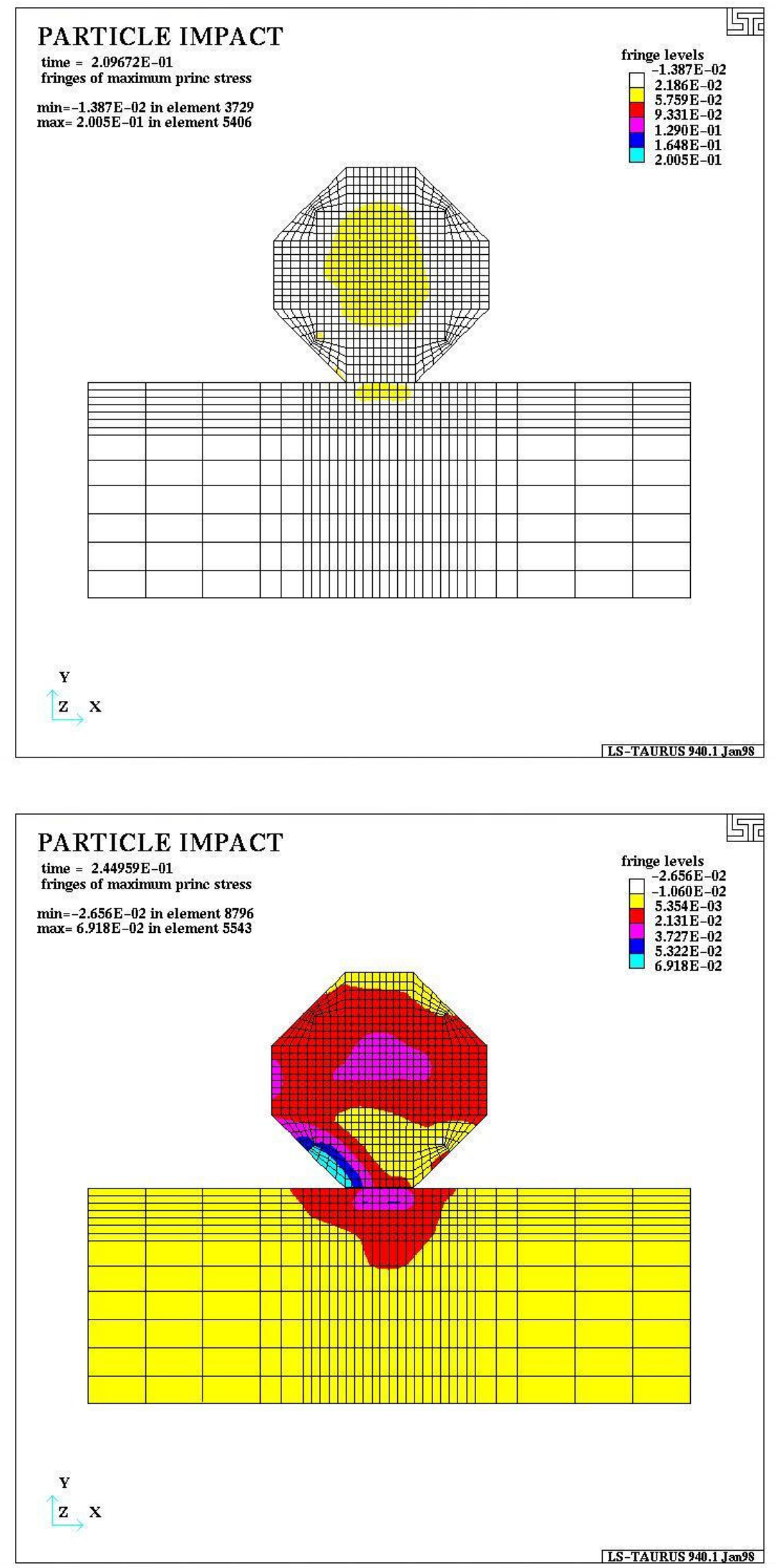


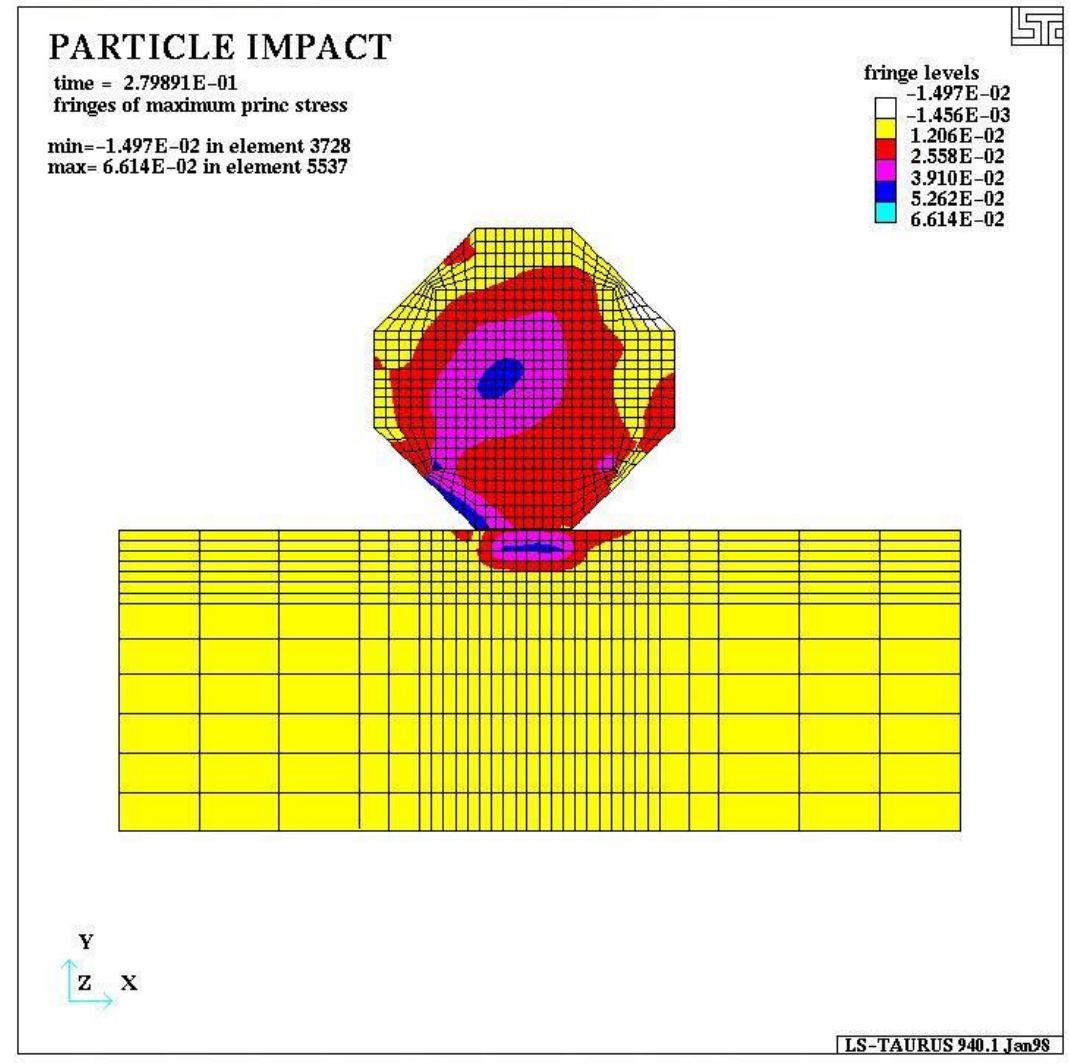

Figure 4.10: Fringes of Maximum Principal Stress of $250 \mu \mathrm{m}$ size particle impacting the plate at $24^{0}$ with a velocity of $40 \mu \mathrm{m} / \mu \mathrm{s}$

The fringes of minimum principal stresses were found to be similar to the maximum principal stresses. In addition, the expansions and contractions in both maximum and minimum principal stresses occur more number of times than in point contact (shape 2) and line contact (shape 3) particles. 

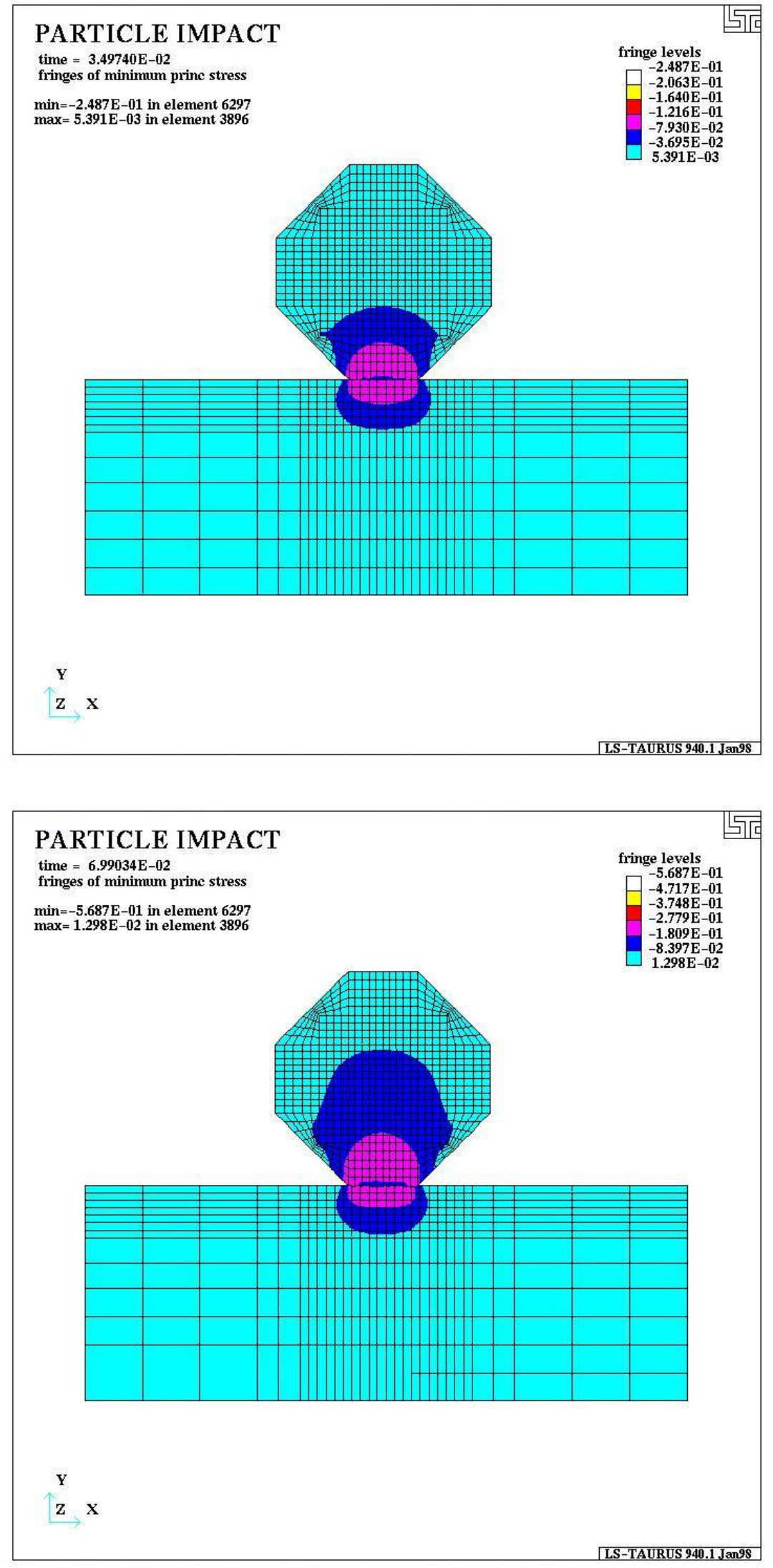

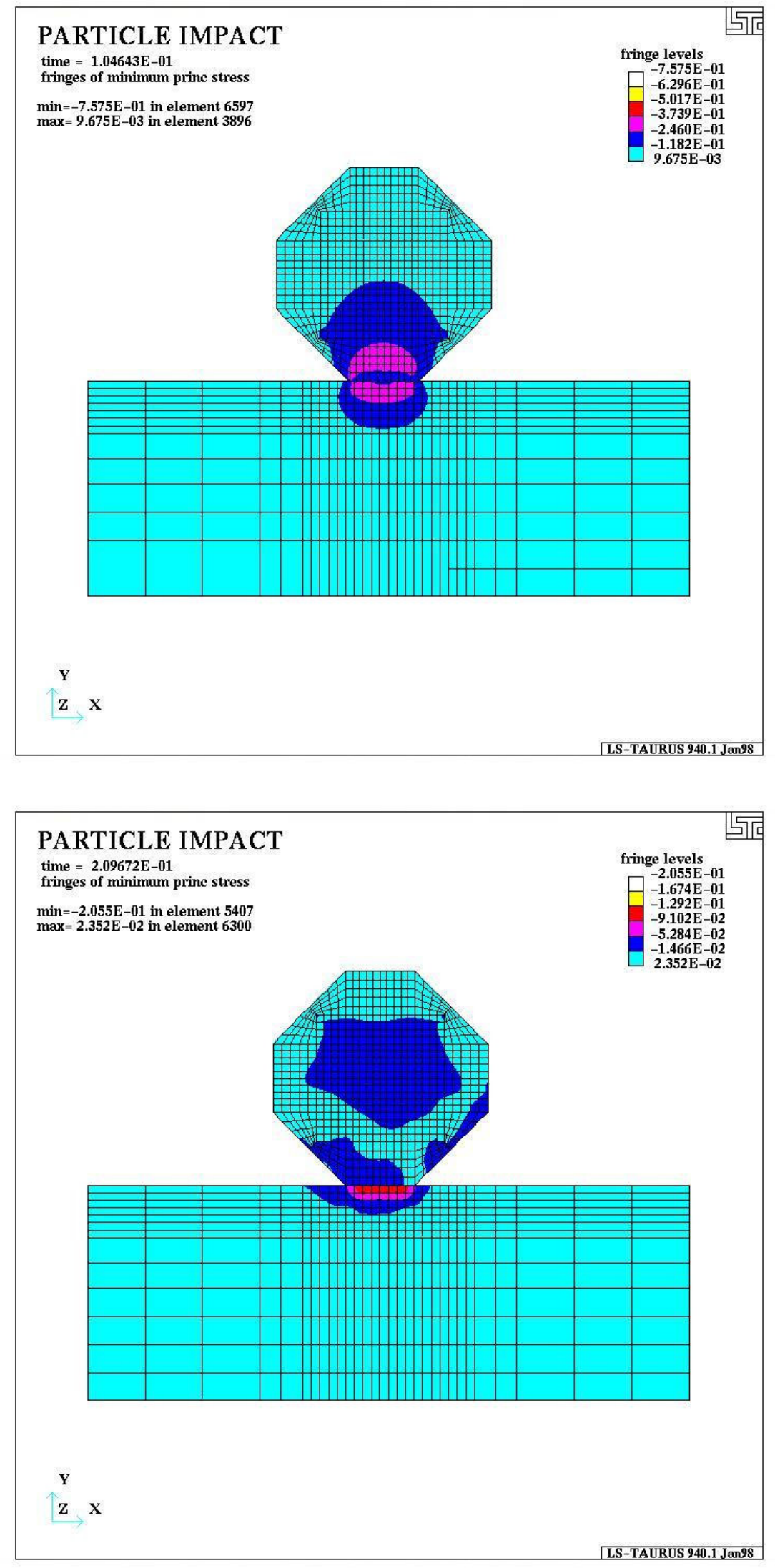

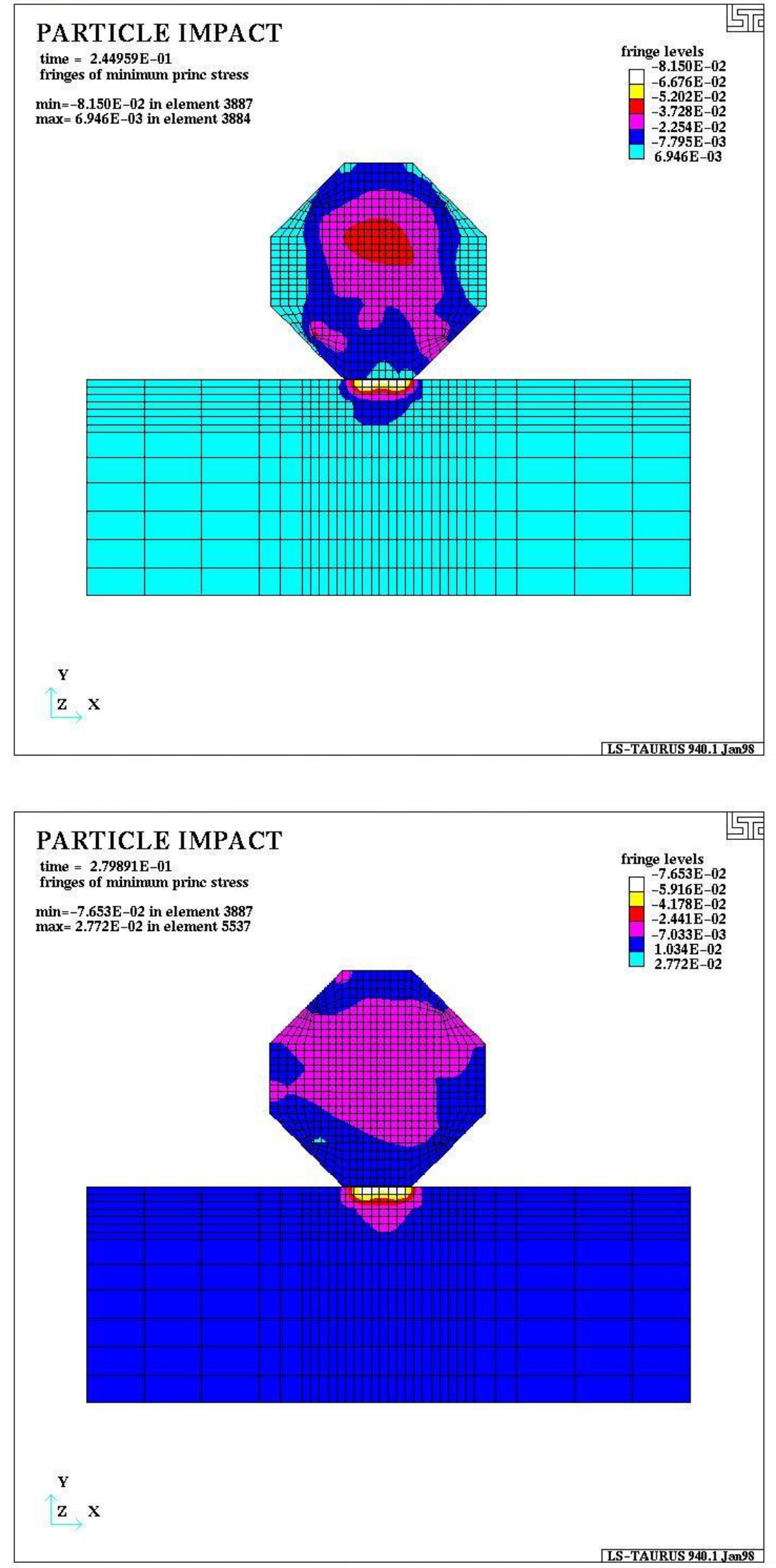


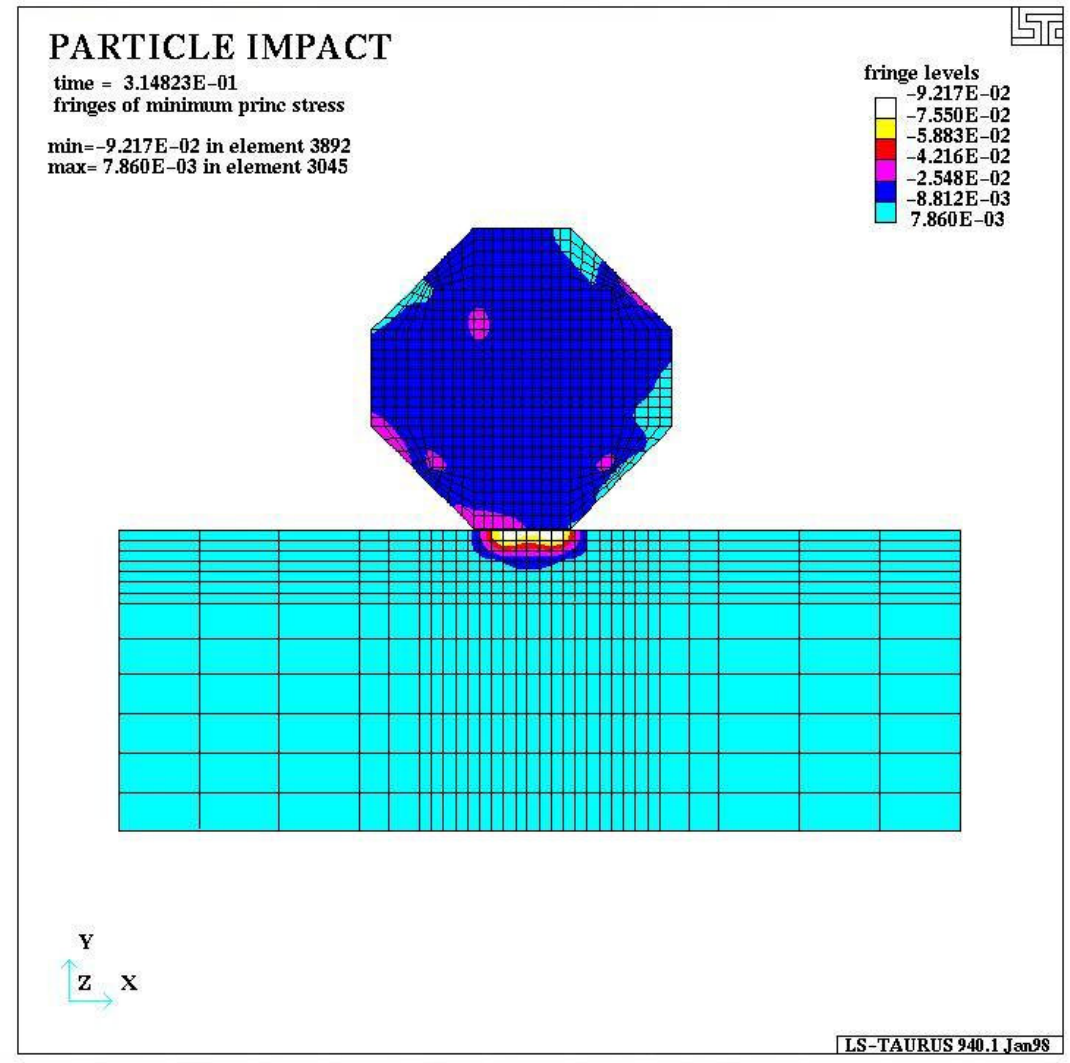

Figure 4.11: Fringes of Minimum Principal Stress of $250 \mu \mathrm{m}$ size particle impacting the plate at $24^{0}$ with a velocity of $40 \mu \mathrm{m} / \mu \mathrm{s}$

Graphs plotted among these parameters indicate that they are similar to those of the point contact, i.e. as the impact velocity, impact angle and particle size increases, the particle volume increases uniformly. Also, the ups and downs in the graphs and the jump in the volume loss for the larger particle are seen in here too; whose reason is the same as mentioned for the sphere. These graphs are shown below. 
Variation of volume loss at a velocity of 30 um/us and impact angle ranging from 16-24degs for a particle diamter ranging from $100-300$ ums

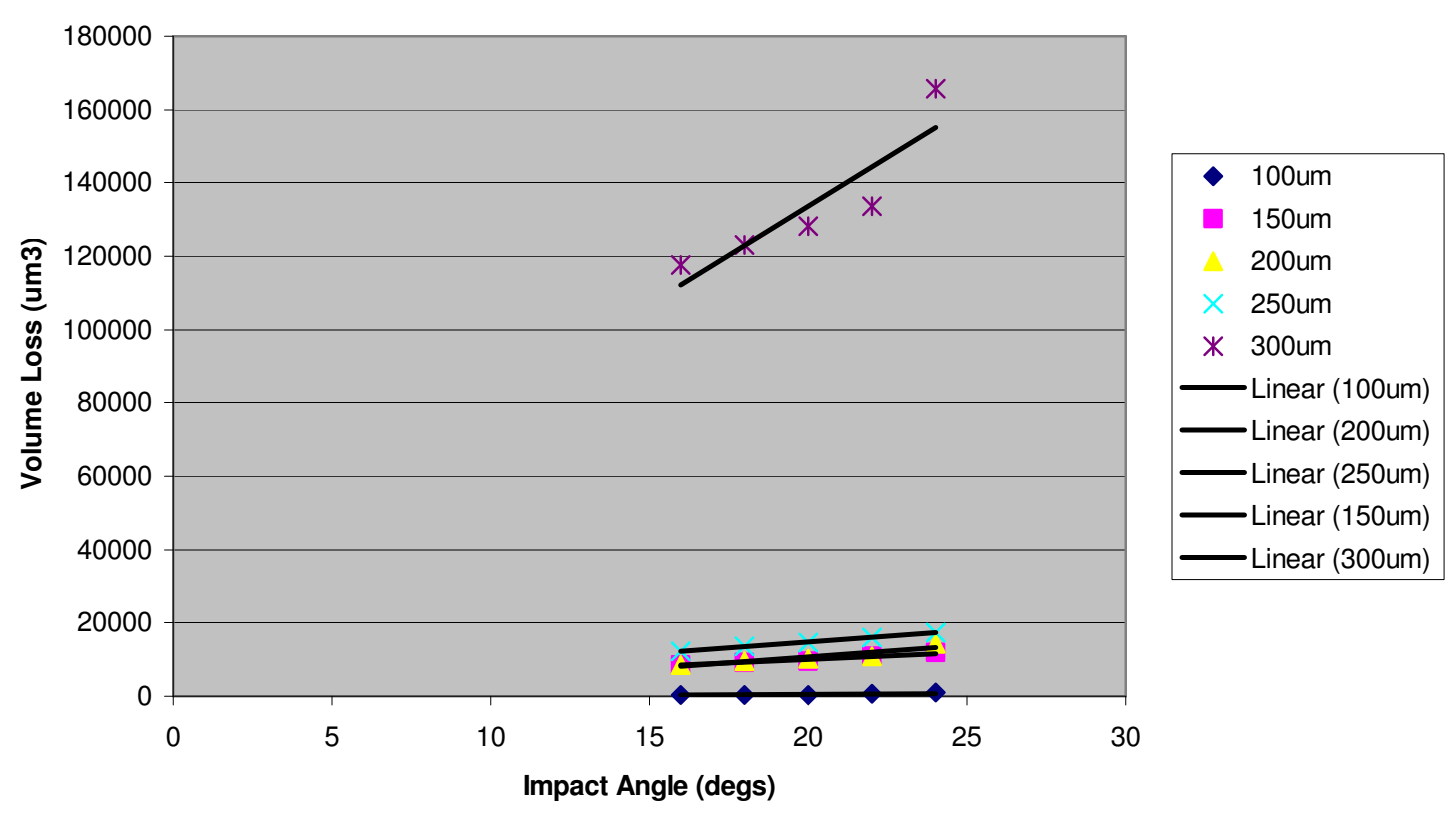

Variation of volume loss ata velocity of $35 \mathrm{um} / \mathrm{us}$ and impact angle ranging from 16-24degs for a particle diameter ranging from 100-300ums

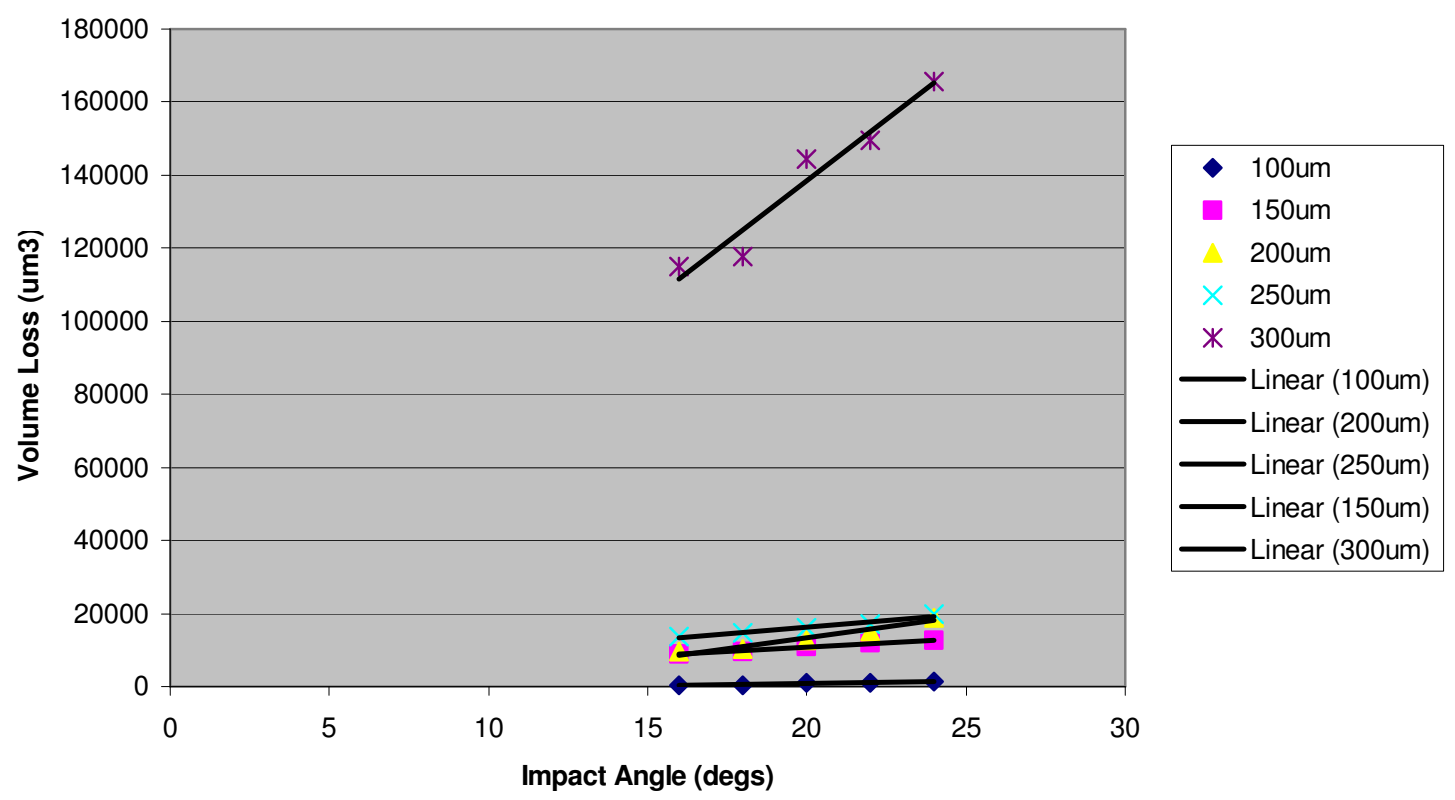


Variation of volume loss at a velocity of 40 um/us and impact angle ranging from 16-24degs for a particle diamter ranging from $100-300$ ums

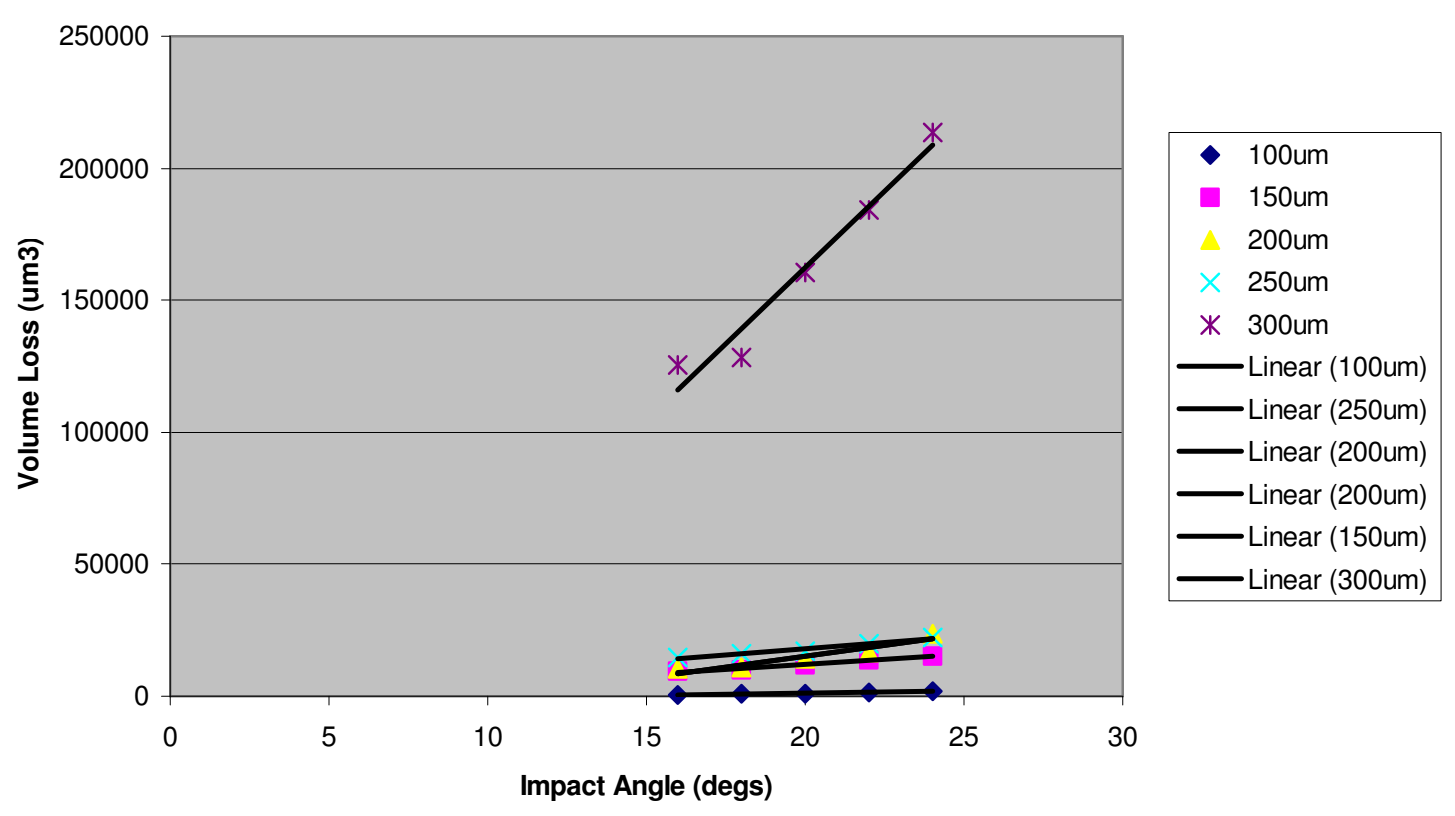

Variation of volume loss at a velocity of $45 \mathrm{um} / \mathrm{us}$ and impact angle ranging from 16-24degs for a particle diamter ranging from 100-300ums

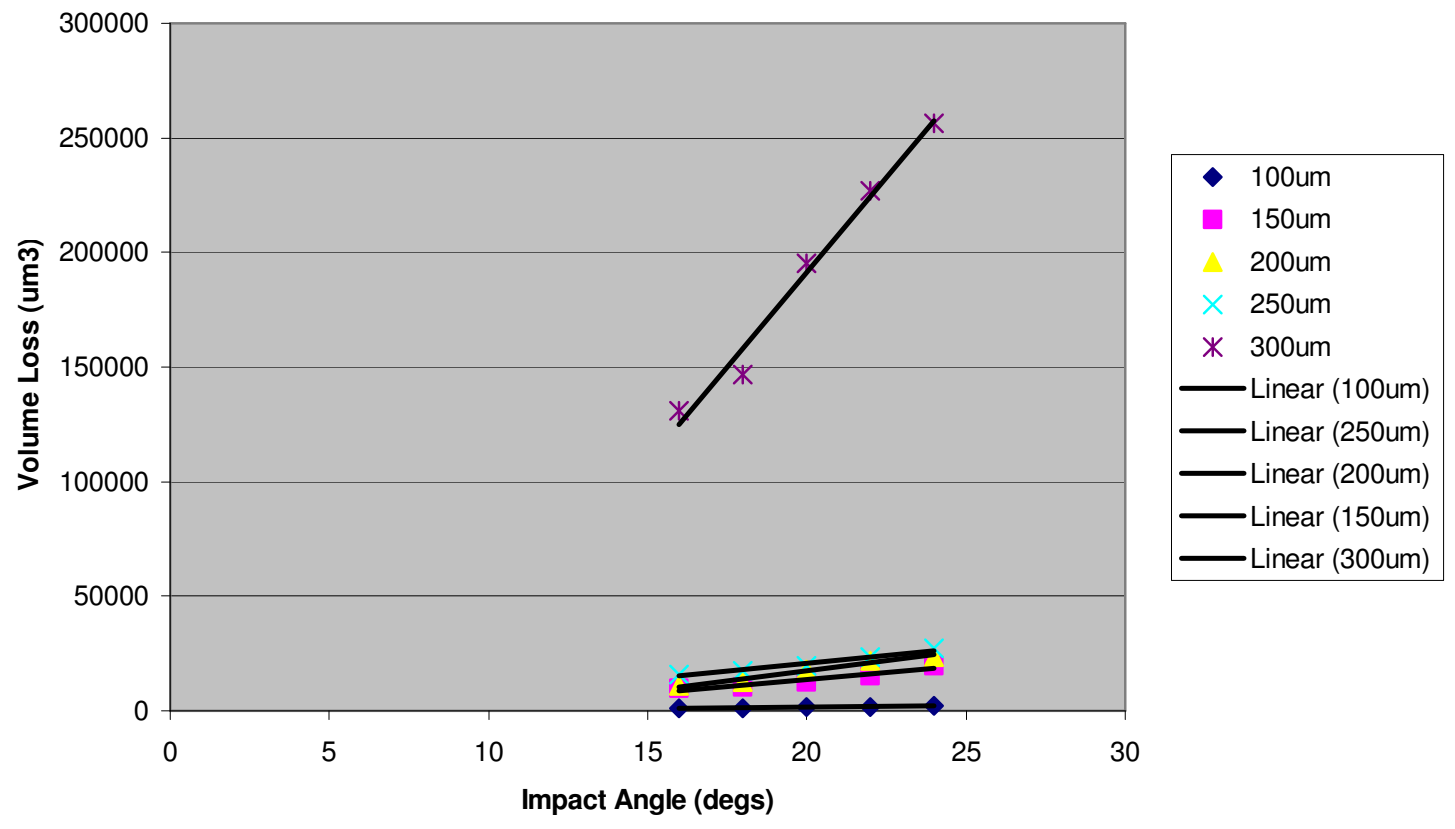


Variation of volume loss at a velocity of 50 um/us and impact angle ranging from 16-24degs for a particle diamter ranging from 100-300ums

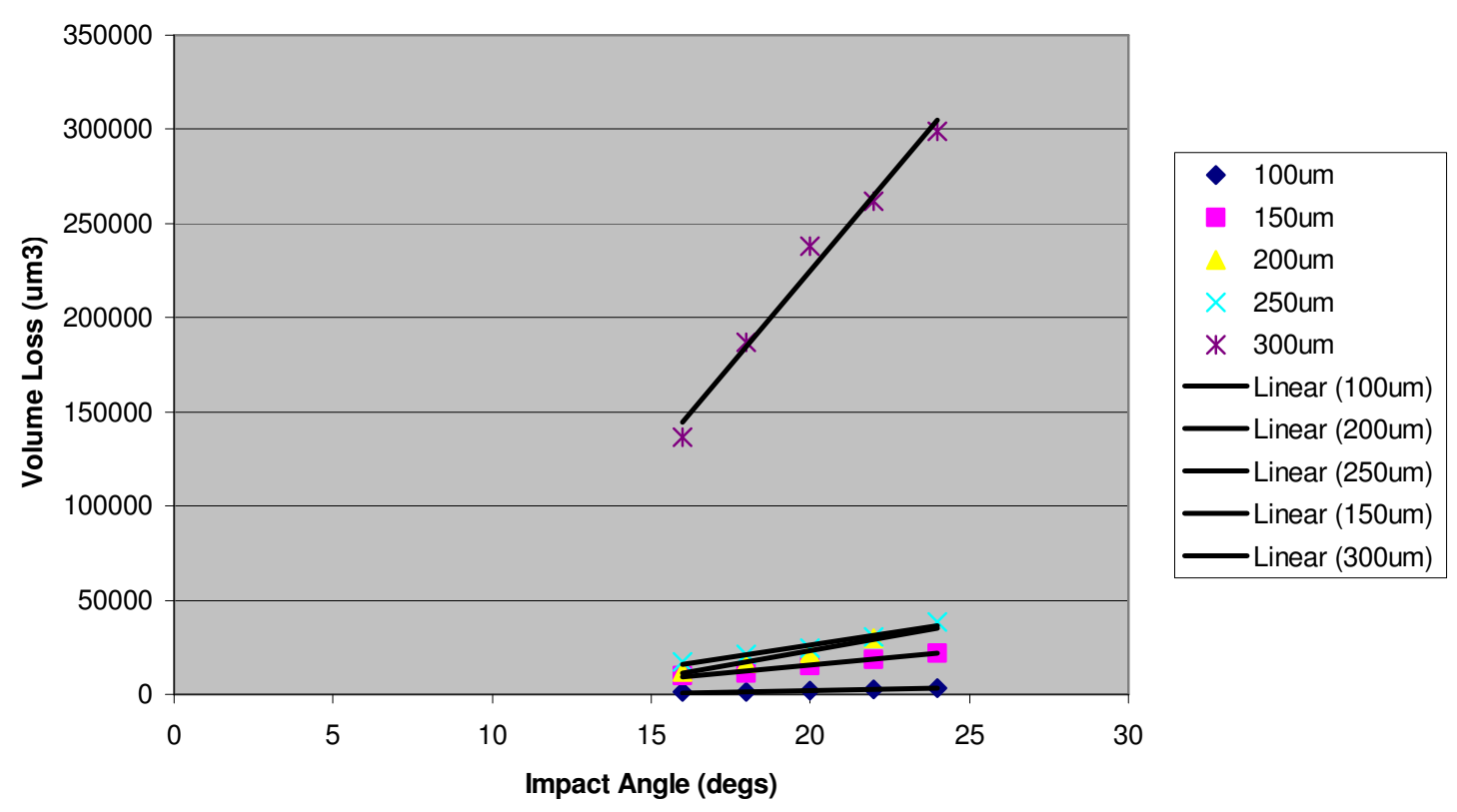

Figure 4.12: Volume Loss versus Impact Angle for Shape 3 (Area Contact)

\section{Variation of volume loss at 16 degs impact angle and velocity in the range of $30-50 \mathrm{um} / \mathrm{us}$ for a particle diamter ranging from $100-300$ um}

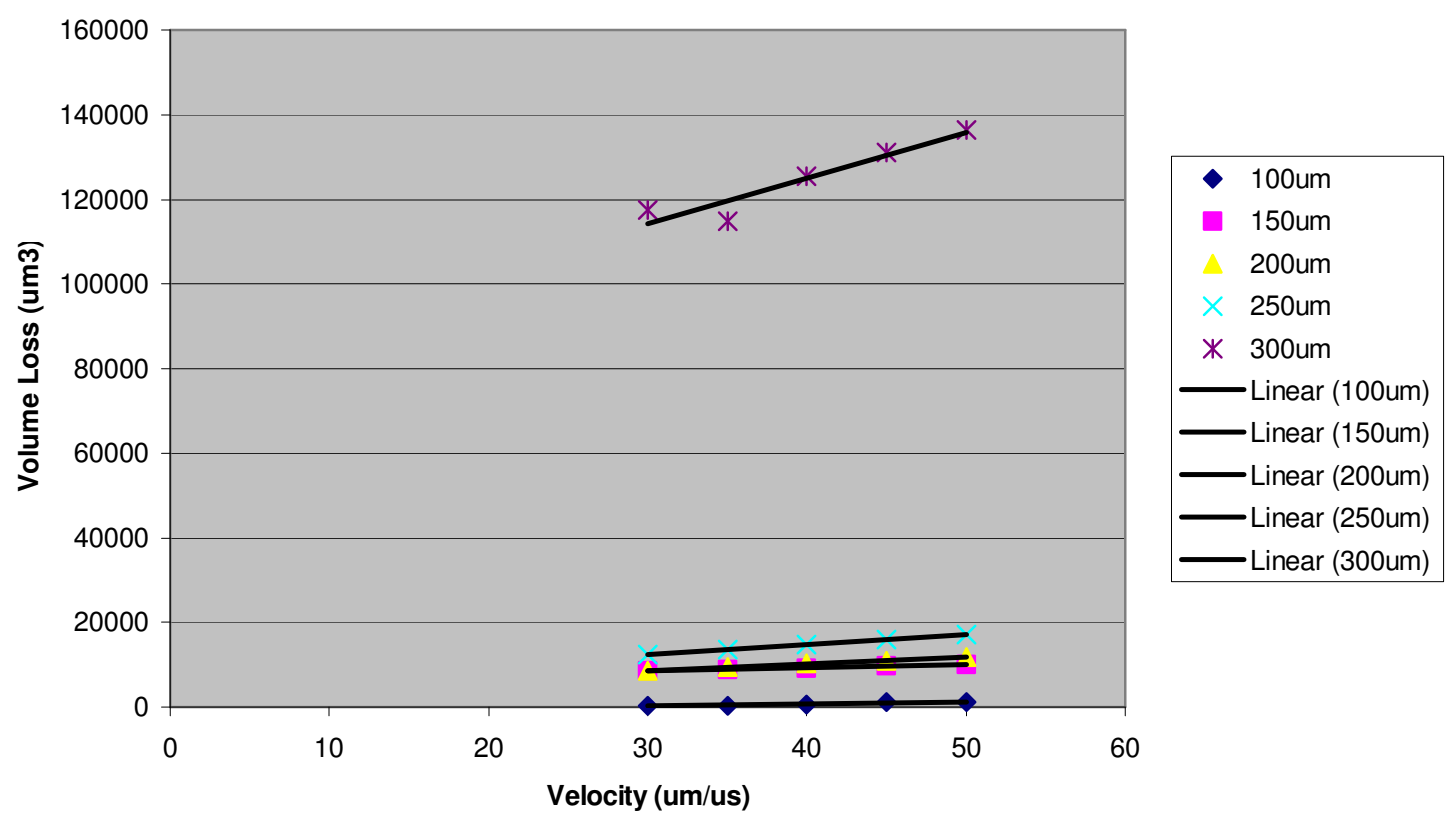


Variation of volume loss at 18degs impact angle and velocity in the range of 30-50um/us for a particle diameter ranging from $100-300 u m$

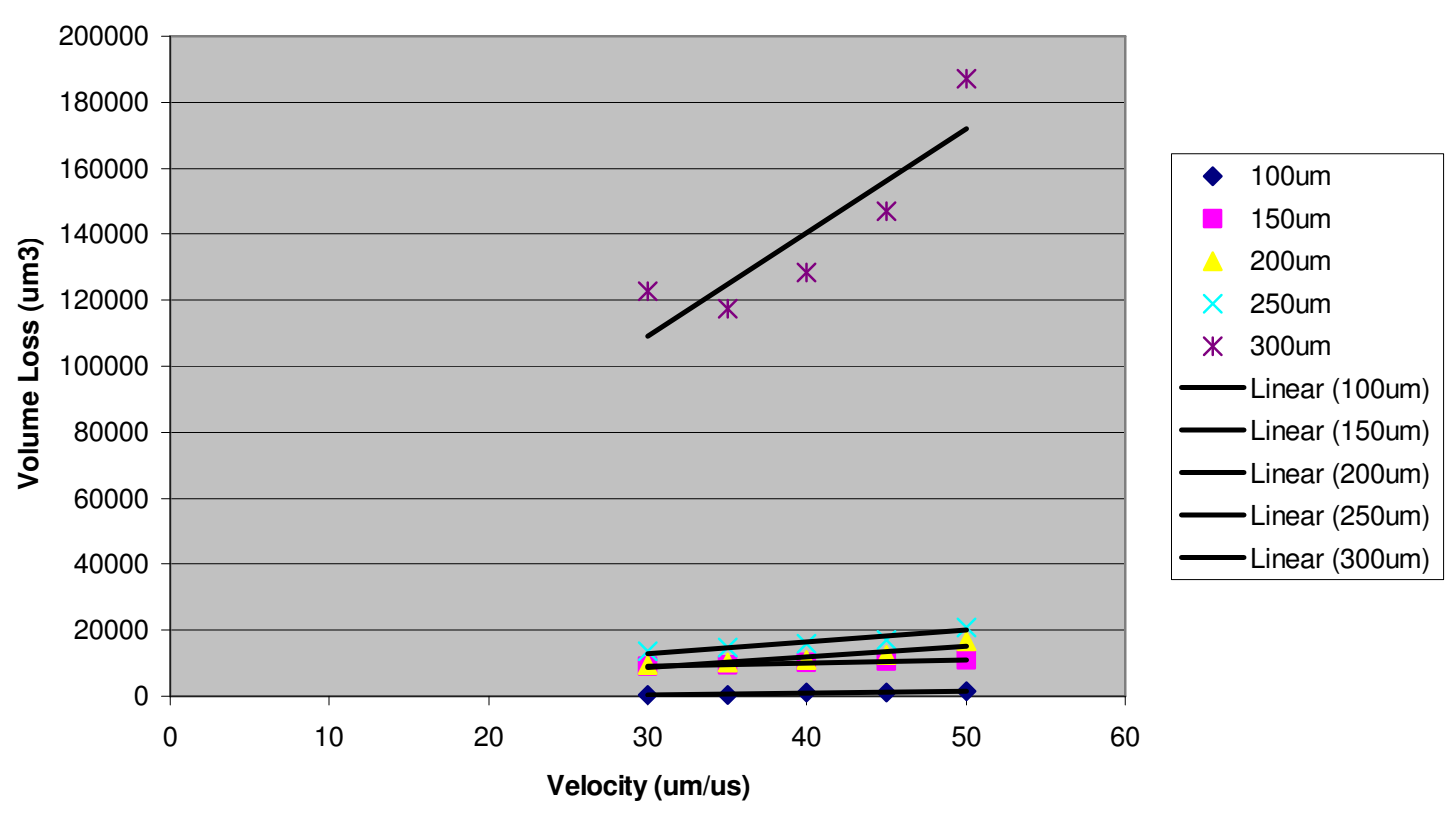

Variation of volume loss at 20degs impact angle and velocity in the range of $30-50$ um/us for a particle diameter ranging from $100-300$ um

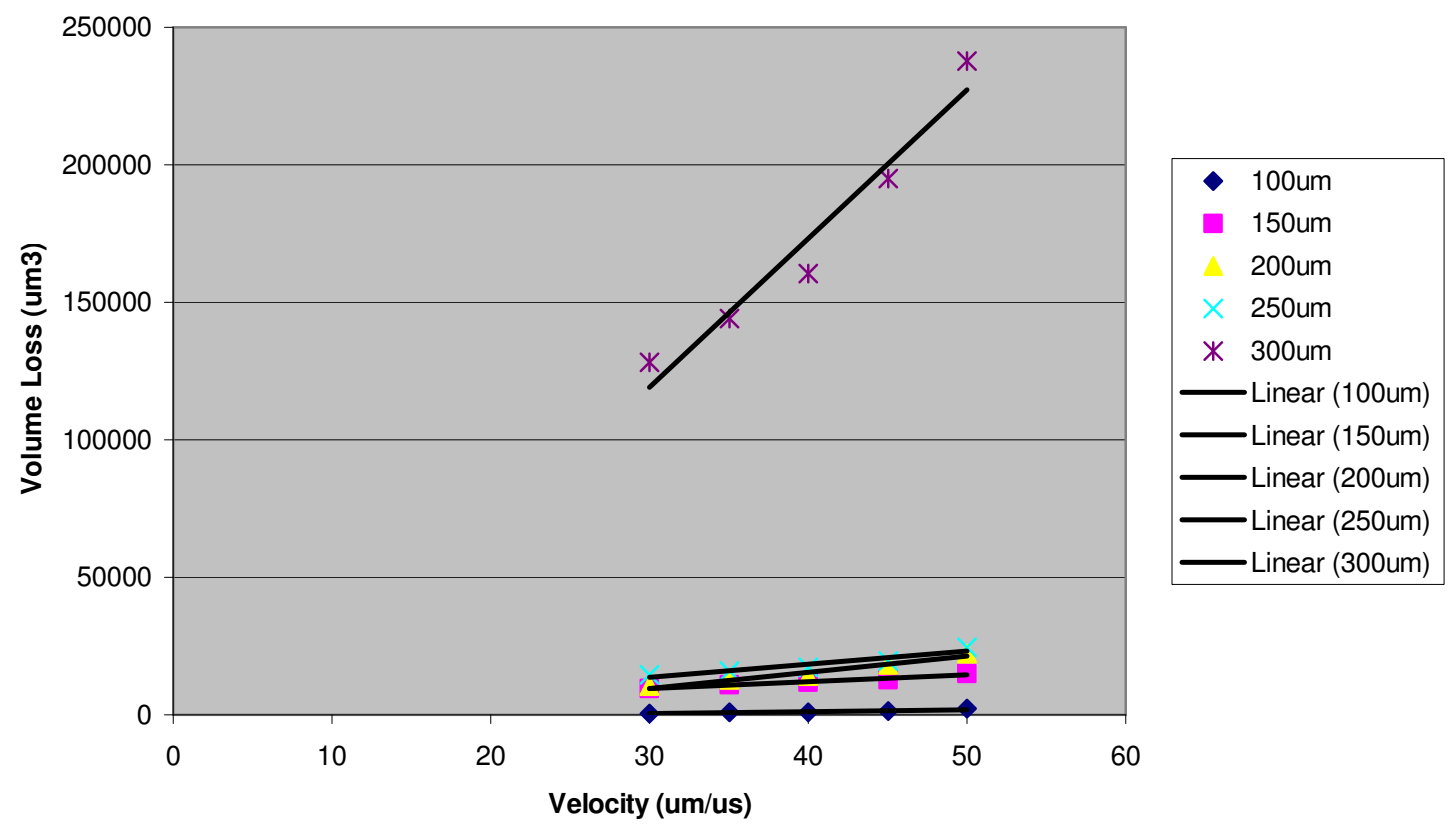


Variation of volume loss at 22degs impact angle and velocity in the range of 30-50um/us for a particle diameter ranging from $100-300 u m$

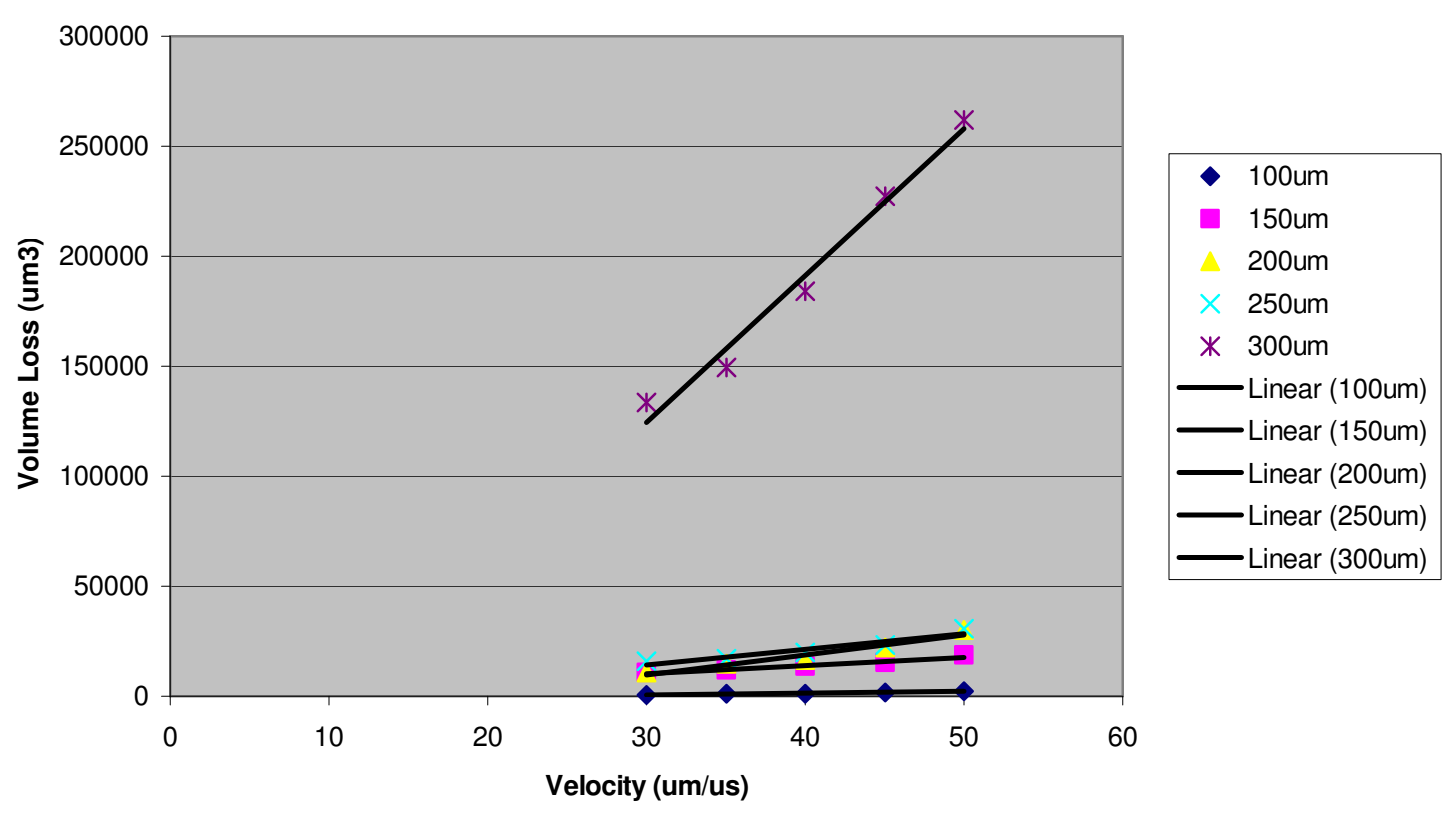

Variation of volume loss at 24degs impact angle and velocity in the range of $30-50$ um/us for a particle diamter ranging from $100-300$ um

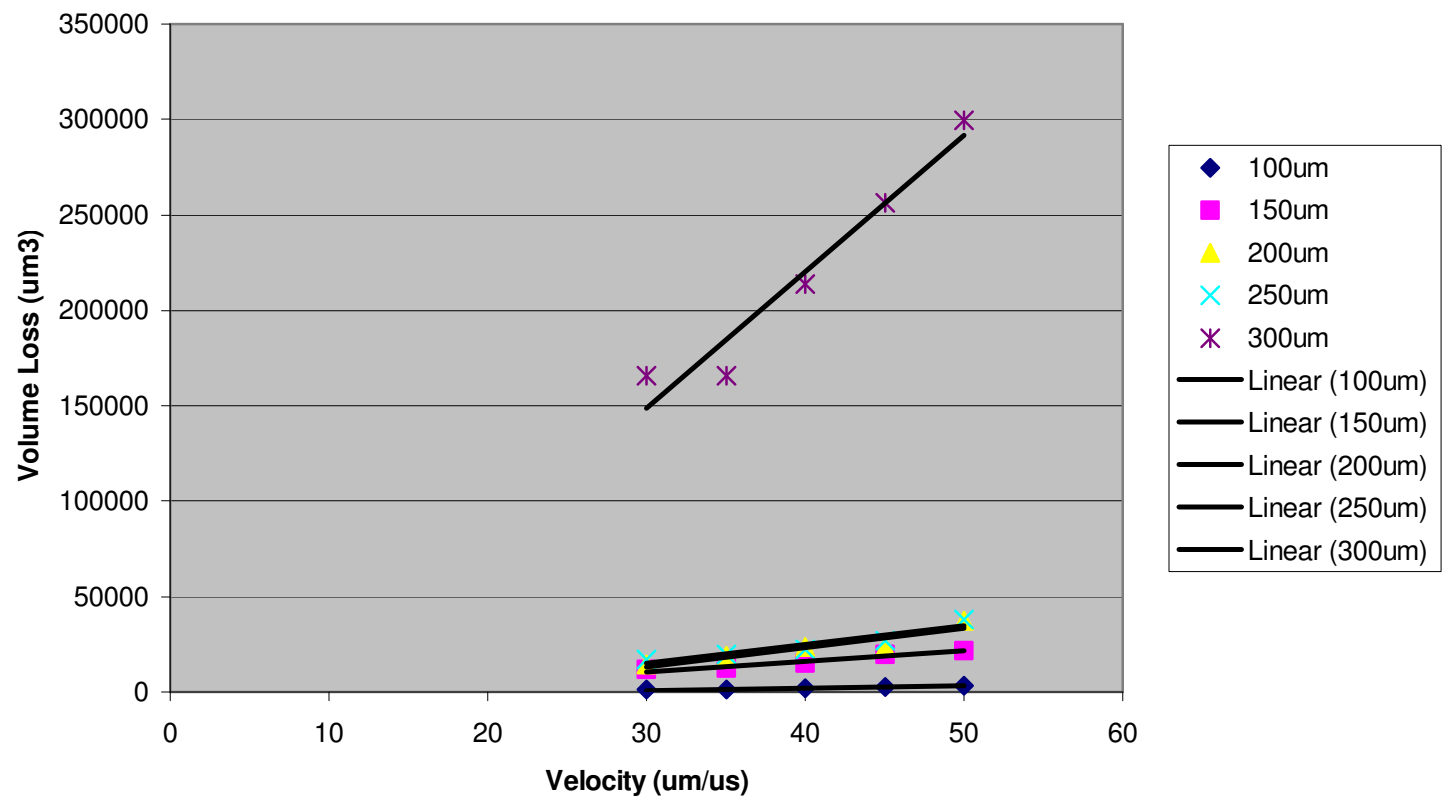

Figure 4.13: Volume Loss versus Velocity for Shape 3 (Area Contact) 


\subsection{Model Validation}

In 1993, A.J.Sparks and I.M.Hutchings performed extensive study on solid particles. They used soda-lime glass spheres (ballotini) and silica sand as erodent particles to impact the target material, silicate glass-ceramic, Silceram SCR19.34. Their work was mainly focused upon the resulting shapes and sizes of the particles after impacting the material, by using different categories of sizes of particles. To have a better understanding of the changes taking place, they recycled the erodent particles 7-10times.

It was seen that repeated impact led to further fragmentation and a progressive reduction in the average particle size. This nature of impact was studied for two particular cases: $30^{\circ}$ and $90^{\circ}$ impact angles. The results showed that in the first case, $\mathrm{SiO}_{2}$ particles fired at $44 \mathrm{~m} / \mathrm{s}$ velocity did not show any significant changes in their size even after impacting 5 times. Whereas in the second case, in contrast, both the $\mathrm{SiO}_{2}$ particles fired at $98 \mathrm{~m} / \mathrm{s}$ and ballotini fired at $89 \mathrm{~m} / \mathrm{s}$ showed extensive fragmentation after every cycle of impact. The size reduction and the percentage mass reduction are shown in the figures below. 


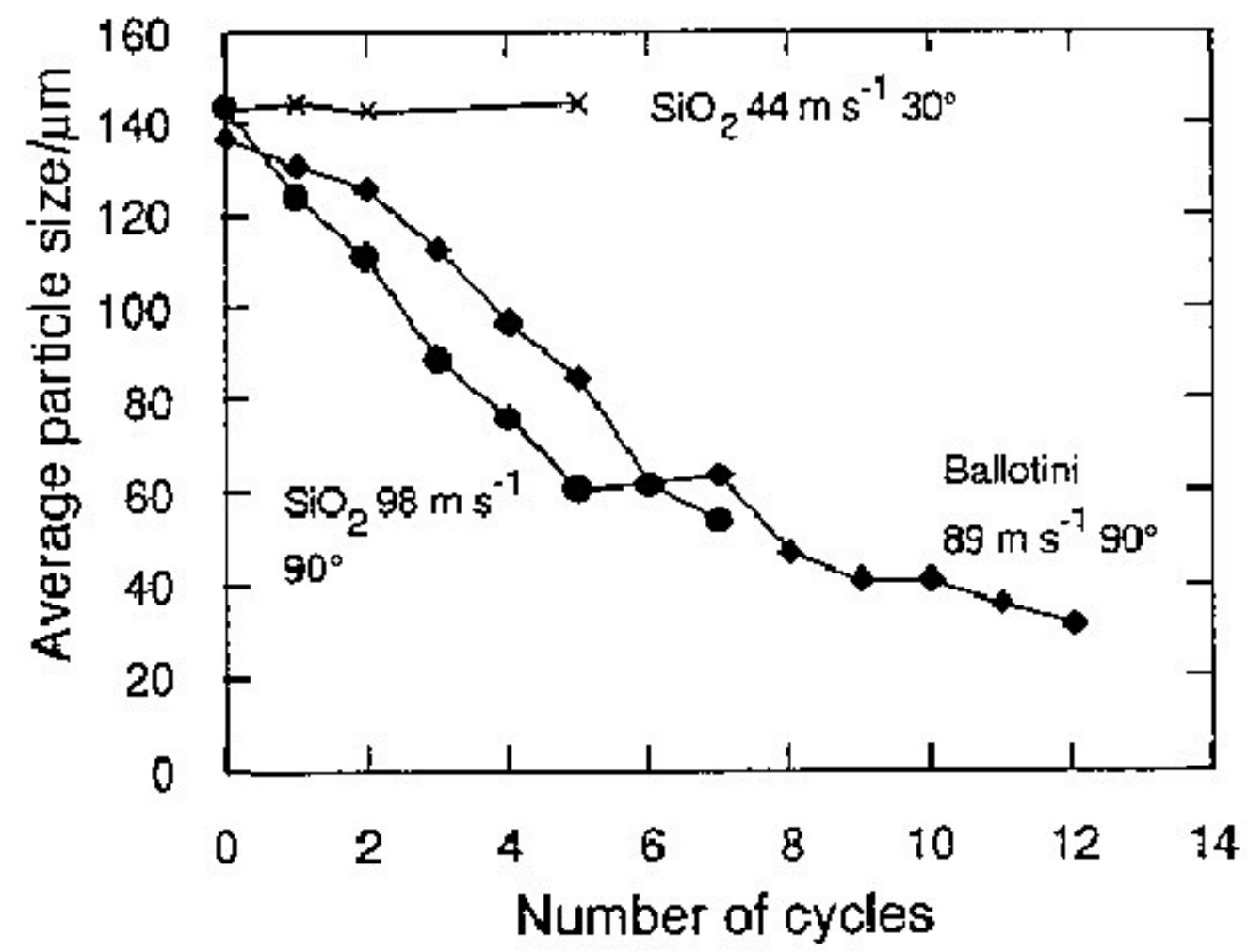

Figure 4.14: Plot of average (mass median) particle size versus number of cycles for silica and ballotini under the conditions indicated ${ }^{[22]}$

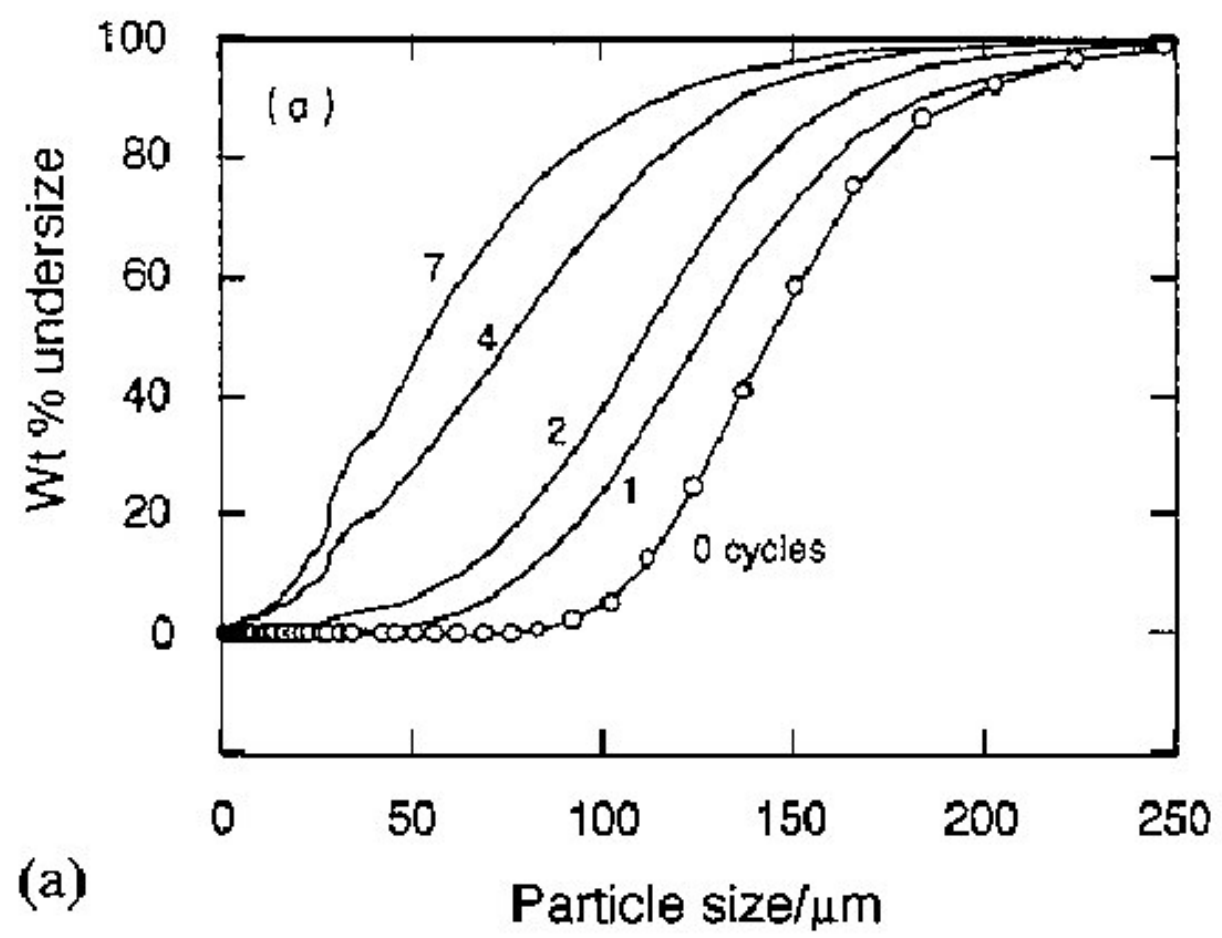




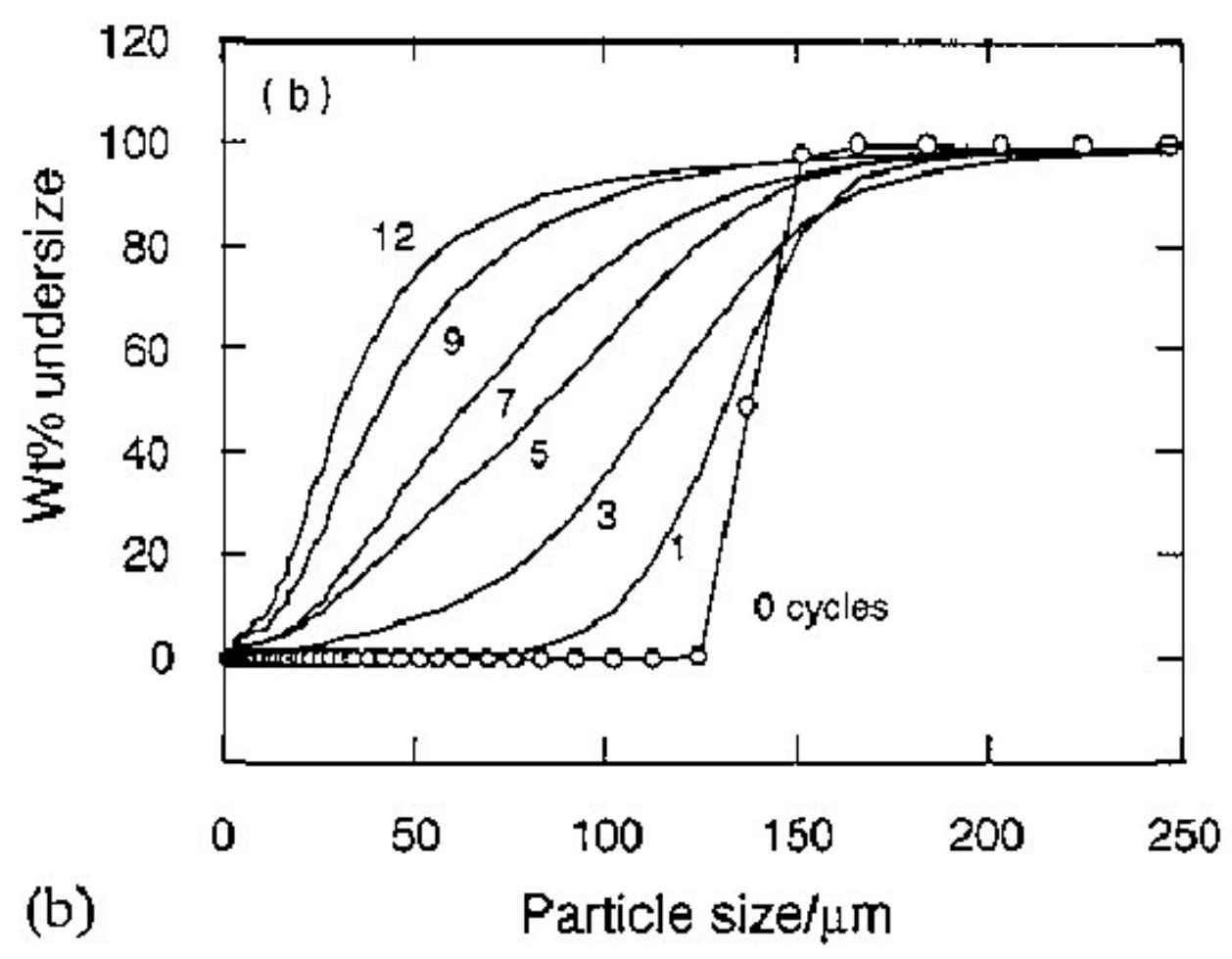

Figure 4.15: Particle size distribution after (cumulative mass undersize) for erodent samples after repeated impact by (a) Silica at $98 \mathrm{~m} / \mathrm{s}$ (b) Ballotini at $89 \mathrm{~m} / \mathrm{s}^{\text {[22] }}$

All the mass fractions were separated using sieving method and optical size analysis. An examination of ballotini after impact through Scanning Electron Microscope (SEM) indicated that the spheres fractured initially in two different ways: detachment of a small cap and breaking into two halves. But, a few spheres were seen to remain intact even after ten times of impact. The same was the case with a few silica particles being fired at $98 \mu \mathrm{m} / \mu$ s at $90^{\circ}$. These results showed that they were consistent with the proposition that a threshold impact condition does exist below which the particles remain intact and beyond which would fracture. In addition, the results indicated that repeated impact led to greater amount of particle damage due to two factors: statistical factors associated with the distribution of particle orientations on impact and progressive growth of cracks under repeated loading. The reason for the diametrical breakage (usually observed in brittle spheres) was observed as the origin of fracture at the point of maximum tensile stress on the surface. Though plane fracture surfaces were evident from 
the fragments of silica and ballotini, their fracture patterns were impossible to analyze. The reason for this was found to be the irregularity of the shapes of the fragments obtained from fractured spheres and of even the original silica particles.

Extensive lateral fracture was found to be the initial mechanism involved with the erosion of angular particles. The repeated use of the same particles for erosion made them rounder and reduced the erosion rate to a much lesser value. The erosion caused in the latter cycles of impact involved a mechanism having a more fine-scale fracture and plastic flow. At these stages, the material removal required multiple impacts. The results of the experimentation showed that for the silica particles impacted at $90^{\circ}$, the erosion rate varied quite significantly. The impact led to fracture of the particles, which developed planar facets and sharp angles on the fragments. This change in particle angularity increased the erosion rate initially and decreased later on. The increase in erosion rate was due to the increased angularity and some increase in velocity after the initial reduction of particle size, that outweighed the intrinsic particle size effect (reduction of erosion rate with decrease in particle size). Whereas the decrease in the wear rate was because of the domination of intrinsic size effect over the un-increasing angularity even after further diminution of size and increased velocity. These changes are clearly seen in the figures below. 

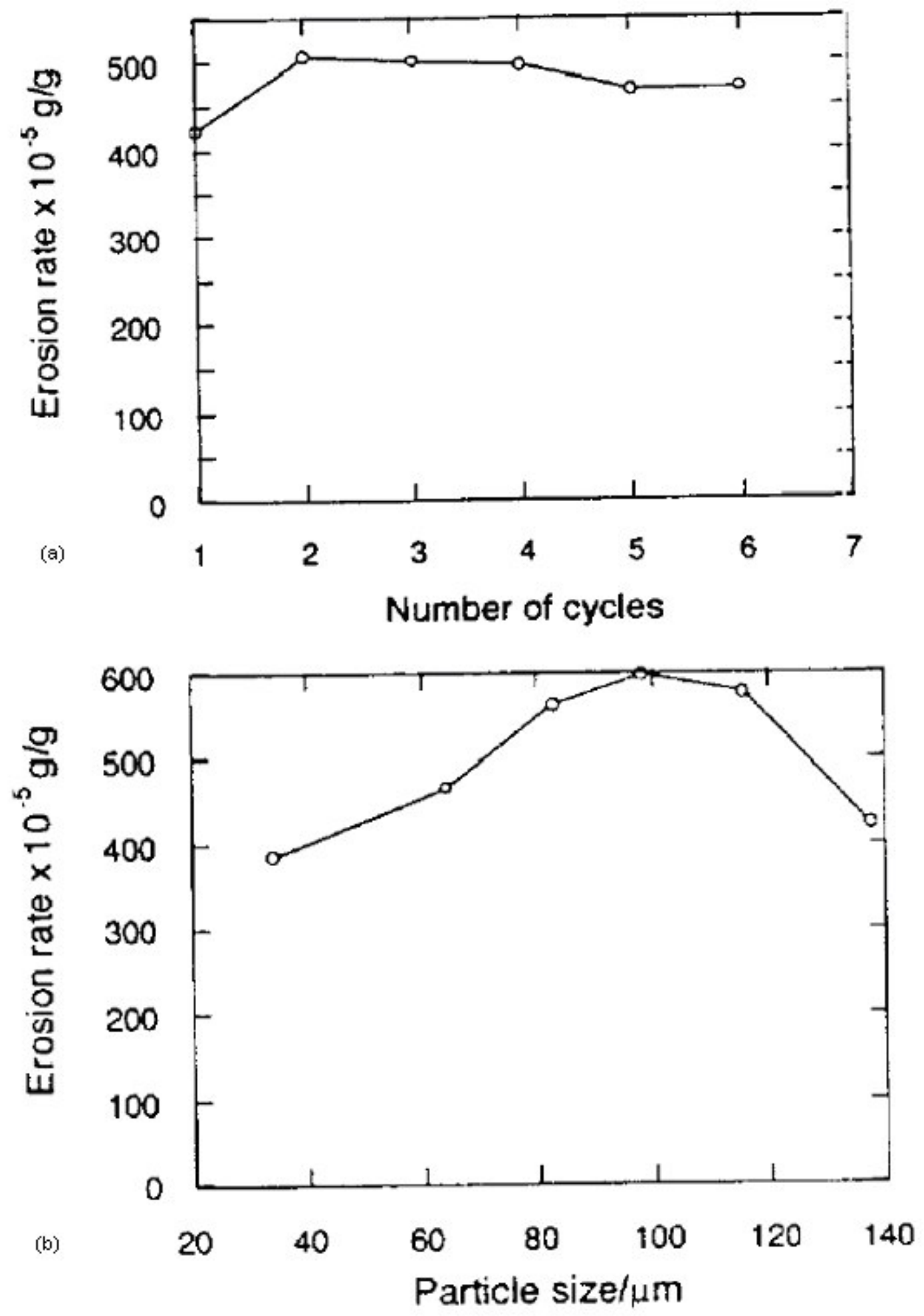

Figure 4.16: Erosion rate of glass-ceramic by silica particles at $90^{\circ}$ plotted against

(a) Number of cycles (b) Particle size ${ }^{[22]}$ 


\subsection{Comparison of FEM and Experimental Results}

For the above-mentioned experimental Study, FEM models for the particles and the plate were created in LS-INGRID, solved in LS-DYNA3D and the results obtained from LS-TAURUS were compared with the experimental results. Its procedure is explained below.

The target material used in the experimental study was silicate glass-ceramic, Silceram SCR19.34. Its composition was given as $\mathrm{CaO} 20 \pm 6 ; \mathrm{MgO} 8 \pm 2 ; \mathrm{Al}_{2} \mathrm{O}_{3} 15 \pm 1$; $\mathrm{SiO}_{2} 56 \pm 3 ; \mathrm{Fe}_{2} \mathrm{O}_{3} 4 \pm 1$ and $\mathrm{Cr}_{2} \mathrm{O}_{3} \approx 1$. In general it is known that ceramics are brittle in nature and are prone to brittle fracture due to many different types of flaws such as cracks, notches, etc. They are stronger than metals, but less tough. Their young's modulus is greater than that of metals. They are much stronger in compression than in tension. Also their tensile stress overlaps with that of the metals. Looking at the relation of the ceramic properties with those of the metals, especially the last two, a greater young's modulus was taken in the finite element model to have close properties. Their approximation was done due to the non-availability of the exact properties of Silceram.

The erodent ballotini or soda lime silica glass, also known as flat glass has the composition of $\mathrm{SiO}_{2} 71 \%, \mathrm{Na}_{2} \mathrm{O} 16 \%, \mathrm{CaO} 19 \%, \mathrm{MgO} 3 \%$ and $\mathrm{Al} 2 \mathrm{O} 31 \%$. The erodent used was silica, which has the composition of 99.4-99.9\% $\mathrm{SiO}_{2}$ and $0.1-0.6 \% \mathrm{Fe}_{2} \mathrm{O}_{3}$. Both these erodents have the same properties, except that the possion's ratio of ballotini is 0.23 and that of sand is 0.17 or 0.22 . Both of them have compressive strengths ten times greater than the tensile strengths. In general, for static loads, the properties of a sand particle of 1-2" size are given as

Young's Modulus E = 60Gpa

Compressive Strength $\sigma_{\mathrm{c}}=200 \mathrm{Mpa}$

Tensile Strength $\sigma_{\mathrm{t}}=20 \mathrm{Mpa}$. 
But the strength of a rock material increases as its size decreases. Also for dynamic properties, the strengths increase. Hence, by taking these conditions into account, the properties were changed to

Young's Modulus E = 100Gpa

Compressive Strength $\sigma_{\mathrm{c}}=800 \mathrm{Mpa}$

Tensile Strength $\sigma_{\mathrm{t}}=80 \mathrm{Mpa}$.

When the models were run using these values, a good correlation was obtained with the experimental results. These values are shown in the table below.

\begin{tabular}{|c|c|c|c|c|c|c|c|c|}
\hline \multirow{3}{*}{ Particle } & \multirow{3}{*}{$\begin{array}{c}\text { Contact } \\
\text { Type }\end{array}$} & \multirow{2}{*}{$\begin{array}{c}\text { Impact } \\
\text { Angle }\end{array}$} & \multirow{2}{*}{$\begin{array}{l}\text { Impact } \\
\text { Velocity }\end{array}$} & \multicolumn{2}{|c|}{ Experimental Results } & \multicolumn{2}{|c|}{ FEA Results } & \multirow{3}{*}{$\begin{array}{c}\text { Percentage } \\
\text { Error }\end{array}$} \\
\hline & & & & Initial Size & Final Size & Initial Size & Final Size & \\
\hline & & Degs & $\mu \mathrm{m} / \mu \mathrm{s}$ & $\mu \mathrm{m}$ & $\mu \mathrm{m}$ & $\mu \mathrm{m}$ & $\mu \mathrm{m}$ & \\
\hline Ballotini & Point & 90 & 89 & 135 & 130 & 135 & 128.84 & 0.89 \\
\hline Silica & Line & 30 & 44 & 140 & 140 & 140 & 132.89 & 5.08 \\
\hline Silica & Line & 90 & 98 & 140 & 124 & 140 & 120.32 & 2.97 \\
\hline Silica & Area & 30 & 44 & 140 & 140 & 140 & 136.27 & 2.66 \\
\hline Silica & Area & 90 & 98 & 140 & 124 & 140 & 122.07 & 1.56 \\
\hline
\end{tabular}

Table 4.1: Comparison of Size Results

\begin{tabular}{|c|c|c|c|c|c|c|c|c|c|c|}
\hline \multirow{3}{*}{ Particle } & \multirow[b]{2}{*}{ Contact } & \multirow{2}{*}{$\begin{array}{l}\text { Impact } \\
\text { Angle }\end{array}$} & \multirow{2}{*}{$\begin{array}{l}\text { Impact } \\
\text { Velocity }\end{array}$} & \multicolumn{3}{|c|}{ Experimental Results } & \multicolumn{3}{|c|}{ FEA Results } & \multirow{3}{*}{$\begin{array}{l}\text { Percentage } \\
\text { Difference }\end{array}$} \\
\hline & & & & Initial Size & Final Size & $\%$ Weight & Initial Size & Final Size & \multirow{2}{*}{ \%Weight } & \\
\hline & Type & Degs & $\mu \mathrm{m} / \mu \mathrm{s}$ & $\mu \mathrm{m}$ & $\mu \mathrm{m}$ & Reduction & $\mu \mathrm{m}$ & $\mu \mathrm{m}$ & & \\
\hline Ballotin & Point & 90 & 89 & 135 & 130 & 5 & 135 & 128.84 & 1.38 & 3.62 \\
\hline Silica & Line & 90 & 98 & 140 & 124 & 20 & 140 & 120.32 & 26.19 & 6.19 \\
\hline Silica & Area & 90 & 98 & 140 & 124 & 20 & 140 & 122.07 & 21.84 & 1.84 \\
\hline
\end{tabular}

Table 4.2: Comparison of Weight Percentage Reduction Results 


\subsection{Discussion}

The FEM results obtained showed less amount of volume loss than the experimental results. This difference could be attributed to the experimental errors and the rounding error in the FEM volume loss estimation procedure. The rounding error occurred as the volume loss was estimated by calculating the average volume of five failed brick element and multiplying it with the total number of failed elements. This is done because there are a few elements whose volume is found to be zero due to the coincident coordinates and the utilization of a standard formula to calculate the volume loss lead to negative volume in some elements. Whereas in real life, the eroded elements are not always brick shaped. Hence there may be little under or over estimation of volume loss. 


\section{CHAPTER 5. CONCLUSIONS AND RECOMMENDATIONS}

\subsection{Conclusions}

The following conclusions were assessed from the present work:

- Finite element models of the sand particle showed that due to the impact, the stresses generated in them traveled upwards from the point of contact and kept expanding and contracting.

- The amount of expansion and contraction increased with the contact area of the particle with the material, i.e. it is least for shape 1 (point contact) particle and greatest for shape 3 (area contact) particle.

- $\quad$ The volume loss increased linearly with impact velocity.

- $\quad$ The volume loss increased linearly with impact angle.

- $\quad$ The volume loss increased linearly with particle size.

- $\quad$ The volume loss was greater for shape 2 (line contact) particle than shape 1 (point contact) particle.

- $\quad$ The number of elements failing due to compressive stresses increased with the contact area of the particle with the material.

- The small volume loss of the ballotini spheres indicated that only a detachment of a small cap took place as was seen in the experimental results.

- Finite element results of the models represented a good match with the experimental results of A.J.Sparks and I.M.Hutchings. The minor variation of FEM results from the experimental results was due to the experimental errors and rounding errors in volume loss estimation procedure.

- The optimum size of the particle that increases the safety of the workers performing sandblasting was found to be $100 \mu \mathrm{m}$ due to its lesser volume loss. 


\subsection{Future Recommendations}

From the results of the present research, the following work can be done in the future:

- The nature of sand particle breakage was not properly understood in the experimental work of A.J.Sparks and I.M.Hutchings. Hence, more detailed studies are required to be done in this area.

- Analytically, greater research could be done by varying the line and area contacts, i.e. taking two line contacts for a single particle or a gap in between the line contact and by looking at different areas like triangular or pentagonal, etc.

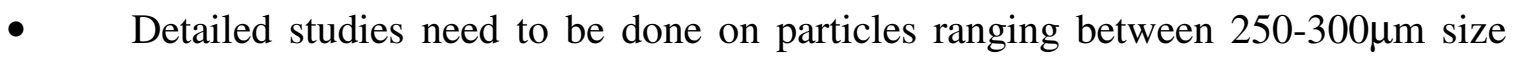
particles, to understand the jump in the volume loss for point and area contact particles.

- $\quad$ The exact volume loss of the particle can be calculated by decreasing the element size, until it converges with the volume loss, i.e. the volume loss remains the same after certain decrease in the size of the element. 


\section{REFERENCES}

1. Bahadur, S. and Badruddin, R., "Erodent Particle Characterization and the Effect of Particle Size and Shape on Erosion”, Wear, Vol. 138, Jun. 1990, pp. 189-208.

2. Balasubramaniyam, S.S., "Computational Modeling of Brittle Impact Erosion Mechanisms", 1998, pp. 1-92.

3. Carter, G., Bevan, I.J., Katardjiev, I.V., Nobes, M.J., "The Erosion of Copper by Reflected Sandblasting Grains", Materials Science and Engineering, Vol. A132, Feb. 1991, pp. 231-236.

4. Fang, C.K. and Chuang, T.H., "Erosion of SS41 Steel by Sand Blasting", Metallurgical and Materials Transactions, Vol. 30A, Apr. 1999, pp. 941-948.

5. Gotzmann, J., "Influence of the Quartz Sand Particle Size on the Blast Wear of Ceramic Materials”, Wissenschafts Forum, Vol. 70, 1993, pp. 611-613.

6. $\quad$ http://custom-glass.com/making8.html

7. http://efunda.com/formulae/solid_mechanics/failure_criteria/failure_criteria.cfm?s earch_string=failure $\% 20$ criteria

8. http://screem.engr.scu.edu/artemis/system/mech/al_data.html

9. http://serve.me.nus.edu.sg/nanomachining/wafer_materials.htm\#Semi-Properties

10. http://twovoyagers.com/metamorphosis/faq/faqvi.html

11. http://www.abrisa.com/downloads/soda_lime_float.pdf

12. $\quad$ http://www.azom.com/details.asp?ArticleID=1114

13. http://www.baaqmd.gov/permit/handbook/s11c01pd.htm

14. http://www.e-composites.com/commonFiles/conversion_table.asp

15. http://www.silicosis.com/about/index.htm

16. http://www.silicosis.com/niosh/index.htm

17. http://www.silicosis-injury-attorneys.com/pages/diagnosis_treatment.html

18. $\quad$ http://www.tau.ac.il/ramot/danvils/VascoMaxC.pdf

19. http://www2.tku.edu.tw/ tkjse/4-4/4-4-3.pdf

20. Rai, C., "Computational Model of Ductile Erosion by Single Particle Impact", 2000, pp. 1-90. 
21. Sevinc, C., Cimrin, A.H., Manisali, M., Yalcin, E. and Alakan, Y., "Sandblasting under Uncontrolled and Primitive Conditions in Turkey", Occup Health 2003, pp. 66-69. 22. Sparks, A.J. and Hutchings, I.M., "Effects of Erodent Recycling in Solid Particle Erosion Testing", Wear of Materials, 1993, pp. 139-147.

23. Townsend, T.G., "Disposal and Reuse Options for Used Sandblasting Grit", July 1997, pp. 10-12.

24. Trezona, R.I., Pickles, M.J. and Hutchings, I.M., "Full Factorial Investigation of the Erosion Durability of Automotive Clearcoats", Tribology International, Vol. 33, Aug. 2000, pp. 559-571.

25. Turenne, S., Simard, D. and Fiset, M., "Influence of Structural Parameters on the Slurry Erosion Resistance of Squeeze-cast Metal Matrix Composites", Wear, Vol. 149, Sep. 1991, pp. 187-197.

26. Yalamanchali, C.S., "Modelling the Effects of Temperature and Particle Shape on the Erosion of Brittle Oxide Scales By Impact”, 1997, pp. 1-110. 


\section{APPENDIX A}

Sample LS-INGRID file to generate a 3D model for angular impacts

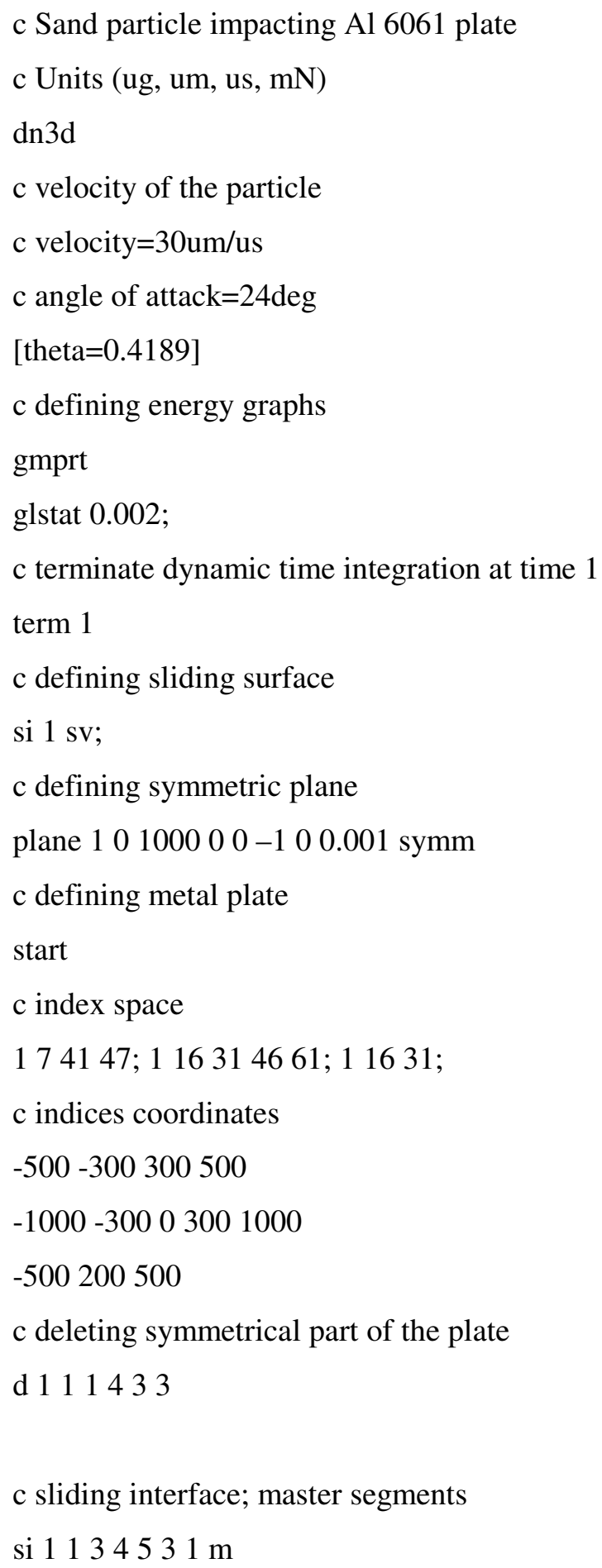


c boundary conditions

b 411453111000

b 151453111000

b 111153111000

b 111451111000

b 111413010000

mate 1

end

c Defining the sphere

velocity $[-50 * \cos ($ theta $)] 0[-50 * \sin ($ theta $)]$

start

c index space

15913 17; 15913 17; 15913 17;

$\mathrm{c}$ indices coordinates

$[-50+0.25 / \tan$ (theta) $][-50+0.25 / \tan$ (theta) $]$

[0.25/tan(theta)] [50+0.25/tan(theta)]

[50+0.25/tan(theta)]

$-50-5005050$

550.25550 .25600 .25650 .25650 .25

$c$ deleting the edges of the cube

di 12045 ; 1204 5; ;

di 12045 ; ; 12045 ;

di ; 1204 5; 12045 ;

c projecting the boundary to a spherical surface

sfi -1 -5; -1 -5; -1 -5; sp [0.25/tan(theta)] 0600.25100

c sliding interface; slave segments

sii $-1-5 ; 3-5 ;-1-5 ; 1 \mathrm{~s}$

$\mathrm{c}$ deleting the symmetric part of the sphere

d 111535

c boundary condition

b 131535010000

mate 2

end

c Material properties 
mat 13

pr 0.33

e $7.20 \mathrm{e}+1$

ro $2.850 \mathrm{e}-6$

sigy $3.2 \mathrm{e}-1$

endmat

mat 23

pr 0.17

e 100

ro $2.650 \mathrm{e}-6$

sigy 8

fs 0.003

endmat

end 


\section{APPENDIX B}

\section{Sample Input File for LS-DYNA3D}

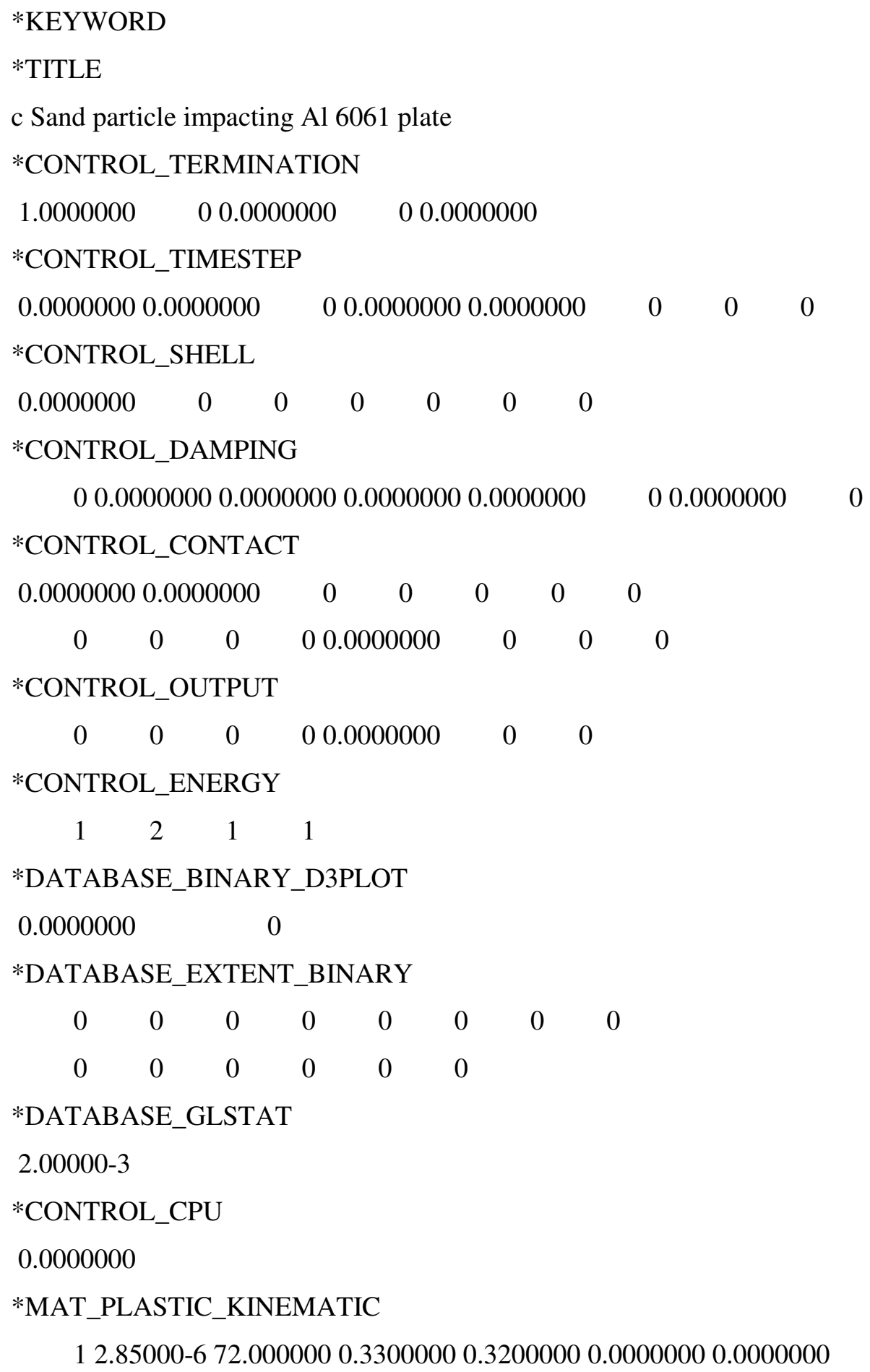


0.00000000 .00000000 .0000000

*MAT_PLASTIC_KINEMATIC

2 2.65000-6 100.00000 0.17000008.4000006 0.0000000 0.0000000

$0.00000000 .00000003 .00000-3$

*SECTION_SOLID

10

*SECTION_SOLID

20

*PART

$\begin{array}{llllllll}1 & 1 & 1 & 0 & 0 & 0 & 0 & 0\end{array}$

*PART

$\begin{array}{llllllll}2 & 2 & 2 & 0 & 0 & 0 & 0 & 0\end{array}$

*NODE

1-5.000000000E+02 0.000000000E+00-5.000000000E+02 $7 \quad 0$

2-4.666666565E+02 0.000000000E+00-5.000000000E+02 $7 \quad 0$

3-4.333333435E+02 0.000000000E+00-5.000000000E+02 $7 \quad 0$

4-4.000000000E+02 0.000000000E+00-5.000000000E+02 $7 \quad 0$

$\begin{array}{llll}5-3.666666565 \mathrm{E}+02 & 0.000000000 \mathrm{E}+00-5.000000000 \mathrm{E}+02 & 7 & 0\end{array}$

$\begin{array}{llllll}46612 & 6.387133789 \mathrm{E}+01 & 4.453900909 \mathrm{E}+01 & 6.635598755 \mathrm{E}+02 & 0 & 0\end{array}$

46613 5.249523544E+01 5.193375778E+01 6.521837769E+02 000

$466145.442898941 \mathrm{E}+015.386751175 \mathrm{E}+016.541174927 \mathrm{E}+02 \quad 0 \quad 0$

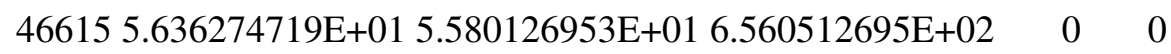

$\begin{array}{lllll}466165.829650497 \mathrm{E}+01 & 5.773502731 \mathrm{E}+01 & 6.579850464 \mathrm{E}+02 & 0 & 0\end{array}$

*ELEMENT_SOLID

$\begin{array}{cccccccccc}1 & 1 & 1 & 2 & 9 & 8 & 113 & 114 & 121 & 120 \\ 2 & 1 & 2 & 3 & 10 & 9 & 114 & 115 & 122 & 121 \\ 3 & 1 & 3 & 4 & 11 & 10 & 115 & 116 & 123 & 122 \\ 4 & 1 & 4 & 5 & 12 & 11 & 116 & 117 & 124 & 123 \\ 5 & 1 & 5 & 6 & 13 & 12 & 117 & 118 & 125 & 124\end{array}$




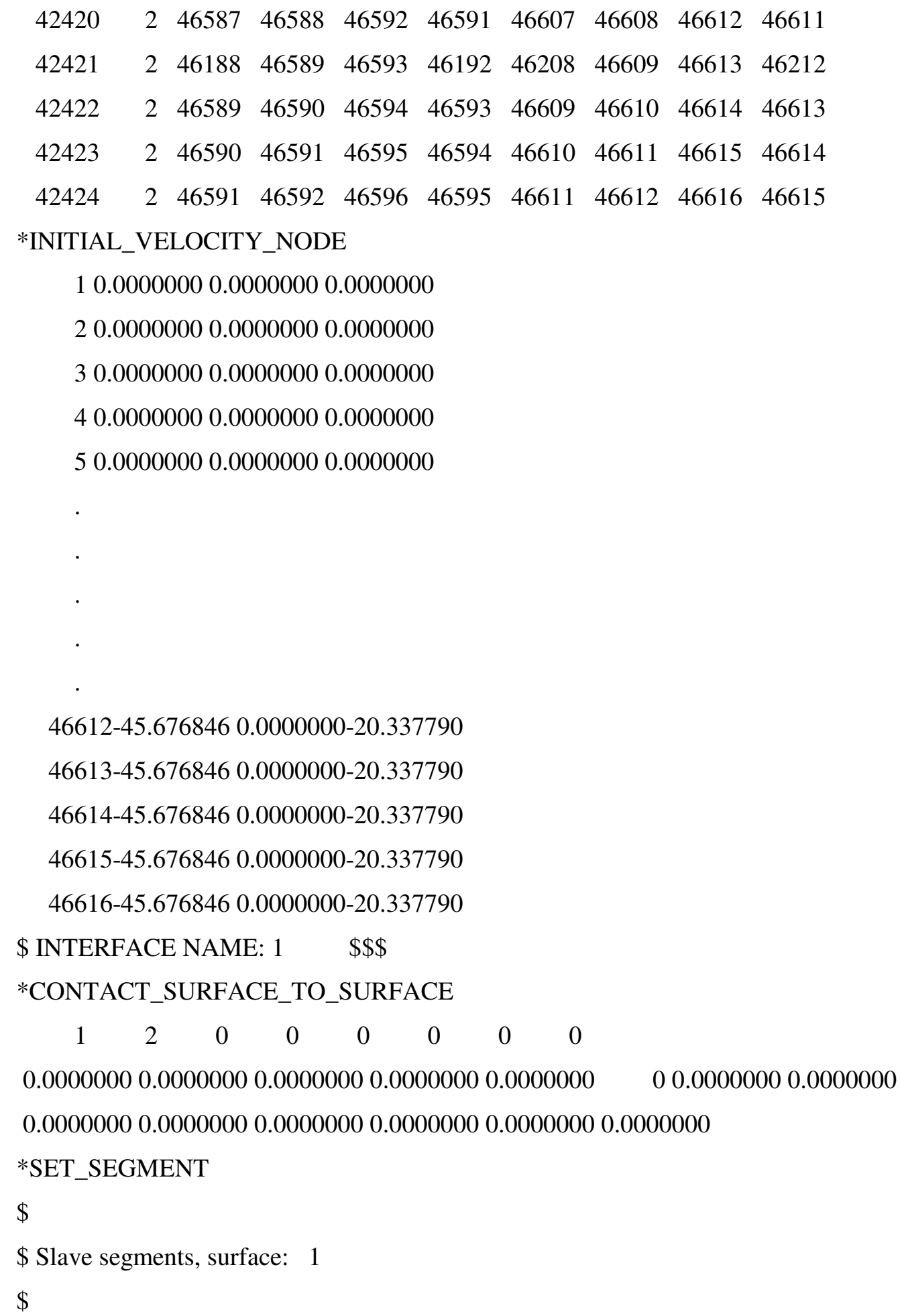




$\begin{array}{llll}1 & & & \\ 45168 & 45193 & 45198 & 45173 \\ 45193 & 45218 & 45223 & 45198 \\ 45218 & 45243 & 45248 & 45223 \\ 45243 & 45268 & 45273 & 45248 \\ 45268 & 45293 & 45298 & 45273 \\ \cdot & & & \\ \cdot & & & \\ \cdot & & & \\ 45136 & 45142 & 45143 & 45137 \\ 45142 & 45148 & 45149 & 45143 \\ 45148 & 45154 & 45155 & 45149 \\ 45154 & 45160 & 45161 & 45155 \\ 45160 & 45166 & 45167 & 45161 \\ * \text { END } & & & \end{array}$

